\title{
PRESENCIA MUSICAL \\ EN LA CATEDRAL DE LA SEU D'URGELL \\ EN LA PRIMERA MITAD DEL SIGLO XVIII A TRAVÉS DE SUS ACTAS CAPITULARES
}

\author{
Jordi RoIG I CAPDEVILA
}

\begin{abstract}
With this essay we wish to contribute to the historical recuperation of our musical and cultural heritage with particular reference to one specific case. It will, therefore, describe the musical activity from 1700 to 1750 of the Cathedral Musical Chapel of La Seu d'Urgell which had been a particularly relevant centre ever since the Middle Ages for its importance as a frontier pass on the Pyrenees between France and Spain. There do exist certain historical studies of the Medieval and Renaissance periods' that led to publications by Higini Anglés analyzing the figure of Joan Brudieu ${ }^{2}$. But, on the other hand, very little is known about the musical life of that "Episcopal" town during the XVIII to XX centuries ${ }^{3}$ (recently being the bishop of La Seu also the prince of Andorra, all together with the President of the French Republic). Taking up where the work of Pedrell-Anglés had left off, this essay initiates the systematic compilation of whatever information concerning music is contained in the Cathedral Archives. Though it is our intention to continue our line of study, on this occasion we are only going to publish the Chapter Acts from the period 1700-1750, which will permit us to form a general idea about the activities and the repercussions of one of the principal Musical Chapel in Catalonia, and also of one of the centres in the Hispanic sphere of influence that Musicology has least studied until recently.
\end{abstract}

\section{Resumen}

El objetivo del presente artículo, es colaborar a la recuperación histórica de nuestra música y nuestro patrimonio, por medio de un caso concreto. Se pretende dar a conocer la vida musical - entre 1700 y 1750 - de la capilla de música de la catedral de la Seu d'Urgell, un centro de particular relevancia desde época medieval, por ser un importante paso pirenaico entre Francia y España. Sobre los períodos medieval y renacentista existen algunos viejos estudios ${ }^{1}$, que culminan con las publicaciones de Higini Anglés sobre Joan Brudieu². Pero, en cambio, apenas se conocen datos sobre la vida musical en esta ciudad episcopal durante los siglos XVIII al Xx $x^{3}$. Empalmando con el final temporal abarcado por el trabajo de Pedrell-Anglés, el presente trabajo inicia el vaciado sistemático de la información alusiva a la música contenida en la documentación catedralicia. Aunque se tiene la intención de continuar, en esta ocasión, solamente se publican las actas capitulares correspondientes al período 1700-1750, lo que nos permite obtener una visión general de las actividades y repercusión de una de las principales capillas de música de ámbito catalán, y uno de los centros de ámbito hispánico menos estudiados por la Musicologia hasta el momento.

1. Pere Pujol i Tubau: "Els dos missals mixtes de la Seu d'Urgell: Les seves donaciones", en Butlletí del Centre excursionista de Vich, ii (1915-1917), pp. 49-55. [El autor de este trabajo, que fuera canónigo archivero de la seo urgelense, escribió asimismo el capítulo titulado "Apèndix: Noves dades per a la biografia d'en Brudieu”, en el conocido libro sobre la catedral, y los madrigales de Brudieu, a cargo de F. Pedrell e H. Anglés, del que trataremos más adelante].

2. Felipe Pedrell; e Higinio Anglés; eds.: Juan Brudieu: Els Madrigals i la Missa de Difunts d'en Brudien. Barcelona, Biblioteca de Catalunya, Institut d'Estudis Catalans, 1921 [vid. pp. 8-9 y 91-93; de interés para los siglos menos tratados -XVII y siguientes-, cfr. especialmente el capítulo a cargo de H. Anglés, "La capella musical de la Seu", en pp. 135-151].

3. Maria Ester-Sala; y Josep Maria Vilar: "Una aproximació als fons de manuscrits musicals a Catalunya", en Anuario Musical, 42 (1987), pp. 229-243. Id.: "Arxius musicals de Catalunya (VII)”, en Revista Musical Catalana, 48 (1988), p. 42. 


\section{Introducción}

La catedral de La Seu d'Urgell ha sido históricamente un centro donde el cultivo de la música ha gozado de particular esplendor. La situación fronteriza de esta localidad impulsó sin duda los intercambios entre Francia y España en determinados períodos históricos, al tiempo que, en otros, supuso sin embargo una intencionada reafirmación nacional hispánica frente al elemento "foráneo" francés. Éste parece ser el caso durante el siglo XVIII, durante el cual, a pesar de compartir una dinastía monárquica común - los Borbones-, da la sensación de que ambas naciones se distancian irremisiblemente, no sólo en lo político, sino también en el modo de entender el fenómeno religioso y el musical. Si en otros aspectos, Francia y España mantuvieron relaciones constantes y relativamente fluidas, en cambio, en el caso de La Seu d'Urgell, y sin duda por su carácter fronterizo, da la sensación de que las autoridades civiles y religiosas reafirman su "españolidad" y se alejan del próximo vecino francés. Esto se trasluce, como se desprende de la documentación conservada, en las nóminas de músicos — todos ellos españoles-; en los temas que se abordan en el cabildo catedralicio con relación a la música; naturalmente, en los repertorios que se trabajan; en las actividades habituales de compositores e intérpretes; etc.

Con el presente vaciado documental entre los años 1700 y 1750 se complementa de forma exhaustiva aquel primer trabajo que hiciera Higini Anglés en 1921 (op. cit.), en el que apenas se daba la lista de los músicos, y únicamente hasta el año 1700, la cual se anota, en los volúmenes correspondientes de actas capitulares, en el denominado "capítulo pascual" que se celebraba una vez al año, y que marcaba el inicio y final del calendario catedralicio. Incluso las publicaciones más recientes al respecto, señalan que "desde entonces [por el año 1700 en adelante], nada se sabe sobre los maestros posteriores"4, de suerte, que puedo hoy aportar aquí, toda una serie de nombres de compositores, músicos cantores e instrumentistas, actividades de la capilla, etc., que hasta ahora no se habían dado a conocer. La intención del trabajo es proseguir más adelante, con la publicación del resto de actas capitulares hasta 1810 (pues entonces, muy posiblemente por motivo de la "guerra del francés", desaparecen los libros de actas, hasta comenzar de nuevo en 1853), así como incluir las actas anteriores al año $1700^{5}$.

4. Francesc Bonastre; Maria Ester Sala; y Josep Maria Vilar i Torrens: "La Seu d'Urgell", en Diccionario de la Muísica Española e Hispanoamericana. Vol. 6. Madrid, SGAE, 2000, pp. 689-690 [cfr. cita concreta en p. 690].

5. Los materiales que hoy presento proceden del trabajo iniciado hace un par de años en el archivo de la catedral de La Seu d'Urgell, bajo la coordinación del Dr. Antonio Ezquerro Esteban. Hasta la fecha, se ha finalizado el vaciado de actas capitulares de todo el siglo XVIII (que no se incluye aquí por lógicas razones de espacio), así como de la primera mitad del siglo XVII. Paralelamente, estoy realizando la catalogación exhaustiva de los fondos musicales conservados en el archivo musical catedralicio, bajo la normativa internacional del RISM (Répertoire International des Sources Musicales). Dicha catalogación comprende no sólo los materiales propios de la catedral, sino también los ahí conservados procedentes de la Colegiata de Agramunt (Lleida), que reúnen composiciones en su mayoría del siglo XVII, así como de una colección de partituras procedentes del seminario de la ciudad (música de los siglos XIX y XX). Se está procediendo en la actualidad a la catalogación integral de los tres fondos, habiéndose comenzado los trabajos por el inventariado de los cantorales y de la música a papeles (tanto manuscritos como impresos), desde los siglos XVI-XVII hasta la actualidad. Por último, se prepara un estudio sobre la personalidad y la producción del compositor, maestro de capilla de la Seu durante la segunda mitad del siglo XVIII, Bru Pagueras, con el correspondiente análisis formal y estilístico de sus composiciones conservadas. (Agradezco al Dr. Antonio Ezquerro su dirección y consejos tanto para la elaboración del presente artículo, como en los trabajos ya emprendidos. Del mismo modo, quiero agradecer todas las facilidades y enorme apoyo de Mosén Benigne Marquès, canónigo archivero de la catedral, por cuanto me ha facilitado en todo momento el acceso, localización y consulta de los fondos). 
A continuación se transcriben las correspondientes resoluciones capitulares, en las que, como se podrá apreciar, es muy habitual la ambigüedad linguiística, en una mezcla peculiar de catalán, latín y castellano. Para su registro, y como criterios de transcripción, se ha utilizado la tónica habitualmente empleada para este tipo de documentación ${ }^{6}$. Finalmente, he elaborado unos listados de los nombres propios que se citan en la documentación (con referencia a los números de entrada concretos, o lo que es lo mismo, al acta capitular en que aparecen), ordenados alfabéticamente, con vistas a facilitar su consulta.

Veamos, pues, la información relativa a la actividad musical que nos arrojan las actas capitulares de La Seu d'Urgell a lo largo de la primera mitad del siglo XVIII.

6. Se aporta la descripción de cada volumen de actas en nota al pie al iniciarse cada nuevo volumen. Todo cuanto se anota entre corchetes, es del transcriptor. Las anotaciones del manuscrito original al margen se indican previamente al cuerpo de texto de cada acta capitular, entre comillas. Se diferencian las líneas del manuscrito por el procedimiento habitual de empleo de barras. Los pasajes que han parecido de escaso interés musical, o bien que faltan en la fuente, se han resuelto mediante puntos suspensivos entre corchetes. Se ofrece la foliación original al comienzo de cada entrada. Cada acta capitular se ha numerado adjudicándole aquí un número de entrada entre corchetes y en negrita, para facilitar su localización al emplear los índices de nombres. Las tachaduras que puedan observarse, como los posibles subrayados, son conscientes: responden a tachaduras, aunque legibles, en el original, y a subrayados, respectivamente. Por último, el cuerpo de texto de cada acta, se anota siempre entre comillas. 


\section{Libros de Actas Capitulares}

\section{[Volumen 1698-1749]: ${ }^{7}$}

[1] Fol. 35r.: «Die 5 January 1700-»: “[Margen: «Admissio de M. Jacinto / Dalmau»] [...] Avens fet relacio lo Mestre de Capella aver trobat habil de cant a / M. Jacinto Dalmau prevere fou resolt admeterlo en las distribucions de me / nuda y spes more solitum y que se li faci fe auctentica perque lucro los guanys / de la Pietat com los demes".

[2] Fol. 35v.: [«Die 12 January 1700.»:] "[Margen: «Mestre de capella»] [...] Fuit resolutum que en atencio de la relacio se ha feta de que Jaume / Forcada era capas y aproposit pera governar y ser mestre de Capella / de esta St.a Ig.a que lo S.r Dega es vinga pera que vinga luego pera exer / cir semblant empleo ab lo mateix salari que los anteccessors y no / altrament y avent precehit la approbacio del Phelip Olivelles mestre / de capella del Palau de la Comptesa de Barcelona y lo ynformi favo / rable del Mn Joseph de Asprer Ar.ca de Andorra y Don Joseph de / Llupia Canonges desta S.ta Ig.a ques troban en Bar.na = se ha / resolt no fer examens, ni altra diligencia que admeterlo".

[3] Fol. 35[bis]r.: «Die 22 Januarÿ 1700»: "[Margen: «Governacio»] [...] Fuit resolutum prevenir al Governador, que no permetia Ballades en / les jurisdiccions del molt Ilt.e Capitol, ni tenir musichs publicament men / tres durava lo any sant".

[4] Fol. 35[bis]r.: «Die 22 January 1700»: "[Margen: «Revocatio de oficial»] [...] fuit resolutum que attes que M. Joan Montau p.e y Bene.at [de] Nsr.a St.a Ig.a y oficial / conductitio del nostre Ilt.e Capitol a fets alguns de merits usant de n.a autoritat se / ha resolt revocarlo del ofici te de cantar los Evangelis y se ha anomenat pera / cantar aquells ab Rt. Joan Forcada u per les Epistoles en lloch de Forcada / [Margen: «Nominatio de ofi.ls»] [...] ab Rt. Joseph Bonet p.es y Bene.ats desta S.ta Ig.a.”.

[5] Fol. 35[bis]v.: [«Die 29 Jan. 1700»:] "[Margen: «Com.o per firmar acte del M.e de Capella»] [...] fuit resolutum fer comissio ab Ar.ca de Cerdanya sobre estant de la capella / pera que puga fer y firmar la concordia y capitulacio ab Jaume Forcada M.e / de Capella elegit expressant les obligacions ab que ha de servir dit ampleo y lo / salaris que lo Capitol acostuma donar".

[6] Fol. 39v.: [«Die 28 Aprilis 1700»:] "Mestre de Capella - Jau.e Forcada clergue. / Organiste - M. Isidro Ferrada. / Baixoniste - M.o Felip Gensana / Faristolers - Los cantors / [Fol. 40v.:] Faristolers de Cor Major - Los mateixos cantors / faristolers de cor menor - Los mateixos cantors / Llevar i posar los habits de cor y almussers - Fermi de Peralta y M.o / Andreu Vilanova / Corneta - Vacat / Sacapuxo - Philip Gensana / Contralt - Vacat / Thenors - Fr. Joseph Codina Fr. Joseph / Cots, y Andreu Vilanova / Manxador - Pere Vila / Treure los gossos de la Ig.a - Preveners / Encendre lo rotlle - Preveners".

[7] Fol. 41r.: [«Die 30 Apr.l Cap. Pasch Continuantes»] "[Margen: «Residencia del cor»] [...] Attes que se exprimente moltes faltes al cor respecte de la residencia per / que acabats los Kiries los demes residents sen van y fins a Santus no tor / nen y molts en aun acabat Santus sen tornen anar./ Fuit resolutum que se observa ab vinguem lo ordenat en lo llibre de la / apuntadora deixan ho per major a la directio del S.r. apuntador / tambe fou resolt ratificar las conclusions fetas pera que ningu puga eixir / del cor antes

7. Libro manuscrito de 434 × $320 \mathrm{~mm}$., encuadernado cosido, con tapas de cartón forradas en piel de color marrón claro; en el lomo hay dos etiquetas; la de la parte superior está deteriorada y en ella se puede leer: «Liber Conclus[io]/num ab Anno / 1698. ad 1749.»; la segunada etiqueta lleva anotado el núm.: «1023». 562 fols., en papel, anotados en tinta negra; de ellos, los trece primeros folios y los tres últimos están sin numerar y en blanco; del folio 14 al 475 están todos ellos numerados (el fol. 35 y 115 están duplicados); hasta el fol. 480 se numeran únicamente cada cinco; hasta el fol. 540 se numeran cada diez (los últimos cinco llevan la numeración 136, 137, 138, 139 y 140, respectivamente); y de los fols.540 al 545, se numeran nuevamente cada cinco. 
del Te Deum ni menos los Capitulars y aquells que estan / parats per poder entrar al Cor quant se comensen los oficis esperant / lo primer Gloria que faci primats de aquella distribucio".

[8] Fol. 42r.: «Die 5 p.torum» [«Maÿ 1700»:] "Capitulum Paschale continuantes / Convocato [etc] In quo inter fuerunt omnes sug.ti. [Margen: «Corneta»] [...] Fou resolt que lo M.e de capella escrega a Joseph Fuentes corne- / ta en la capella de St Joan de Valencia de que si vol venir / en esta S.ta Ig.a se li farà la conveniencia de donarli cent sin- / quanta lliures de salari tots los anys a mes de la entrada del / Chor, y quatre dobles per lo viatge".

[9] Fol. 42v.: «Die 6 p.torum» [«Maÿ 1700»:] “[Margen: «Statut Epistoles y / Evangelis pugan dir / Missa»] [...] Fuit resolutum de que en atencio de experimentarse que / los Sr.s Capitulars a qui toca lo cantar la Epistola y Evangeli no / tenen lloch de dir Missa en lo temps del estiu sels dispensa que / en los dias Dobles y Dominicas [etc] non alias pugan eixir del Chor / al ultim Psalm de Laudes antes del Benedictus sens pregudici de / les distribucions pera que los demes Capitulars que no poden / eixir fins acabar dit Psalm no pugan ocupar les capelles antes / que dits Sr.s que han de cantar la Epistola y Evangeli".

[10] Fol. 44v.: [«Die 12 p.tor. Cap. Pasch. Cont. Maÿ 1700»:] "[Margen: «Admissio de / Argany»] [...] Fuit resolutum anomenar per cantor ab les distribucions del cor / a Caetano Argany germa del M.e de Capella".

[11] Fol. 44v.: «Die 13 ptor. Cap. Pasch. Cont.» [«Maÿ 1700»:] “[Margen: «Com.o pera ado- / bar lo orga»] [...] Fou feta com.o al sobrestant de capella y al obrer per fer totas las di- / ligencias necesarias pera adobar lo orga que segons diu lo M.e Ser- / rada no pot esperar mes".

[12] Fol. 44v.: «Die 14 ptor. Cap. Pasch. Cont.» [«Maÿ 1700»:] “[Margen: «Com.o Cantor»] [...] Fou feta com.o al sobrestant de capella pera fer venir un / [Fol. 45r.:] Musich de Perpinyà à gastos de la Ig.a y segons sa habilitat se / pendrà resolucio [etc] admetrerse".

[13] Fol. 47v.: «Die 8 Juny 1700»: "[Margen: «Admissio de corneta»] [...] Fuit resolutum que se admetie Joseph Fuentes per corneta ab lo / salari que se resolgue lo dia de Maig proposat y que tingue / obligacio de ensenyar als preveners que voldran apendre la sua / abilititat".

[14] Fol. 48r.: «Die 18 Juny 1700»: "[Margen: «Admissio de prevener»] Fuit resolutum admetrer en prevener al nebot del M.e de Capella dit Ivanco / y que se li fassa cota com als demes".

[15] Fol. 48r.: «Die 22 Juny 1700»: "[Margen: «Sup.ca del R.t de Vilanova»] [...] Fuit resolutum admetre a les distribucions aixi de menuda com Espes al R.t Joan / Riu R.t de Vilanova com á obtenir lo Benefici de Sant Salvador more solutio los / señors canonges Zaydin y Ferrer son del vot que no se admetia que no aya dimi / tit la Rectoria".

[16] Fol. 48r.: «Die 6 July 1700»: "[Margen: «Ad.o del M.t Joan Riu»] [...] Fuit resolutum que atesa la relacio a fet lo mestre de capella de aver exa / minat de cant al R.t Joan Riu R.t de Vilanova per ser admes a las distribucions / y obtenir la suficiencia necessita se abmetia a totes les distribucions axi de / menuda com de Espes y que si li faise certificatoria per a puga lucrar los guanys / de la Pietat".

[17] Fol.: 48v.: «Die 20 July 1700»: "[Margen: «Adm.o del R.t Genis / Fulla»] [...] Fuit resolutum que atesa la relacio a fet lo mestre de capella de aver exa / minat de cant al R.t Genis Fulla R.t del Quer y tenir la suficiencia / se admet á totes les distribucions axi de menuda com de Espes y que si li faci / certificatoria com als demes".

[18] Fol. 49r.: «Die 13 Ag.st 1700»: “[Margen: «Fermesi»] [...] En attensio que Fermisi de Peralta cantor de la S.ta Ig.a a demanat llicencia / pera anarsen en sa terra se li ha concedida, y se li revoque lo sindicat".

[19] Fol. 49v.: «Die 20 Ag.st 1700»: "[Margen: «Exoneracio dels cantors»] [...] Fou resolt que imposturum los cantors menos los dos sacristans no tin / gan obligacio de asistir al posar y que legar las colgaduras de vellut de la Ig.a [...]”. 
[20] Fol. 50r.: «Die 31 Ag.st 1700»: "[Margen: «Adm.o de Canals»] [...] En forsa de la sup.ca donada per M.o Joseph Canals p.e y Bene.at del benerat y / del Sant spirit, segons lo mestre de capella á fet relacio de averlo examinar de cant / per la raho en dita suplica a demanat / y assista que dit M.e dici te la suficiencia fuit reolutum que se admetia á / totas las distribucions aixi de menuda com de Espes".

[21] Fol. 50v.: «Die 20 p.torum» [«7.bris 1700»:] "[Margen: «Admissio de tres cantors»] [...] Se proposa que Domingo Gensana baixoniste, Joseph Planes corneta y Joseph Girvet tenor desitjavan servir en esta S.ta Ig.a ab sas abilitats / y fou resolt assenyalar salari a cada un de ells en esta forma al tenor $50 £$ al corneta $50 £$ y al baixonista o sargant $70 £$ adme / terlos a tots junts a las distribucions del cor dels quals salaris se aconten / taren uns y altres y obteniren lo corneta i baixonista ensenyar als pre / veners que lo mestre de capella coneixeria ser aptes pera poder apen / dre de eixos instruments y dels demes que los referits sabran en / senyar".

[22] Fol. 50v.: «Die 24 7.bris 1700»: “[Margen: «Admissio de M.o Pere Net»] [...] En attencio de la sup.ca donada per lo R.t Pere Net p.e y bene.at de esta S.ta / Yg.a del Benefici sots muncatio de fet Antoni de Padua y per ser germa de / un capitular - fou resolutum admeterlo á totes las distribucions / aixi de menuda com de Espes fent li gratia del examen de cant".

[23] Fol. 51r.: «Die 28 7.bris 1700»: "[Margen: «Admissio de contralt»] [...] Fuit resolutum admetre al R.do Antonio Rubio per Contralt de la capella ab lo / salari de $60 £$ cada un any y admes a les distribucions del cor y fou resolt tambe / que lo S.r receptor done bestreta a dit contral y als demes cantors que se an admes de sou / fins a dos dobles a cada un que se li faran donar".

[24] Fol. 52v.: «Die 19 8.bris 1700»: "[Margen: «Accio de gracias / per la millora de sa / Mag.t»] [...] Avent tingut noticia lo dia 11 del corrent de que sa Mag.t avia / estat de cuidado de forma que se li avia ministrat lo viatich pero que / ja se trovaba fora de perill se resolguè en accio de gracias fer Profesio / per lo claustro y Missa solemne ab asistencia de esta ciutat y com lo dia pre- / sent se tinga altra noticia de que la desgana ha continuat des del / dia tres fins al dia 9. del corrent ab alguns perills y per conseguent aja / quedat ab pocas forsas se ha resolt fer rogativas per a que N.e S.r lo re- / integre enterament en sa perfecta salut y per est efecte se envia lo M.e de / cerimonias à convidar à la ciutat per a que asistis mati y tarda a / las funcions y que anàs tambe à participar la noticia a R.n Jo- / seph Xales Sarg.to Major de Aragon y Governador al punt de es- / tas fronteras à risolt de posarho en sa noticia, la forma de las rogativas es la seguent. A laudes y vespras se dirá la An / [Fol. 53r.:] tiph[on]a Sub tuum proesidium y los preveners los Versets de Maria SS.ma / pro Rege lo semaner las dos collectas corresponents, acabada Tersia se fa / rà Professo per la ciutat ab ornaments morats cantantse la Lletania ma- / jor, y tornats a la Ig.a toca la clerecia en lo chor y los diacas drets en lo / Altar major cantaran los versets de N.a S.a S.t Ermengol y S.t Od propeccat.s / \& pro Rege y lo Hebdomedari las Collectio proporcionadas à dits Versets. / Y lugo se començarà la Conventual. A la tarde alguns de las qua- / tre horas se exposarà lo SS.m conforme en dia de Minerva eixint la Pro- / feso del cor al tercer vers del Himne Pange Lingua y los dos primers ver- / sos se dirán mentres los capellans aniràn donant y repartint los ciris / encessos, y posada tota la Professó dins del Presbiteri de rodillas eixi- / rà lo Hebdomadari, y al Tantum ergo se exposara lo SS.m y acabat lo / Himne los preveners diran los versets del Sacrament y lo Hebdomadari / la collecta y restituits en lo cor se començaran Completas solem- / nes y acabadas aquellas tornarà à ferse Professo sens cantarse res y / arribada al Presbiteri diran los cabiscols la Lletania de Maria SS.ma / acabada aquella los preveners diran los versets del Sagrament de la / Verge, y pro infirmo, y lo semaner las collectas acabades les quals se / reservarà tot en un temps".

[25] Fol. 53v.: [«Die 26 Octubris 1700.»:] “[Margen: «Bestreta»] [...] Testes p.ti Puig, \& Vidal / Se ha resolt que lo receptor done quatre dobles de bestreta a cada / un dels quatre cantors nous comprenenthi tot lo que fins vuy tenen / rebut del S.r Receptor". 
[26] Fol. 53v.: «Die 5. Novembris 1700.»: “[Margen: «Bestr.ta»] [...] Con.to [etc] In quo omnes supra nominati / Fuit resolutum que lo receptor posia en bestreta al manxador lo sa / lari del p.nt any attes que deu alguna venda".

[27] Fol. 56r.: «Die 19 January 1701»: “[Margen: «Comissio acerca del / M.e de Capella»] [...] Fou feta comissio per a mirar lo modo millor podia tenir lo fer ordenar á / Jaume Forcada M.e de Capella señors canonges Montaner y Llorens".

[28] Fol. 56r.: «Die 21 January 1701»: "[Margen: «Perpetuacio del M.e / de Capella a les distri / bucions»] [...] atesa la relacio feta per los canonges Montaner, y Llorens en ordre a la com.o sels / feu lo 19 propassat se ha resolt perpetuar al licenciado Jaume Forcada M.e / de capella en les distribucions del cor de la catedral vuy posa y quant aquellas / no arribasen a la congrua per a poderse ordenar fou resolt assegurarli fins a sentan / ta sinch lluisos compresos ditas distribucions".

[29] Fol. 56r.: «Die 21 January 1701»: “[Margen: «Carta de favor»] [...] Fou resolt tambe donar carta de favor a dit M.e de capella perque lo señor / Bisbe ha servit ordenarlo".

[30] Fol. 57v.: «Die 15 p.torum» [«Febrero 1701»:] "[Margen: «Llicencia»] [...] Fou resolt donar llicencia al M.e de Capella per portarsen son germa / à ordes ab ell y que si li donie carta per lo S.r Bisbe".

[31] Fol. 61r.: «Die 12 Aprilis 1701 Capitulum Paschales Continuantes»: "M.e de Capella - Serrada per interim / Organista - Isidro Serrada / Baxonista - Felip Gensana / Faristolers - Los cantors / Faristolers de chor major - Los cantors / Faristolers de chor menor - Los cantors / [Fol. 61v.:] Corneta - Joseph Planes / Sacaputxo sargant y altres oficis - Domingo Gensana / Contralt Antonio Rubio - Ant.o Rubio / Martirologi - Felip Gensana / y Andreu Vilanova / Tenors - Andreu Vilanova / y Joseph Girvet / Traurer los gossos de la Ig.a - Los preveners / Encendre lo rotlle - Los preveners / Manxador Pere Vila - Pere Vila".

[32] Fol. 62v.: «Die 13 Aprilis 1701 Cap. Pasch. Cont.»: "[Margen: «Despedir a Caie- / tano»] [...] Fuit resolutum ques despedesca Caietano Aregany, y ques bor- / ro de la apuntadoria".

[33] Fol. 62v.: «Die 13 Aprilis 1701»: "[Margen: «Despedir lo Mes- / tre de capella»] [...] Fuit resolutum ques despedesca lo M.e de Capella Jaume / Forcada".

[34] Fol. 62v.: «Die 13 Aprilis 1701»: "[Margen: «Dissentiment»] [...] Son de contrari sentir lo S.r Ard.a de Cerdanya Rovira / Ubach, Er. Ubach, Llorens, Llupia, y lo S.r Dega y dit S.r Dega / posa dissentiment".

[35] Fol. 62v.: «Die 13 Aprilis 1701»: “[Margen: «Moderacio de / salari à Gensana»] [...] Fuit resolutum que à M.o Felip Gensana se li done de / salari seixanta lliures y no mes".

[36] Fol. 63r.: [«Die 13 Aprilis 1701»:] "[Margen: «Moderacio de sa- / lari á Fuentes»] [...] Fou resolt que a Joseph Fuentes corneta se li done de salari cent / y deu lliures y no mes, attes que lo S.r Cabiscol lo anomena so- / ta cabiscol, en forsa del que se li rebaixa quaranta lliures del salari que tenia".

[37] Fol. 63r.: [«Die 13 Aprilis 1701»:] "[Margen: «Augment de / salari á Planes»] [...] Fuit resolutum que a Joseph Planes corneta se li done de salari / seixanta lliures".

[38] Fol. 63r.: [«Die 13 Aprilis 1701»:] “[Margen: «Augment de / salari a Domingo Gen- / sana»] [...] Amphius fuit resolutum que à Domingo Gensana se li done de / salari vuytanta lliures".

[39] Fol. 63r.: [«Die 13 Aprilis 1701»:] "[Margen: «Augment de sala- / ri à Rubio»] [...] Fuit resolutum que à Antonio Rubio contralt se li done de sa- / lari vuytanta lliures".

[40] Fol. 63r. : [«Die 13 Aprilis 1701»:] "[Margen: «Augment de sa- / lari à Girvet»] [...] Denique fuit resolutum que a Joseph Girvet se li done de sa- / lari seixanta lliures”.

[41] Fol. 63r.: «Die 14.Aprilis 1701. Cap. Pasch. Cont.»: “[Margen: «Com.o»] [...] Fou feta com.o al S.rs Cang.es Blanch y Llorens pera habilitar lo / dissentiment donat per lo S.r R.t Pau Vilana Perles Degà desta / S.ta Ig.a". 
[42] Fol. 63r.: «Die 15 Aprilis 1701. Cap. Pasch Cont.»: "[Margen: «Relacio del dissen- / timent»] [...] Avent feta relacio los S.rs Cang.es Blanch y Llorens de la / comissio que lo dia de ayr sels feu per mirar un paper de dis- / sentiment que lo S.r dega avia donat si venia ab aquella / decencia ques devia han dit aver mirat aquell y que / tant solament avian trobat una o dos paraulas un tant disso- / nants y que lo demes anava ab la deguda urbanitat y decoro. [Fol. 63v.:] En atencio del que fou resolt que mudás eixa paraula y ques / llegis".

[43] Fol. 64r.: «Die 21 p.torum cap. Pasch. Con.tes» [«Aprilis 1701»:] “[Margen: «Dissentiment donat / per lo señor Dega Vi- / lana Perles»] [...] A la sobredita resolucio discenti lo Dega Vilana Perles considerant de poca o ningu / na subrastemia tots los motius que se allegan per a revocar al licenciado Jaume / Forcada la nominacio de M.e de Capella que lo Molt Hn.e Capitol fou sevit ferli / en diada de [esp. en blanco] de [esp. en blanco] 1700 Perque al que primerament se li fa quixa de no / haver obehit al Señor D.n Ignasi de Cruyllas cabiscol y canonge prelat de esta S.ta Ig.a / quan li mana de sentas en la cadira del cor ahont tenia lo retol sempre / que agues o volgues ocupar cadira alta, li asisteix la disculpa de haverli ordenat / dit Dega antes y despres de dit mandat, que se asentas primer que ningun / dels Beneficiats fins y atant que lo H.e Capitol agues decidit lo punt per averli / assegurat a dit Dega que en sa conformitat se havia practicat sempre / [Fol. 64v.:] y en consideracio de ser cosa tant favorable a la Ig.a ab menos resolutio que cada / Il.tre Capitol no hi aparegue ni ara li apareéis interromprer semblant pocessio no / havent hi altre motiu que lo de fer posat un retol en altra cadira pero lo que / mes es fou proposada en Capitol esta deficultat considerantla digna de $\mathrm{mi} /$ rarse no se prengue altra resolucio que anomenar comissaris pera averiguar / la en lo arxiu y dit Forcada precisament hauria de quedar perplexo an lo / temps que se ha suspes pendrer dita resolucio, pres si obehia antes al / Señor Cabiscol faltava al Il.tre Capitol qui es son pr.pal al señor. Y axi com / prench que per est motiu dit Señor Cabiscol fassa molt be en despe / dirlo si unicament dependia de sa ma pero lo Il.tre Capitol comprench y / per est motiu deuria premiarlo - / SECUNDO se li fa quixa que per sa causa an deixat esta S.ta Ig.a lo / P. Fran.co Cots, y Fermin contralt sobre del que podria dir y asegurar / molt pres los referits an obligat y ha vist dit Dega plorar agrissimament / a dit Forcada per haverlo ultrejat moltas vegadas sols perque creyent / servir al Il.tre Capitol y desempenyar sa obligacio y desitjava redressar / alguns abusos que se exprimentavan en la Capella tals que fou menes / ter que lo Il.tre Cap. Ordenas als referits y demes cantors que regonegas / sen per Cap. de la Capella al dit Forcada sens faltarli a la menor atten / cio que com a tal se li devia y desitjava lo Il.tre Capitol se li tingues / altrament se tinguessen per despedits; pero los referits dos cantors no / deixaren la Ig.a fins a que lo Il.tre Capitol lliurarlos la / Missa de $3 £$ que havia ofert donar cada dia a quiscun dels dos y / al despedirse de dit Dega per lo menos pot jurar que no allegaren / altre motiu pera deixar la Ig.a que la referida a sancío y quant dit / Forcada agues ajudat en asso lo que no crech sensa por aver vol / gut redressar alguns abusos com esta dit y procurar que no se li faltas / a les attencions que com a p.[rincipa]l official del mol Il.tre Capitol se li deurian / y se li hauria ordenat no passar per menos, del que apar que lo / molt Il.tre Capitol ne deura fer maÿor estimacio per ferla dit For / cada del empleo que regentava, o per lo menos a par li avia / de donar orde contrari. / TERTIO se li acrimina que feu venir y aprobar la habilitat de Joseph / Fuentes per corneta de la Cath.l en satisfacio del que se ha de fer posar / que havent dit Forcada insinuat al Ilt.re Cap.l en ocasio que estava / sa Capella sens corneta de que en la Ig.a de Sant Joan de Valencia / se trovaba una habilitat que daria plena satisfacio y offerintli / [Fol. 65r.:] $150 £$ de salari podria ser que vingues se resolgue en dia de [esp. en blanco] de [esp. en blanco] $1700 \mathrm{fer} /$ servicer a dit Fuentes ab la reserva que si no agradava despues de ser ohit pagantli / son viatge (com se acostuma als que venen sens cridarlos o per lo menos sels assenyala / alguna ajuda de carta) sen degues tornar a sa terra. Y avent hoit a dit corneta y / la approbacio de dit Forcada resolgue lo Ilt.e Capitol admeterlo ab lo dit salari podent / sens faltar a la resolucio despederlo a les hores y ara, pero presendint si dit Fuentes es / ho no habilitat que en asso no puch votari, sols puch dir que [el] Mestre Cabanillas / de Valencia lo aprobá com á tal y M.o Isidro Serra- 
da M.e de Capella jubilat y or / ganiste desta S.ta Ig.a assegurá y ara assegura que es la millor habilitat de la / Ig.a sens exclourerse a ell pero en tot no agradant podra despedirse al dit Fuen / tes y no al dit Forca$\mathrm{da}=$ / QUARTA se li acrimina que á encabit un Germa, un Nebot y altre de sa patria / per escolans de grana y que a estos los tracta ab diferencia aixi en la ensenyança / com en lo menjar y preheminensia, pero a par que lo primer sels deuria molt estimar / pres los dos cantan de tible menos mal que dos de altres que creure se an adme / sos per trobarne de millors, y en lo segon dificulto prega venificensa y en tot cas / podran deixarse de admetrer y ara poden despedirse los dits set preveners y / aixi per est motiu no comprench que dit Forcada meresca ser despedit / TOTAS las referidas opperacions que ara serveixen per a despedir dit / Forcada avian passat quant sona suplica al Ilt.e Capitol en dia de [esp. en blanco] de / [esp. en blanco] 1701 en força de la qual se resolgue nemine discrepante sino me enganÿo / assenÿalantli congrua pera poderse ordenar y demanantho al S.r Bisbe - / QUINTO se allega que podria ser motiu de formarse algun empenÿo ab lo / señor Bisbe per haver S. Ilt.ma promes ab una carta que respongue al Ilt.e Capi / tol de que ordenaria a dit Forcada en força de la congrua que lo Ilt.e Capitol / fou servit assenyalarli lo dia de [esp. en blanco] de / [esp.en blanco] 1701 en les distribucions del / cor pero despues de haverli donat su Ilt.ma la Epistola li feu entendrer per / son secretari que sino decretava en sa curia, lo acte de la perpetuacio y no pa / gava los gastos no tenia que tornar a buscar ordes y dit Forcada per escusar / a dit Ilt.e Capitol este asigut seri que á su Ilt.ma una carta que li forma / dit Dega suplicantli permetes lo poderse fundar un patrimoni per acabarse / de ordenar pus no se atrevia ni sabia com representar al Ilt.re Capitol que / se mudassen los stils de la Ig.a per la causa y havent pochs dies antes ordenat / ab patrimoni a M.o Phelip Gensana baixonista desta Ig.a creya dit Forcada / no tocar en la ralla dels respectes que devite al S.r Bisbe y al Ilt.e Capitol. / Pero S. Ilt.ma respongue que si volia ordenarse [ho] avia de fer en la forma que / li tenia dit son secretari y li tenia promes lo Ilt.e Capitol per lo que se remi / raren las cartas de recomandacio que se havian donat a dit Forcada / [Fol. 65v.:] y per a evitar aixi mateix un disgust al dit Ilt.e Capitol permete dit Dega / ensenyarlas al secretari de su Ilt.ma lo qual offeri [esp. en blanco] / rer a son señor que los stils de la curia segons trobava eran en contrari / del que manava S. Ilt.ma allegantli los exemplars de M.o Pujolar y de / Fermmi de Peralta, y que li permetes duptar S. Ilt.ma en que lo Capitol li / agues promes semblant decret lo que podrá assegurar per aver vist ditas / cartas y dit Forcada ab la mayor submissio repecti a su Ilt.ma la primera / suplica, ab altra carta, que dit Dega li forma; pero a una ni altra respon / gue que no crya poderlo ordenar sino es de la manera que ja tenia dit. A les / hores regoneixent dit Dega quant fasilment podia errar y que podia / ser no tingues dificultat lo Ilt.e Capitol en donar permis a dit Forcada per a / decretar dit acte se proposa, resolgue, y se digue á dit Forcada que tingues / paciencia fins a que y agues ocasio de algun altre benefici ó que vingues lo / V.[ostre] G.[erma] de Gremio ab que poder confabular esta materia, y dit Forcada ab la resignacio / que devia se conformá sens mostrar lo menor sentiment de trobarse lli- / gat en aver de ser Eclesiastich, y tractantse com à tal tot lo temps q. / lo Ilt.e Cap.l tingues gust oferint no obrir la boca per a demanar lo Evan- / geli y Missa fins à que sa S.ria loy manàs. Esta es Testor Deum / la veridica relacio del q. ha passat, lo ponderarla y aplicarla en lo cas / present per motiu de despedir à dit Forcada ò deixo a la comprehen - / cio del que aura pres la pena de oyr ó llegir esta verdadera enca- / ra que mal llimada relacio. / Ultimament me obliga à ser de contrari sentir lo no aver ohit / a dir may ni quizá auran vist los S.rs Capitulars que son p.[resents] que se aja despedit lo menor oficial de la capella pero no deixa de / ser blasò que pot servir dels malt a la gran nobleza del Ilt.e Cap.l / lo mantenirse en esta antigua pregmatica y consuetut, pues sols / ella obliga que ab menos salari algunas habilitats vingan gusto- / sas de altras parts = Molt mes podria y desitjaria dilatarse / dit Dega en apoyo de son sentir, sino tenia de ser enfadós al / Ilt.e Cap.l y aixis salvant sempre son sentir ceñeix son vot dient / que per tot lo sobredit que se allega [en] contra del Lic.do Jaume Forcada / no sols creu merezca lo major castich que se li podria donar pero no / la menor reprehensio, he dit lo major castich perque revocantlo del / Magisteri no sols se li malogra eixa conveniencia y lo aparato / de casa, que ab tant breu

Anuario Musical, 58 (2003) 
temps avia sabut plantar, sino que res - / ta casi impossibilitat de ordenarse y molt mes de elegir al- / tre estat, cosa que ningu la compendra sens grave prejudici / [Fol. 66r.:] de la estimacio de dit Forcada per ser tant inusitat en totas las Ca- / thed[r]als y molt en particular en esta lo despedir M.es de Capella sens / donar majors motius - [esp. en blanco] Este es mon sentir. Salvo semper \& y aixi / ho firmo vuy dia 14. de Abril de 1701.".

[44] Fol. 66r.: [«Die 15 Aprilis 1701. Cap.Pasch. Cont.»:] "Responsio dicti Dissentimenti. / Lo Dissentiment que lo D.r Pau Vilana Perles Dega y Canonge Prelat / desta S.ta Ig.a ha posat a la resolucio que feu lo Capitol de Cang.es Prelats de la / mateixa ig.a lo dia tercer dels corrents Capitols Pasquals que conta- / vem als 13. del corrent mes de Abril del p.nt añy 1701 . en y ab la / qual fonch resolt no anomenar en M.e de Capella desta Ig.a al Lic.do / Jaume Forcada en suma com.o que los motius y fonaments ha pres lo / Capitol per fer dita resolucio son de poca ó ninguna subsistencia ni / menos suficients per a q. dit Forcada sia digne de la menor reprehencio. / Y si be lo Capitol podia dissimular lo respondrer à dit dissentiment empero / veyent que dit Dega sens tocarli per ningun motiu (antes be lo contrari / per molts titols) ha empres impugnar la referida resolucio, li ha apare- / gut respondrer perque ab lo silenci no sia vist aprobar lo que en lo dis- / sentiment se discorreix. / Son moltas y grans las equivocacions que se prenenen dit dissentiment / la p.ra equivocacio que pateix es en lo que assereix que lo Capitol ha re- / vocat la nominacio de dit Forcada per lo que se deu suposar que la / nominacio que lo Cap.l quiscun añy acostuma fer en Capitols Pasquals de / M.e de Capella y demes oficials es sols per un añy, que acaba en arribar / los immediats y subseguents Capitols Pasquals y semblants nominacions / tenen dos limites ò termens, lo un en beneplacit del Cap.l que com a / dueño absolut y usant de sa libera facultat que li competeix los pot / remourer sempre que vulla, y quant be li apareix, y sens causa. / Lo altre fi y terme es espirat lo añy. Aixi mateix se deu / suposar que en los Capitols Pasquals del añy 1700. lo Capitol / anomenà en M.e de Capella al dit Forcada. / Suposat lo referit se ha de dir que lo averse despedit dit Forcada / no es revocacio de nominacio en manera alguna adhue / [Fol. 66v.:] imppriè, ò quasi, pues ja avent espirat lo añy de sa nominacio / estava finida extincta y no y havia ja nominacio, et non entes / nulle sunt qualitates. / Altra equivocacio pateix dit dissentiment en lo que diu a la fi de q. / es consuetut y pregmatica del Capitol no despedir oficial algun de la / Capella. Per quant la veritat del fet es en contrari de tal manera / que sempre que li ha aparegut al Cap.l usar de sa libera facul- / tat ha despedit qualsevol de sos oficials indistinctament en- / cara q. ajan estats oficials de la capella y ni aja tingut cau- / sa ni motiu algun per despedirlos y remourerlos sens que / per aixo aja deixat de encontrar oficials de cabal satisfac- / cio aventne despedit molts y diferents que eran mes utils y / necessaris que no lo del M.e de Capella en prova del que en / lo referit per a procehir ab tota claredat se respondra á / dit dissentiment en cada un de sos cap.s ó punts. / Primere.t diu lo dissentiment que dit Forcada no te culpa en / no aver obtemperat al que li manà D.n Ignasi de Cruylles Ca- / biscol y Cang.e Prelat desta S.ta Ig.a de que sempre que volgués / ocupar cadira alta en lo chor se assentàs en la cadira de son / retol per averloy aixis ordenat dit Degà, al qual se li avia as- / segurat q. se avia practicat sempre de assentarse lo M.e de / Capella p.r que ningun beneficiat, y que aventse proposat es- / ta dificultat al Cap.l considerantla digna de mirarse no pren-/ gue altra resolucio sino q. se elegissen comissaris pera que ave/ riguasse en lo arxiu. Y que despues de aquella dit Forca- / da avia de quedar perplexo; pues si obehia al Cabiscol / faltava al Cap.l concloent de tot lo referit lo dissentiment / que lo cap.l no ha pogut pendrer per motiu per fer dita reso- / lucio lo no aver dit Forcada obtemperat dit mandato / Este punt te facil resposta. Perque precindint si lo M.e de Capella deu / tenir, ó no la precedencia en lo seurer en lo chor als demes Benefici- / ats opcupant cadira alta, lo cert es que lo Dret de presidir en lo / chor, corregir y castigar las faltas y excessos que en ells se come- / ten per los residents aixis Cang.es com Beneficiats y demes no radica / persona alguna particular sino es lo mateix Capitol y del Cap.l / refundeix y dimana al Premisser Cantor ò Cabiscol segons la / [Fol. 67r.:] consuetut de cada Ig.a y en esta S.ta Ig.a aquesta facultat se troba / refundida y dimanada al Cabiscol, com aixi es en casi totas las Ig.as de / Españya, Per lo que dit Forcada 
devia atendrer al que li manava / dit Cabiscol com a legitim y degue superior y no al que li ordena- / va dit Degà, sens dirne cosa al Cap.l ni à dit Cabiscol, sino pp.o marte / et mittendo falum in messm alienam. Majorment avent lo Cabiscol / advertit per tres vegades que lo gobernar y castigar los excessos en lo / chor tocava à ell y no al Dega. Y per conseguent dit Forcada faltá / gravement deixant de obtemperar al dit mandato volentse fer ab / aixo de millor condicio q. los Cang.es (los quals estan subjectes a la correc- / cio del Cabiscol en las faltas que cometen en lo cor) com tambe exi- / mirse de ipso dita correcciò y lley tant lloable y santa or- / denada la mes puntual y duent reverencia atencio gravedat y / autoritat solemnitat y decoro del chor en la decantacio de horas Cano- / nicas y celebracio dels Divinos oficis. Per altra raho faltá dit Forca- / da perq. vehent que de la contrafaccio de dit mandato avia de / seguirse algun empeño, ò disgust entre dits Dega y Cabiscol podia / y estava en sa ma evitarlo sens faltar al orde de dit Dega ni man- / dato de dit Cabiscol, escusant dit Forcada ocupar cadira alta / y si agues importat deixar de residir, majorment podent com podia / promptement y ab facilitat recorrer y sup.car al Cap.l se servis manar- / li lo que devia obrar. / Despues de seguida la referida resolucio faltà tambe gravement dit Forcada / no obtemperant à dit mandato no constantli com no li podia constar / que fos revocat. Perque quant se feu la referida resolucio no se resol- / gue ni menos proposá si se revocaria ò no dit mandato sino que / tant solament se resolguè (conforme diu lo dissentiment) ò proposà lo / punt de la precedencia fent comissio pera que se mirás en lo ar- / xiu en lo que procehi ab gran madureza lo Capitol per no trobarsi / com no si trobava dit Cabiscol quant se feu dita resolucio y / avent de ser ohit aquell per poder passarà pendrer reso- / lucio en y à cerca la revocacio de dit mandato. Ni menos / dit Forcada seguida aquella podia quedar perplexo si obeint al / Cabiscol faltava al Capitol no constantli com no li podia constar / que se hagués proposat a lo menos la revocacio de dit mandato / y en cas dit Forcada agués tingut en asso alguna perplexi- / [Fol. 67v.:] tat, podia facilment eixir de aquella sup.nt al Cap.l las declaràs. / Segonament diu lo dissentiment que lo Cap.l no ha pogut pendrer per motiu / per a fer la p.nt resolucio, lo dirse que dit Forcada es estat causa que lo / P. Fran.co Cots thenor, y Fermin contralt han deixat esta Ig.a perque / quant aquella se despediren de dit Dega, digueren que la ocasio de / anarsen era perque lo Cap.l los avia alçat la Missa de Charitat / tres sous que los avia ofert. / Se respon que à demes es publich y notori que dits P.Cots y Fermin / deixaren esta Ig.a per respecte de dit Forcada, y aqueix fou lo unich / motiu que tingueren y no altre y es cert que aquells no do- / naren ocasio alguna à dit Forcada à lo menos que se sapia / perque esta S.ta Ig.a haja quedat privada de dits dos oficials, que / ab la satisfacio se avia experimentat la avian servida dit P. / Cots en ofici de thenor y sustentor y tocar lo orga en totas las / ocasions que se oferia y era menester, y dit Fermin avent / servit de continuo catorse ò quinze añys p.[rime]r de Tible y despres / de Contralt y semblantment tocar lo orga y per son medi aver / servit molt temps y cantar de Tible dos germans seus, lo un / dels quals cantá y servi ab tota satisfacio que no se te recort que / la Ig.a aja tingut millor Tible. Be es veritat que en certa oca- / sio dit Forcada y ja al principi que fonch en esta Ig.a proposá al / Capitol alguna queixa que tenia contra dit P.Cots (que seria / quant lo Degà veguè plorar al dit Forcada) al que lo Cap.l procehi / y aplicar lo remey mes convenient y despues may mes dit Forca- / da se queixà de dit P.Cots del Fermin may se ha queixat al / Cap.l dit Forcada. / Ni es de relevancia lo que diu lo Dissentiment de que quant dits P.Cots y / Fermin se despediren de dit Dega no allegaren altre motiu que aver / sels alsat la Missa. Perque ademes q. ells no digueren q. eix era lo unich / motiu, y que non tenien altre que los mogues deixar esta Sancta Ig.a se / ha de creurer que dit motiu fonch colorat y parlat majorment ses / considera que dita alsacio se feu en los Capitols Pasquals passa molt temps / despues della quant dits P. Cots y Fermin sen anaren que fonch al / setembre, ó, octubre y ho califica ab molta singularitat si se aten que no / ignoravan dits P.Cots y Fermin que haverlos alsat las missas era perque / novament se havia encontrat que las missas sels havia offerts segons / [Fol. 68r.:] dispossitio expressa y lley de sas resp.s fundacions se hauran de celebrar per los / Canonges y en los altars desta Ig.a ahont sols celebrants diuen missa los $\mathrm{Ca}=/$ nonges y que en eixa conformitat havia resolt ni menos donar semblants / missas al Canonge jubilat, ni als Canonges ausents de la 
residencia desta / Ig.a per no poderlas dir en los altars de aquella com disposan sas respectiva[s] / fundacions-, / Tercerament diu dit Dissentiment que havent dit Forcada proposat al Capitol q. / en la Capella de Sant Joan de Valencia y havia una abilitat de corneta que donaria / plena satisfacio (que es Joseph Fuentes) y que oferintli cent sinquanta lliures / de salari podria se vist, resolgue lo Capitol que vingas y que sino agradava sen / tornas y havent ohit a dit Fuentes y la repprobacio de dit Forcada resolgue adme / terlo podent aleshores lo Capitol sens faltar a la resolucio admeterlo. Y que / Mestre Cabanilles de Valencia lo aproba, y lo R.t Isidro Serrada M.e de Capella / jubilat desta S.ta Ig.a assegura que es la millor habilitat de la Ig.a conclohent / del referit discentiment que dit Forcada no ha faltat en cosa encara que aya / estat causa de que lo Capitol aja admes à dit Fuentes ab tant cresent salari per cor- / neta y que de aixo no pot ni ha pogut pendrer motiu per a fer la p.nt resolutio / Perque se respon dient que passant per lo que diu lo discentiment en sas premissas / lo cert es que dit Fuentes fonch fet venir y admes ab dit salari per habilitat / de corneta, y en força de la paraula que dit Forcada empenya al Capitol y con / firma quant se admete de que donaria plena satisfacio - Semblantment / es cert que per la habilitat de corneta per la qual se feu venir y admet[r]e dit / Fuentes lo salari de $150 £$ es molt exorbitant y exces de dit salari no obstant / que dit Fuentes toca tambe los instruments de xirimia y baixonet y a exer / cit lo offici de sustentor molt temps y servit ab molta quietut y lo crego? / estos Capitols Pasquals nemine discrepante ha resolt lo Capitol rebaixar lo / salari a dit Fuentes $40 £$ y posarlo a $110 £$ vegas pues si es molt just / lo sentiment que en est particular deu tenir lo Capitol contra dit Forcada / Quarto se dedueix y allega en dit dissentiment que lo Capitol no / pot queixarse de dit Forcada per aver encabit en preveners un / germa un nebot y altre de sa Patria y tractar a estos ab dife- / rencia que als demes aixis en la enseñança com en lo vestir y pre- / heminencia; per quant los dos cantan menos mal que altres dos, los / quals han estat admesos per no trobarse de millors, y en quan tal / segon diu que no creu se puga justificar. / [Fol. 68v.:] En lo tocant a est particular diu lo Capitol que la principal que- / ixa que te contra dit Forcada es lo aver encabit en prevener / a son nebot lo que no nega dit dissentiment, sino que ho po- / sa en silenci com tambe per donar la preeminencia en lo / cantar à son germa, sent mes antich en lo servey de la Ig.a Mi- / quel Allet Prevener no cantant com no canta menos mal que lo ger- / ma de dit Forcada, donantla sols al dit Allet en las cosas pe- / nals y servitut que solen fer los Preveners en casa del M.e de / Capella. / Quinto se diu y allega en dit dissentiment que los motius ha / pres lo Capitol per a fer la present resolucio y operacions referi- / das de dit Forcada avian passat y succehit quant lo Capitol / resolguè asseñyalarli congrua y demanar al S.r Bisbe lo ordenàs / En satisfaccio del que se deu suposar que dit Dega sens donar / suplica dit Forcada proposà al Capitol se servis discorrer algun / medi per a poderse ordenar dit Forcada y demanarlo al S.r Bis- / be y considerant lo Capitol era materia ardua y molt difi- / cultosa no responguè altra cosa sino que se elegissen comis / saris per a que la premeditasen y premeditada fessen relacio / al Capitol los quals en altre Capitol despres de premeditada la / materia en execucio de sa comissio fesen relacio que no avian / sabut discorrer altre medi que lo de asseñalarli congrua sobre / las Distribucions, si be los apareixia que aqueix patia algunas / dificultats, tenia per apoyo lo exemplar de Fermin, y feta dita / resolucio se passà à votar y resoldrer y asseñyalar congrua so- / bre las Distribucions del chor, y demanar al S.r Bisbe que orde- / nás à dit Forcada ab gran contrarietat de vots, los uns insistint / absolutament que no se li asseñyalás considerant y pensant qui/ ssá que lo Capitol en sent a Capitols Pasquals per las referidas ope- / racions de dit Forcada pasaría à pendrer la present resolu- / cio. Altres foren de vot que lo cas de Fermin no era / adaptable per poder demanar al S.r Bisbe que ordenàs á / dit Forcada ab la assignacio de dita congrua, perque quant / lo S.r Bisbe ordenà a dit Fermin avia mes de dotse añys y des- / de miñyó que habitaba en la p.nt ciutat y se asegura al / S.r Bisbe que molt temps antes que no penses en ordenarse / estava ab animo de habitar perpetuament en la p.nt ciutat / [Fol. 69r.:] y que ninguna destas circunstancias concorria en dit Forcada / Altres insitiren fortament que apareixia devia lo Capitol reparar en / fer dita demanda al S.r Bisbe fins y a tant se agues terminat (que en / breu esperava terminarse[)] la que lo S.r Bisbe en ple Cap.l y ab repetidas / ab tantas y 
ab tant grans expressions avia demanat al Capitol en y à / cerca la dependencia de la sagristia. Ab las ref[e]ridas suposici- / ons y de ellas y de las cicumstancias qualsevol de mediana in- / telligencia y sens fatigar lo discurs compendra lo formal de la / dita resolucio, y quant poch fa al cas que las referidas operacions / de dit Forcada aguessen precehit à no quant aquella se feu major- / ment podent com ha pogut lo Capitol com à dueño absolut y usant / de sa libera facultat despedirlo ad suum nutum sens aver de atendrer / à causa ni motiu algun com se ha dit y es constat. / Sexto diu lo dissentiment que lo empeño podria formarse ab lo S.r Bisbe / en cas de passarli à demanar que continuás y acabás de ordenar à dit / Forcada ab la assignacio de dita congrua y lo S.r Bisbe no condecendis á / esta peticio, se evita ab la oferta que ha fet dit Forcada de no obrir la / boca ni ordenarse fins y à tant sia del gust del Cap.l y estar molt con- / tent de aguardar la ocasio de algun benefici. / Te facil la solucio, y es que lo Capitol no te seguretat alguna de la oferta / de dit Forcada, antes be tem y ab molt fonament que si se aparta de la / present resolucio dit Forcada se retractarà de dita oferta, y quiça los / primers ordes vinents se solicitarà instarà y sup.carà al Capitol que / escriga al S.r Bisbe per a que continue en ordenarlo y donat cas lo / Capitol tingues alguna seguretat de dita oferta com no la te y que / dit Forcada aguantas à ordenarse fins y à tant obtinguès al / gun benefici, no obstant aixo deu persistir lo Capitol en la present reso / lucio, y la raho de aixo es clara, perque quant se proposà en Ca- / pitol que lo S.r Bisbe no volia continuar en ordenar a dit For- / cada sino que fos interposant lo Decret a la assignacio de / dita congrua no sols se donà per constant que semblant in- / terposicio era prejudicial à la jurisdiccio del Cap.l sino q. / tambe se diguè y assentá per indubitat que ho seria tam / be si lo S.r Bisbe ordenava à dit Forcada ab titol de Benefici y / [Fol. 69v.:] no ab la referida assignacio de congrua, fent perço per a que po- / guès servir de exemplar als S.rs Bisbes successors una declaracio / de animo, dient que ordenava à dit Forcada ab titol de Bene- / fici y no ab titol de dita assignacio. / Y encara que apar que si dit Forcada despues de ser fora desta / Ig.a diu al Prelat que demanarà lo acabe de ordenar que lo S.r / Bisbe de Urgell lo ordená de subdiaca ab la assignacio de dita con- / grua podra ser que à dit Prelat li cause asso alguna admiracio / y que de aquí tinga lo S.r Bisbe algun sentiment; empero en cas lo referit ocasionàs algun sentiment al S.r Bisbe lo que nos / creu en asso nos podria imputar culpa alguna al Cap.l y fi- / nalment es de major è imponderable consequencia lo procurar / evitar lo menor rompiment ab lo S.r Bisbe que no la sentiment / se pondera / Finalment se diu en dit dissentiment que dit Dega may ha ohit a / dir y quiçà ningun dels Capitulars que son vuy aura vist que se aja / despedit oficial algun de la Capella avent de son temps donat motiu al- / gun que estantse la present resolucio en son punt, dit Forcada queda / impossibilitat de ordenar y elegir altre estat y que aquella ningu la com- $/$ pendrà sens grave prejudici de la estimacio de dit Forcada per ser inu- / sitat en las Cathedrals y majorment es esta lo despedir los M.e de Cape- / lla sens majors motius. / Al primer se respon que lo Cap.l los oficials que mes de ordinari ha / acostumat despedir ha estat los de la Capella en prova del que se / podrian allegar molts exemplars los quals nos refereixen per ser no- / toris evitar prolixitat y ab facilitat poderse escontrar en los llibres de / Conclusions. Al segon se diu que no sap compendrer lo Capitol que / dit Forcada que de impossibilitat de ordenarse estantse a la p.nt resolu- / cio nada y originada de les operacions. de dit Forcada que han / obligat al Capitol usar de son dret y facilitat que com à dueño / absolut li competeix de despedir qualsevol de sos oficials sempre que / li apareix. Al tercer á demes que los motius y circunstancias q. / concorden en la present ocasio son a notori molt relevants y super / abundants, se respon que no creu lo Capitol se puga justificar y / en cas se pugues justificar seria estat perque al Capitol no hi ague - / ra apregut usar de sa libera facultat poder y domini absolut / [Fol. 70r.:] que en esta materia li competeix com hi ha aparegut usarne en / est cas en particular ab las ocurrencias de las referidas circunstancias. / Concloirse ab tota evidencia del que queda discorregut en resposta del dit / dissentiment que la p.nt resolucio y determinacio del Capitol es molt justa / incontrastable lloable precisa y necessaria, y que tot quant se dedueix y / allega en lo dissentiment es notoriament irrelevant y frivol y per conseguent / que ha y deu estarse a la p.nt resolucio. Per lo que extitit resolutu / standum esse in decisis die 13. currentis men- 
sis \& anni. Y aixi / pague lo que se le degá, al que foren de contrari sentir los S.rs / Cang.es Rovira, Llorens, y D.r Joseph de Llupiá".

[45] Fol. 70r.: [«Die 21 Aprilis 1701 p.torum Cap. Pasch. Con.tes»:] "[Margen: «Com.o per buscar / Mestre de Capella»] [...] Fou feta comissio als señors canonges Salamo y Ferrer per a cercar mestre de capella".

[46] Fol 70r.: «Die 25 p.torum Cap. P. C.» [«Aprilis 1701»:] “[...] Fou resolt lo continuar a llegir lo sobredit dissentiment sobre dol qual no se na / pres resolucio".

[47] Fol 72v.: [«Die 11 May p.torum Cap. Pasch. Con.tes 1701»:] "[Margen: «Orgue»] [...] A cerca de fer acomodar los que fuit resolutum fer com.o al obrer so / brestant de capella y señor canonge Rovira per a mirar y reconeixer / aquell y que gastan lo que sia necesari".

[48] Fol 72v.: «Die 11 p.torum Cap. P. C.» [«May 1701»:] "[Margen: «Obligacions te lo mestre de / capella»] [...] Fuit resolutum que se admetia a Jaume Forcada per mestre de capella / ab les limitacions que estan continuades en lo paper seguent [:] Nota del que diu observar lo mestre de capella Jaume Forcada [:] / P.mo te obligacio de assistir al cor cada dia una hora antes de vespres / per ensenyar de cant pla menos los dies festius y los dies que faltava lo / sobreestant de capella lo puga fer multar de un sou / Item te obligacio cada anÿ de compondrer una Missa solempne / y un cantic de Magnificat / Item te obligacio de cantar a contrepunt lo Introhits de la Missa / solempnes de las quatre festes anyals y dia del Corpus X.sti y Sant / Ermengol y Sant Od / Item te obligacio de ensenyar de contrapunt a qualsevol dels / musichs y cantors que vulla apendrer o perficionarse de / contrapunt / Item te obligacio de tenir tota la octava de Corpus tres quarts / antes de vespres y tres quarts despres de vespres si esta / Item qualsevol querela o quixa que tinga dels officials tocant de la Capella / en cas que sia digna de remediarse acudira al sobeestant de la capella / privative a qualsevol altre / Item que los preveners tinga en bona custodia ab igualtat aixi, en / la enesenÿansa com en lo demes y que lo poder anar ells a cantar fora / de la Cath.l sie ab llicencia del sobreestant de la Capella / Item que anant á cantar la Capella aixis en sa pietat com fora de / la Cath.l no puga deixar de anari sent beneplacit dels sobreestant de / Capella / Item que quan voldran musica los Batestiris se dega observar lo / [Fol. 73r.:] lo mateix que en lo precedent Capitol / Item que sens faltar a la ensenyansa de cant y musica ensenye els preve / ners de llegir y escriurer / Item que prenga en inventari totas las obras y papers de musica que / son desta Ig.a y que entregue una copia de dit inventari als Arxivers de / scriptures / Item que en tot lo demes se dega conformar si y conforme an practicat / sos antecessors".

[49] Fol. 76r.: «Die 5 July 1701»: "[Margen: «Acerca la perp.o de Anto- / nio Rubio»] [...] Lo señor Cang.e Farrer sobrestant de la capella ha feta relacio que lo dia de air / junt ab lo S.r Dega Rosenach passaren a fer lo acta de perpetuacio á Antonio Ru / bio contralt de la S.ta Ig.a ab lo salari de vytanta lliures".

[50] Fol. 77v.: «Die 9 p.torum» [«7.bris 1701»:] “[Margen: «Admissio de cantor»] [...] Fou resolt admetre a Blas Galindo Capo per cantor ab lo ma / teix salari que tenia Joseph Gervet tenor de di[ta] [etc] cada any".

[51] Fol. 79r.: [«Die 11 9.bris 1701»:] “[Margen: «Ad.o de Subirats»] [...] Fuit resolutum que se admetia a Carlos Subirats per cantor de la capella y ques / despedesques lo Capo pasat Nadal".

[52] Fol. 81r.: «Die 31 January 1702»: "[Margen: «Com.o»] [...] Fou feta com.o al A.ca de Berga per a fer apoca al M.e de capella Serrada per lo / que ha pagat per la renda de Vilanova que tenia junt ab lo quandam M.o Cambo".

[53] Fol 81r.: «Die 31 January 1702»: "[Margen: «Peticio dels Beneficiats / per a obrar en la capella / de la Pietat»] [...] Isidro Serrada en nom dels benificiats a demanat al S.r Dega, que proposa al Capi / tol se designar permetre a dits beneficiats lo posar una vidriera en la finestra de la sacris- / tia de la capella de la pietat y posar las bastidas que per a conseguiro si an menester / oferint refer tots los danys que de dita obra se podran originar". 
[54] Fol 81r.: [«Die 31 January 1702»:] “[Margen: «Ad.o de M.o Barber»] [...] Fou resolt admetre a totes les distribucions del chor aixi de menuda com de Espes / al R.t Joan Barber p.e y Benefi.at del bene.i de S.ta Cathd.a fenli gratia del examen de / cant".

[55] Fol. 85r.: [«Die prima mensis May»] «Capitulum Paschale anni MDCCII»: "Mestre de Capella - M.o Jaume Forcada / Organiste - M.o Isidro Serrada / Baixoniste - M.o Philip Gensana / Faristolers - Los cantors / Faristolers del cor major - Los cantors / Faristolers de cor menor - Los cantors / Corneta - Joseph Planes / Contralt - Atonio Rubio / Martirologi - Philip Gensana / y Andreu Vilanova / Tenor - Carlos Sobies / Traurer los gossos de la Ig.a - Los preveners / Encendre lo rotlle - Los preveners / Manxador - Pere Vila".

[56] Fol. 87v.: «Die 9 p.torum Cap. P. C.» [«May 1702»:] [Margen: «Te Deum»] [...] En attencio de aver tingut certa noticia del feliz arribo de sas Mag.ts / en Napols y Zaragoza fou resolt que diumenge primer esment se cante / lo Te Deum i cesson les rogatives".

[57] Fol. 87v.: «Die 11 p.torum Cap. P. Con.» [«May 1702»:] “[Margen: «Com.o orgue»] [...] Fou feta com.o al Ar.ca de Cerdanya y Can.ge Rovira per a que mire / ab lo mestre Serrada que se designe al organiste mayor satisfacio / dientli que tal vegada se auria de adobar los que desta S.ta Ig.a / si tindria cami de passar a regoncixerlo".

[58] Fol.88r.: «Die 12 p.torum C. P. C.» [«May 1702»:] "[Margen: «Estatut en orde al / cantar dels S.rs Capitulars»] Considerant lo gran zel y cuidado ab que molts Pontífices y Sants / pares an procurat y disposat que los divinos officis se canten ab la degu / da decencia ab mas o menos solempnitat segons la qualitat de festes y temps / per mes augment del Culto divino y mourer als faels a mes devocio lo que es mes / conforme al serveÿ de Deu se observe ab mes rigor en las Ig.as Cath. y se haya / exprimentat que alguns Capitulars sens saber de cantar an pres Epistoles Evan / gelis, Obits y Missas conventuals ocasionant mes risa que aprecio y venera / cio deguda a las cosas divinas y santas y que sino se prenia lo remey a / tant grave abus per temps se perdia lo lloable stil y modo de cantar / que sempre han observat nostres antecessors en mayor credit del / ritu de la Ig.a. Perço estatuim y ordenam per status perpetuo que / ningun Capitular que veÿes y per temps sera si no te la noticia practica / del modo de cantar que se deu observar en los divinos officis stil y consue / tut de esta santa Ig.a no puga fer de semmaner en lo Chor cantar Episto / las Evangelis Obits Missas conventuals ni altres officis y encar de fer / lo contrari lo Dega ó son llocht tenint instancia de algun parti / cular dega proposar en Capitol (observant lo decret se li encomanava) / si dit Capitular es pratich y pot continuar en cantar y feta dita proposicio / se votara per scotrini y si se resolra que es ni habil no puga tornar a can / tar encara que sie per raho de servituts tocant a son canonicat o dignitat / sens tenir primer lo xpres beneplacit del Capitol lo qual aixi mateix se / li concedira per escutrini".

[59] Fol. 90v.: «Die 13 Juny 1702»: “[Margen: «Aument y rebaixa de / salari a Subies y Gen / sana»] [...] Attesa la representacio ha fet Carlos Subias Tenor de que se li aumentas / fou resolt afegirli vint lliures rellevant al Felip Gensana de son sala / ri $10 £$ y en eixa forma quedara $50 £$ per dit Gensana y $80 £$ per / dit Carlos attesa la servitut de un y comensava a correr al p.r de juliol / p.r vinent lo tal salari”.

[60] Fol. 95v.: «Die 10 8.bris 1702»: "[Margen: «Privacio de cantor»] [...] En attenssio que lo contralt Domingo Gensana sen anaren per lo mon / sent alguns jochs de mans indignes de oficials de Capitol fou resolt / que lo Gensana se despedesca y lo contralt se prive per un mes com / en efecte se executa luego".

[61] Fol. 95v.: «Die 10 8.bris 1702»: "[Margen: «Cantors»] [...] Fou resolt que qualsevol oficials cantor que vulla anar fora per vuyt / dias sols dega demanar llicencia al sobrestant de capella y anar al / mestre pero passant dels vuyt dies degan demanarlo al Dega".

[62] Fol. 97r.: «Die 24 9.bris 1702»: “[Margen: «Orgue»] Attesa la relacio que an feta lo señor Ardiaca Mayor y Canonge Rovira de haver concer / tat adobar lo orgue ab mestre Jaume Grulla per trenta 
sinch dobles com ve / al dit a prest conforme se ha capitulat ab dit Grulla la qual capitulacio es com / se segueix $=$ Noti del que se ha de treballar en la afinacio y demes necessari $/$ dels orgues $=$ Primo per restituhir los dos orgues y cadireta en son prístino / estat y segons estan compostos posats aquells en perfecta afinacio se necessita / traurer tota la flauteria de los quicis per a limpiarla perfectament y traurer la / pols y demes immundicia de sobre los secrets y remirar aquestos si jugan be / los registres = Item se á de alsar y mudar las teclas a proportio y mudar / las teclas pus estan ja menjades del exercici del tocar = Item se á de adobar las / contras ab sos tornillos y vergats y renovar las fustas que per est effecte sian mes / sucias y aixi mateix en lo açiento de la cadireta mudar la dispositio que vuy te / com tambe fer una porta al traves del vergat nou se fara per la cadireta de forma / ques puga obrir per la part de la cara del orgue per evitar lo entrar dintre si / acas se ha de acomodar algunas varillas de la cadireta = Item se ha de fer / un peu nou a la primera flauta del registre del tapadillo o afigir estanÿ en / altra flauta que vuÿ supleix una pedra = Item se ha de cobrir de nou / totas las manxas tant de un orgue com de altre $=$ Se nota que part del Il.tre / Capitol se an de donar tots los materials necessaris perla obra y un fuster que / treballe en lo necessari a costa de dit Il.tre Capitol y tambe manxador y / als 23 9.bre 1702 se ha concortat ab lo S.r Ja.[um]e Grulla adobador de orgues que ab / lo sobredit pacten a di[a] adobarlos per 35 dob. Lo que a promes als Com. que son lo S.r A.ca / de Cerdanya y Cang.e Rovira".

[63] Fol. 98r.: «Die 15 January 1703.»: "Lo R.nt Isidro Serrada p.e y Bene.at de la S.ta Ig.a de Urg. Procu.r substitut del S.r Jaume Joan Solans procu.r constituit del S.r Joan Mir y Roy provist de la / cabiscolia y can.t [canonjia] desta S.ta Ig.a Consta de la procura en poder del R.t Pau Mitjany / not.i [notari] de B.a a 8. del corrent y de la substitucio en poder del secre.ri a 13 / del corrent en dit nom p.nta al molt H.e Capitol los Butllas ap.cas de dita Cabis / colia Can.t una carta de cancelleria demanant se li entregue posessio y dit / [Fol. 98v.:] Il.e señor Dega en nom del capitol a respost que acceptaran aquells / ab lo degut honor y que se procurara donar la deguda providencia / [...]".

[64] Fol. 99r.: «Die 9 February 1703.»: "[Margen: «Com.o»] [...] fou feta com.o als señors Dega y Llorens per a mirar lo benefici de S.ta Ma / ria del Pont si vaca[nt] y si es unit ab algun altre bene.i y encar que lo capitol pu / ga presentarlo divolut [podria fer-ho?] ques presente luego a Jaume Forcada mestre de / capella".

[65] Fol 99r.: «Die 17. p.torum» [«February 1703»:] “[«Margen: Relacio de aver rego / negut una casa de / un capitular»] [...] Lo señor Dega y Don Joseph de Llupia feren relacio de que los oficials / del General los anaren a buscar en casa, y de alli partiren pera re / goneixer la casa del S.r Canonge Llorens en la qual no sey troba cosa al / guna del que pensaven y sabent que esta demostracio era ocasionada / de Phelip Gensana cantor de la sancta Ig.a lo qual se troba taules del / General faltant a la attensio que deura al S.r capitular encara que / [Margen: «Despedir a Gensana»] fos estada verdadera la sua suspita per lo tant fou resolt despedir / a dit Gensana de tots los lucros y salaris [que] tenia en esta S.ta Ig.a com en fer/se executantes de vespres del mateix dia / Aixi mateix fou resolt fer gratia y presentar lo Benefeci / baix la Invocatio de N.a S.ra del Pont fundat en esta S.ta Ig.a al / licentiado Jaume Forcada M.e de Capella en attencio de la rela / [Fol. 99v.:] cio que an fet los comissaris de que dit Bene.i esta realment va / cant sens trobar de vuy tanta anys a esta part collatio ni obten / tor algun que des del any 1619 se dona per inixigible en los / llibres de quarta en tots los quals se troba continuat y conte de sa / Fundacio y tambe fou resolt de que sino menester gixar editures / per la collacio de dit Bene.i que dits com.ris satisfaesin per la / primera ocasio que lo capitol se trobas junt".

[66] Fol. 99v.: «Die 19 Feb. 1703»: "[Margen: «Collacio del B. de S.ta / Maria del Pont»] [...] Fuit resolutum collar lo Benefici de S.ta Maria del Pont al llicen.do / Jaume Forcada mestre de capella com en efecte se li colla sens prec hir / edictes y ab les demes sircunstancies que se acostuma y seguidament / se ordená al capeller de Sant Ermengol que si li entregar pocessio". 
[67] Fol. 99v.: «Die 24 p.torum» [«Feb.1703»:] "[Margen: «Admissio de M.o Pere Agui / lar y dispensat en examen / per ser de familia del Capitular»] [...] Fou resolt admetre a les distribucions de Menuda y Espes del cor de / N.tra Cath. a M.o Pere Aguilar despensarli lo examen per ser de familia / del Capitular y per obtenir lo Bene.i sots invocatio de la anuntiateu fun / dat en N.a S.ta Ig.a".

[68] Fol. 100r.: [«Die 27 Feb. 1703»:] “[Margen: «Admissio de M.o Jaume / Joan Vidal»] [...] Fou resolt admetre a les distribucions del cor y Espes a Jaume Joan Vidal per ser parent / de Señor Canonge Fiter com a obtenir lo Benefici Sant Salvador de Masanet".

[69] Fol. 100r.: [«Die 27 Feb. 1703»:] "[Margen: «transport de diner»] [...] Fou resolt fer venir los diners que lo Ar.ca de Berga com á receptor tenia en Guissona / per medi del mestre de capella".

[70] Fol. 100v.: [«Die 9 Marty 1703»:] “[Margen: «Admissions»] [...] En attensio de la propositio feta per lo Señor Dega de que tenia entes que / los dos Bene.ats que se admeteren ultimamament en lo cor no eran admesos a la / Pietat avants presentats en estas temporas passadas com se acostuma $=$ fou $/$ resolt que dit señor Dega envias a buscar als presidents en sa casa y que / de part del Capitol los digues quant se estranyava esta dilacio per oposarse / totalment a la Concordia ternari feta y jurada y ser contra dispusitio de esta / y de la Consuetut Immemorial inconusament observada en esta S.ta Ig.a y / que donasen los motius que tenran per a dilatar dita admissio per a que / lo Capitol pugues donar la deguda providencia a esta novedad".

[71] Fol. 101r.: «Die 16 Marty 1703»: “[Margen: «Admissions»] [...] Lo S.r Dega feu relacio de la resposta que los Presidents de la Pietat li tornaren / lo dia 13 a la tarde: y fou dient que son comu aura resolt admetrer a la Pietat / a M.o Pere Aguilar altre dels bene.ats p.[rese]ntats y que no fent mencio de M.o Jau.e / Joan Vidal que era lo altre que se presenta pregunta dit dega si era admes y / respongueren de que en las temporas vinents se admetia per faltarli ara algun / requesit y avaent dit dega averiguat quin requisit podrà faltarli troba / que dit Jau.e Joan Vidal traure certificatoria del secretari del capitol / de com era admes a las distribucions del cor de esta S.ta Ig.a com se acostuma y se / pactat en la ultima concordia, sino que sols feu ostentio de la sup.ca decretada / per lo Capitol y que se valyan de eix descuyt per a dilatarli dita / admissio = en attencio de tot lo qual se ha resolt que supuesto dit Jau.e Joan / Vidal es ausent y no ha donat la menor quixa ni noticia de aixo al / Capitol, que se suspenga lo donari per ara nova providensia".

[72] Fol. 101v.: [«Die 23 Marty 1703»:] “[Margen: «Contralt»] [...] Fou resolt no attendrer a la sup.ca donada per lo contralt demanant en / ella lo salari del temps que estigue fora per quant es contra stil passant / de quinse dies la ausencia no sent per cosa de la Ig.a".

[73] Fol. 104v.: [«Die 24 Aprilis MDCCIII Cap. Pasch. Continuantes.»] "Mestre de Capella - Forcada / Organiste - Serrada / Baixoniste - [esp. en blanco] / Faristolers - Los cantors / Faristolers de cor mayor - Los cantors / Faristolers de cor menor - Los cantors / Corneta - Joseph Planes / Contralt - Antonio Rubio / Martirologi - Andreu Vilanova / y Gensana / Tenor - Carlos Sobies / Traurer los gossos de la Ig.a - Los preveners / Encendre lo Rotlle - Los preveners / Manxador - Fahena".

[74] Fol. 106v.: [«Die 24 Aprilis MDCCIII Cap. Pasch Continuantes»:] "[Margen: «Aguilar Cantor»] [...] Lo R.nt Pere Aguilar p.tre Bene.at de la N.a S.ta Ig.a fou nomenat entre los demes cantors per a que pugue seguir y cantar en la capella si y con / forme feyan M.o Sol, M.o Gual y altres ab salari de sinch lliures cada / any".

[75] Fol. 106v.: [«Die 24 Aprilis MDCCIII Cap. Pasch. Continuantes»:] “[Margen: «Com.o»] [...] Fou feta com.o al señor Ardiaca de Cerdaña y sobrestan de capella per a mirar si / si lo mestre de capella cumple ö no a les obligacions [que] te ÿ se li donaren en sous".

[76] Fol. 106v.: «Die 25 Aprilis 1703. Cap. Pasch. Con.tes»: “[Margen: «Com.o per la Pan / decta] [...] Fou feta Com.o al Señor Canonge Zaÿdin per a que junt ab los dos / comissaris Montaner y Verges reconegan la pandecta vella y nova y segons ellas statuescan lo que mes consernesca al culto / divino y 
decencia de la Ig.a y tambe per a formar un paper / per a posar a la porta del cor per a que no pugan faltar los residens / del cor en el Te Deum".

[77] Fol. 107r.: «Die 28 Aprilis 1703 Cap. Pasch. Con.»: “ [Margen: «Rellenar salari á / Fuentes y aug.ar a Planes»] [...] Fou resolt lliurar deu lliures del salari a Fuentes les quals se augmen / ten a Joseph Planes corneta".

[78] Fol. 107v.: [«Die 28 Aprilis 1703 Cap. Pasch Con.»:] "[Margen: «Acerca de les admissi / ons dels Bene.ats»] [...] En attencio que los bons [moneda] de nostra S.ta Ig.a se van deteriorant / per ocasio que los bene.ats no saben de cant per lo tant en aug / ment de lo culto divino y altrament fuit resolutum que en / avant no se admentia bene.at algu als husos y ganancies de / nostra S.ta Ig.a que primerament no sia examaninat rigu / rosament de cant pla per lo M.e de capella en p.ntia dels SS.rs / Cabiscol y Sobrestant de Capella ÿ constatant de la relacio / en escrits feudora per dit M.e de capella que lo bene.at se / aura de admetrer [si] es habil de cant pla a les hores solament / se admetia entes empero que la p.[rese.]nt sulucio no comprenga / als bene.ats que seren graduats y que en eixa for / ma se suspengen als Bene.ats per raho de la representacio / [que] tenen feta per medi dels SS.rs Dega Ar.a de Berga y Canonge / Montaner com conste lo dia 29 de marty y propassat".

[79] Fol. 108r.: [«Die 30 et Ohmia Aprilis 1703 Cap. Pas. Con.»:] "[Margen: «Despedir u prevener»] [...] Fou resolt que lo Peret de Llivia prevener se torne a casa los pares per / que arme mal servida la Yg.ta y si a la incumbencia del obrer en lo ves / tirlo y enviarlo quant antes y que lo canonge Salamo se informe a lo / mestre Serrada si lo Juanet nebot del mestre de capella done esperances / de poder servir ab la veu y demes a la capella desta Santa Ig.a y que / se pose la cota y que se se envie a casa del M.e al Aragones ques vingut / pagant a Carlos Subies tot lo que se li degue donar fins al dia p.[rese]nt / per raho de la despesa y que lo niño de Cervera venint lo obrer / se envio al siminari com se acostuma".

[80] Fol. 108v.: «Die 7. maÿ 1703 Cap. P. Con.tes»: “[Margen: «Admissio»] [...] Fuit resolutum qur Philip Gensana se torne admetrer am vista / de la gran submissio oferta ab les seves supliques adonades y ab lo / mateix salari de $90 £ "$.

[81] Fol. 112r.: «Die 15. Maÿ 1703.»: “[Margen: «Gracia a Ser / rada»] [...] Avista de la relacio que a feta lo señor canonge Montaner y de la / conclusio feta a 17 de novembre [de] 1692 y a 8 de novembre [de ] 1694 y a 27 / del mateix fou resolt que no se puga demanar en ningun temps al / R.nt Isidro Serrada mestre de capella jubilat y organiste de esta S.ta / Ig.ta los gastos que se feren en la causa que lo R.nt Joseph Sellera aporta / va contra dit Serrada en la Curia Romana sobre la impuna del / Benefici que dit Serrada obte com, ni tampoch en ordre dels gastos / se feren en la causa que dit Serrada aportava contra los bene.ats / de esta S.ta Ig.a".

[82] Fol. 112r.: [«Die 15 Maÿ 1703»:] “[Margen: «Subies»] [...] A vista de la suplica donada per Carlos Subies thenor desta Santa / Iglesia y en attencio de haver anat a Arago a buscar un minÿo de / bona veu y haverlo vingut en sa casa serca de dos mesos fou / [Fol. 112v.:] oyt lo que lo obrer li done una dobla y lo señor canonge Mon / taner com a receptor de rossechs de censals li deixie fins a setanta / lliures si son menester per a quitar una pessa de terra que te / empeñada la qual aja de quedar obligada a la Iglesia fins que / dit Subies aja pagat lo que se li dexara ab quatre anys y ab / quatre iguals pagues carregantho a la recaptoria major".

[83] Fol. 113r.: «Die 26 p.torum» [«May 1703»:] “[Margen: «Com.o de examen»] [...] Fou resolt en attencio de la suplica donada per Sagimon Ermengol / p.btre y porter major desta Santa Ig.a fer Com.o al señor Ar.a de / Cerdaña y señor Cabiscol junt ab lo mestre de capella".

[84] Fol. 113r.: «Die 29 Maÿ 1703»: “[Margen: «Admissio de Ermengol»] [...]Avista de la relacio han fet los señors Ar.a de Cerdanÿa Cabiscol / y mestre de capella fou resolt admetrer a les distribucions de Espes / y demes del cor desta S.ta Ig.a a dit Sagimon Ermengol p.btre y porter / major della". 
[85] Fol. 116r.: «Die 3 Augusti 1703»: “[Margen: "Gracia al M.e de / capella»] [...] Fou resolt donar llicencia al mestre de capella per a anar / a sa casa per lo termini de un mes ÿ mig y ques / despedeix / a son nebot Joanet a vista de la actuacio que se ha feta de no ser / de profit per la capella".

[86] Fol. 115[bis]v.: «Die 16 8.bris 1703»: "[Margen: «Perpetuacio de Fuentes»] [...] En attencio de una suplica donada per Joseph Fuentes / cantor de nostra Santa Iglesia y dela cabal satisfacio / que dona de sas habilitats de son bon obrar = fou resolt / assenÿarlarli per congrua $80 £$ cada un any per / petuarlo en ellas si de poder ab dita congrua aspi / rar al s[eli].bat de sacerdot assegurantli la mitat sobre / les distribucions de esta Santa Iglesia y la altra mitat / sobre del salari que vuy en dia gosa y que desta re / solucio se lin entrego copia autentica de la manera que / suplica".

[87] Fol. 124r.: [«Die octava Aprilis Capitulum Paschale annis MDCCIV»:] "Per cantar los Evangelis ab salari acostumat $210 £$ - M.o Joan Forcada ben.at / per cantar las Epistolas ab salari acostumat $210 £$ soes / sinch lliures la Ig.a y sinch lliures lo stador de Vilamitjana - M.o Joseph Bonet B.t / Mestre de Capella ab salari de $200 £$ - Jaume Forcada p.e / Organista ab salari de $100 £$ y $50 £$ per ser ju / bilat - M.o Isidro Sarrada B.t / Baxonista ab salari de 50£ - Phelip Gansana p.e / Faristolers -Los cantors / Faristolers del cor major - los cantors / Faristolers del cor menor - Los cantors / Corneta ab salari de $10 £$ - Joseph Planes / Contrahalt - vaccat / Cantar lo Martirologi ab salari de quatre lliures / so es dues lliures la Ig.a y dues lliures lo stador de Vilamitjana - Felip Gansana / Thenor ab salari de 80£ - Carlos Sobies / Obrir y tancar lo cor de la catedral ab salari de $1,10 £$ - los preveners / Traurer los gossos de la Ig.a ab salari de 1,10£ - los preveners / Ensendrer y apagar lo Rotlle ab sal. de 1,10£ - los preveners / Manxador dels organs y escombrador ab sal. de $20 £$ - Pere Fahena".

[88] Fol. 126v.: [«Die X5 Aprilis 1704»:] "Memorial del modo que se han de pagar las distribucions / als interessants en las funerarias fahedoras als señors / Capitulars en los tres dias del Enterro Novena y Cap de any / primo als señors Capitulars so es celebrant, assistents / capers, y demes axi en la distribucio com en lo vistuari / y caritat de missa (la qual sesmersa per una de les / tres que quiscum deu celebrar per lo capitular di=/ funt) Nihil, sed omnis gratis. / Item als preveners un sou a quiscun per quincun / dia que essent quatre sera doble so es diem - 0,12£ / Item al mestre de capella vuÿt reals per quiscun dia / [ $]$ $2,8 £$ / Item per quiscun dels demes cantors quatre sous per quis / [Fol. 127r.:] cun de dits tres altres que essent deu cantor[s] sume sis- / lliures - $6 £ ”$.

[89] Fol. 128v.: [«Die XXV. Aprilis 1704»] «Dicto Die hora sexta post meridien»: "[Margen: «Proroga del can.t / Penitencies»] [...] Lo molt Hbl.e Capitol pr[o]roga y prorogar dins lo termini Edicte / y Concurs del canonicat penitencier de aqui al dia 20 de matg primer / vinent Ine hisine Dequibus \& [etc] / Testes sunt R.dus Jacubus Forcada magister cantus \& / Josephus Fuentes cantor ambo almce Ecc.ta Urg.n".

[90] Fol. 131v.: [«Die sexta junÿ 1704»:] “[Margen: «Te Deum en accio de / gratias»] [...] Fuit resolutum en attencio de una carta que ha escrita sa Eme / nencia al Capitol de haver retirar la armada Inglesa ques / cante esta tarde un Te Deum en accio de gracias, danatse / part a la ciutat per a que assiste efecte".

[91] Fol. 136v.: «Die 18 X.bris 1704»: "[Margen: «Sota capiscol / Subies»] [...] havent proposat lo señor capiscol a Carlos Subies per a / exercir lo ofici de sota capiscol per lo cor en N.a S.ta Ig.a fuit resolutum / se li done las distribucions del chor acostumades guanÿar per los que exer / ceixen dit ofici sens esser oficials del capitol si sols del mateix capiscol".

[92] Fol. 140r.: [«Die 28 Aprilis Cap. Pasch. Con. 1705»:] "Per cantar los Evangelis ab salari acostumat de $10 £$ - M.o Joan Tarrada bene.at / Per cantar las Epistolas ab salari acostumat de $10 £$ / soes $5 £$ de la Ig.a y $5 £$ de lo Estador de Vilamitjana - M.o Joseph Bonet bene.a[t] / [Fol. 140v.:] Mestre de capella ab salari de $150 £$ - Jaume Forcada p.e / Organista ab salari de $100 £$ y per sa jubil.o $50 £$ - Isidro Serrada p.e B.t / Baixonista ab salari de 50£ - Fhilip Gensana p.e / Faristolers del cor major y menor - Los cantors / Corneta ab salari de $70 £$ - Joseph Planes / Contralt - vacat / Martirologi ab salari de quatre lliures soes $2 £$ 
/ la Iglesia y $2 £$ lo estador De Vilamitjana - M.o Jansana / y Vilana. / Tenor. Ab salari $=50 £-$ Carlos Subies / Traurer y expellir los gossos de la Ig.a ab / salari de $1 £ \mathrm{i}-$ los preveners / Obrir y tancar lo cor de la catedral ab salari / de $1 £ 10$ sous - los preveners / Ensendrer y apagar lo Rotlle ab salari de $1 £$ i - los preveners / Manxador y escombrador ab salari de $20 £$ - Pere Fahena”.

[93] Fol. 141v.: «Die 30. Aprilis 1705 Cap. Pasch. Con.tes»: "[Margen: «Professons dels dissaptes»] [...] Per quant en lo llibre de conclusions y resolucions capitulars del / 1469. se llitg[eix] una ordinacio feta per nostres predecessors, (nota a peu: p.nts los consols de dita ciutat) en que / dispose se fassa tots los disaptes del anÿ al mati una professo solemne / per la ciutat a fi y efecte de conseguir la pau y de no arribar a las mans / dels enemichs: la qual ordinacio se troba continuada en lo llibre de / conclusions de dit anÿ fol. 23. / [...] [Fol. 142r.:] [...] y com ab lo discurs del temps dita professo solament se feÿa fins vuÿ tots los / dissaptes de maig al mati; y de pochs anÿs de esta part ajan deixat de assistiri / los consols y pro[ho]ms de esta ciutat ni menos altra persona, essent de sa / propia obligacio; perço y altrament statuim y ordenam que la dita pro- / feso se continue de ferse no per los carrers que acostumava ferse de dita / ciutat sino sols per los claustros de esta S.ta Ig.a cantan los Imnes / de la Mare de Deu com axi se acostumava".

[94] Fol. 142r.: [«Die 30 Aprilis 1705 Cap. Pasch. Con.tes»:] "[Margen: «Reduccio de / misses»] Item fou feta comm.o als S.res Capiscol y Canonge Ubach per solicitar la / reduccio y condonacio de misses de la Ig.a fent per es efecte las diligen= / cia necesarias per escriurer a Roma y tot lo demes que conduesca a la / consequncio de ella".

[95] Fol. 143r.: [«Die 5 Maÿ 1705»:] “[Margen: «Disminucio de 50£ / al M.e de Capellá»] Item fuit resolutum que per replasar las $50 £$ se donan a Carlos Subies thenor / per son salari estas se lliuren al mestre de capella Jaume Forcada del salari / [que] te de $200 £$ ".

[96] Fol. 145v.: [«Die 24 Julÿ 1705»:] “[Margen: «Vilans de la Ig.a»] Fou feta comissio als señors canonges Net y Rovira per a que / fassan quant antes lo vilans de que se troba decent la iglesia fins / al dia present; y axi mateix del que si li deu, y del que se troba de / positat en lo arxiu de pecunies que es de la Ig.a; y que si fet lo dit / vilans se troba que la Ig.a no te per a pagar lo que deu aixi de / gastos que portan los plets com del demes, se passe a despedir la / capella per enter y quedant sols lo organista y quatre pre = / veners y los dos sota capiscols sens salari; y juntament / que se lliuren totes les missas de tres sous de caritat ques donen / per raho de las atrasadas a diferents particulars, distribuintse / sols las quatre quotidianas que estan fundadas. Aixi mateix / se suspenga pagar als S.rs Capitulars los sinch dobles de las pro= / fessons y matinas de Nadal, fins atant que estiga la Ig.ta / replassada y libera de estos gastos: Y entenir per a referlas / a dits señors capitulars que pugan repartirlas de la Ig.a no sols / los que havant discorerant sino tambe las disconegudas y / no pagadas".

[97] Fol. 146r.: «Die 21 Septembry 1705»: “[Margen: «Gracies a N.e S.r»] [...] Havent feta dita relacio los dits / señors comissaris de haver executat la comissio, sels feu lo dia de air, vuÿ a la- / [Fol. 146v.:] y que lo comandant gustaria que lo dia 23. dia de S.ta Tecla se cantes / lo Te Deum (etc) en attencio del que fou resolt executaro en exa forma / y que dit dia se celebresi los oficis ab la tota solemnitat y que des $=/$ pres de tersia se fassa professo general per la ciutat partici $=/$ pantho als consols $=$ y per quant la com.o no tingueren temps a fer / lo acte de sacrament de fidelitat se li feu com.o special per a firmarlo".

[98] Fol. 149r.: «Die 19. Januarÿ 1706.»: “[Margen: «Perpetuacio a Jo=/ seph Planes corneta»] [...] En attencio de la suplica donada / per Joseph Fuentes corneta de N.a S.ta Ig.a fou resolt perpetuar a dit $\mathrm{J}_{\mathrm{O}}=$ / seph Planes en dit ofici assenÿalantli assenÿalantli setanta lliures de / [Fol. 149v.:] congrua y las distribucions del chor per lucrar en dita N.a S.ta Ig.a / compres lo salari se li acostuma donar, per a que puga ordenarse de / ordes sacros". 
[99] Fol. 151r. [«Die 19 Februarÿ 1706»:] "[Margen: «Entrar al ofici a les / 10 hores lo Dijous S.t»] Item fuit resolutum que lo Dijous al cetero [en endavant] Se entre als divinos oficis / a les deu hores del mati sempre que no se aja de dir de pontifical respecte de / haverse experimentat que a les onse hores ja se exia de la Ig.a".

[100] Fol. 154r.: [«Die 20 Aprilis 1706»:] "Per cantar los Evangelis ab salari acostumat de $10 £-$ M.o Joan Torrada B.t de S.ta Ig.a / Per cantar las Epistolas ab salari acostumat $10 £$ / so es sinch lliures la Ig.a y alores sinch lo Estador de Vila / mitjana - M.o Joseph Bonet p.btre / y Bene.at de N.a S.ta Ig.a / [Fol. 154v.:] Mestre de capella ab salari de $150 £$ - M.o Jaume Forcada / Organista ab salari de $100 £$ y per la jubilacio $50 £$ - M.o Isidro Serrada B.t / Baxoniste ab salari de 50£ - Phelip Jansana / Faristolers del cor major y menor - los cantors / Corneta ab salari de $70 £$ - Joseph Planes / Posar y llevar los obits del cor als S.rs Capitulars - los cantors / Contralt - [esp. en blanco] / Martirologi ab salari de $4 £$ so es $2 £$ la Ig.a y / dues lliures lo stador de Vilamitjana - M.o Jansana / y M.o Vilanova / Tenor ab salari de 50£ - Carlos Subies / Traurer y expellir los gossos de la Ig.a ab salari $1 £ 10$ [sous] - los preveners / Encendrer y apagar lo Rotlle ab salari de $1 £ 10$ - los preveners / Manxador y escombrador de la Ig.a ab salari de $20 £$ - Pere Fahena".

[101] Fol. 155v.: [«Die 21 Aprilis 1706»:] "[Margen: «De reformatione Ecc.tes»] Sobre la reformacio de la Ig.a fou conclos que lo señor cabiscol / no permetia parlarse en lo chor y que ho porte ab tota rectitut / y que dit señor cabiscol los fasse apuntar. / fou resolt que en lo chor nos precipito lo cant, y ques fasse la / [Fol. 156r.:] pausa ques deu fer als dos puns y que lo dit cor no puga comensar / lo vers fins que lo altre cor aja acabat lo que te principiat, y que / lo govern del chor sia del señor cabiscol y que ho aja de advertir / a tots y que cada mes ho aja de portar a capitol".

[102] Fol. 156r.: [«Die 21 Aprilis 1706»:] "[Margen: «Apuntadoria, ningu / hi pose las mans sino / capitular»] Per quant se ha experimentat alguns desordres entre los Beneficiat de esta S.ta Ig.a y / Joseph Fuentes cantor per ocasio de haver puntat dit Fuentes, y a no haverse esdevin $=$ / gut algun señor capitular, sens dupte se hauria arribat á algun exces / dins la Catredal; y per obviar estos y semblants desordes fuit resolutum / que a cetero lo apuntado que es vuÿ y per temps sera no puga valerse / de altre substitut per a apuntar que no sia capitular com axi esta disposat / y previngut quan tingue principi la Apuntadoria ordenant que ningu exer= / cesca lo empleo de dit offici, sino capitular".

[103] Fol. 156r.: «Die 24 Aprilis 1706.»: "[Margen: «Rogativas per la / guerra»] [...] En / [Fol. 156v.:] consideracio de trobarse lo Reÿ nostre señor D.n Carlos Tercer / deu lo guarde assitiat dins la capital de esta provincia per lo / señor Duch de Anjou ab un exercit numeros de francesos y / altres mons de 27.mil homes 15000. cavalls, segons se diu, / y ab semblants casos haventse acostumat sempre pregar a nostre /señor per defensa de la providencia; fuit resolutum ; que dema / dia de Sant March antes de vespres se descobre lo SS.mo sacra= / ment, y seguidament se canten vespres completes / solemnes y despres de del cor se vage al presbiteri y alli se canten / las lletanias majors per dos cantors ab tota solemnitat y decencia / u al ultim lo celebrant diga las oracions solitas y a la ultima se / reserve tancantse las portas del sacrari == y los demes dias / fahenens se expose lo SS.m antes de completes y seguidament se digan / completas solemnes y acabadas se canten en la mateixa conformi / tat en lo Presbiteri ditas lletanias majors. Y per dit effecte se avise / a la ciutat per lo mestre de serimonies com se acostume".

[104] Fol. 158v.: [«Die 23. Julÿ 1706.»:] "[Margen: «Acceptar lo censal de / pensio $2 £ 196$ que offereix / Fran.o Peire»] [...] fuit resolutum / que se accepte lo censal de preu sinquanta nou lliures deu sous / que ha offert Francisco Peyre cirurgia de la p.nt ciutat en paga y sa=/ tisfacio del que deu per la renda dels censos de Vilanova de Banat com / a fiansa de Antonio Rubio contralt que fou de N.a S.a Ig.a lo qual censal / fan y prestan los conjuges Escuders de Estamariu”. 
[105] Fol. 159r.: «Die 11. Octobris 1706.»: "[Margen: «Missa de 3 [sous] a Jansana»] [...] Fuit resolutum que a M.o Felip Jansana cantor de nostra Santa Ig.ta se li done / missa quotidiana de caritat tres sous de aquelles que lo capitol te endarrerides".

[106] Fol. 159v.: «Die 6. Novembry 1706.»: “[Margen: «Vestir preveners»] [...] Fuit resolutum que lo señor / obrer fasse vestir á tres preveners novament han entrats".

[107] Fol. 159v.: [«Die 6 Novembry 1706»:] “[Margen: «Bestraurer a Planes»] Item fou aiximateix resolt que lo señor receptor quiscun mes done de bestreta a Joseph Planes corneta sis lliures fins [que] aja pagat lo que / [Fol. 160r.:] dega, y li done una monicio ben carregada en eix particular".

[108] Fol. 161r.: «Die 18. Marty 1707.»: “[...] Fuit resolutum que per quant se ha tingut no- / ticia certa que Jaume Forcada p.btre mestre de capella no donava la / deguda asistencia als preveners en son sustento y ensenÿansa al ques / tinga per despedit y per tota la semmana de Pascua primer vinent / busque en elora part sa conveniencia, y que no puga proposar a lora / vegada en capitol y axi los notifique nostre Dega".

[109] Fol. 161r.: [«Die 18 Marty 1707»:] "Item fuit resolutum que lo señor Dega envio a buscar als cantors de / nostra S.ta Ig.a y los digan que assistescan a totas las funcions de / antifonas y altres que tene obligacio de cantar y se aguarde a Cap.ls / Pascuals lo resoldrer sobre lo despedirne alguns".

[110] Fol. 161v.: «Die Nona Aprilis 1707.»: “[Margen: «Com.o per cercar M.e de Capella»] [...] Fou feta com.o als señors Ardiaca de Cerdanÿa Cabiscol y sobrestant / de capella pera cercar mestre de capella".

[111] Fol. 163r. [«Die X Maÿ 1707. Paschale Cap. Con.tes»:] "Per cantar los Evangelis ab salari acostumat de $10 £$ - M.o Joan Forcada B.t / Per cantar las Epistolas ab salari acostumat de $10 £$ soes sinch / lliures la Ig.a y altres sinch lo stador de Vilamitjana - M.o Joseph Bonet B.t / [Fol. 163v. :] Mestre de capella / exerceix est offici Carlos Subias - vacat / Organista ab salari de $100 £$ y per sa jubilacio $50 £$ - M.o Isidro Serrada B.t / Baxonista ab salari de 50£ - M.o Felip Gensana p.e / Faristolers del cor major, y del cor menor - los cantors / Corneta ab salari de setanta liures - Joseph Planes / Posar y llevar los obits als S.rs Capitulars en lo cor - los cantors / Contrahalt - Vacat. / Martirologi ab salari de $4 \mathfrak{f}$ soes dues lliures la Ig.a / y dues lliures lo stador de Vilamitjana - M.o Jan[s]ana p.e / y / M.o Andreu Vilanova / Tenor ab salari de sinquanta lliures - Carlos Subias / Traurer y expellir los gossos de la Ig.a ab sal. de $1 £ 10$ [sous] - los preveners. / Encendrer y apagar lo Rotlle ab salari de $1 £ 10$ [sous] - los preveners / Manxador y escombrador de la Ig.a ab sal.de $20 £$ - Pere Fahena".

[112] Fol. 164v. «Die 11. Maÿ 1707. Cap. Pasch. Con.»: “[Margen: «Apuntador»] Item com se exprimentia gran relaxacio en la residencia del cor / aixi per los señors capitulars com tambe per los beneficiats y / cantors entant que molts de ells asistiesen molt poch temps / als divinals officis y anantsen del cor despres de aver / llevat Deu y no tornari fins acabat lo offici de la missa con- / ventual y celebracio dels obits o anniversaris; y desitjant evitar / tant gran abus, statuhim y ordenam que de qui en havant / lo señor apuntador observe exactament tot lo que esta / [Fol. 165r.:] ordenat y estatuit en las conclusions antigas sobre esta relacio- / y en lo llibre de la apuntadoria se troba continuat".

[113] Fol. 165r.: «Die 12. May 1707. Cap. P. Con.»: "[...] Haventse reprsentat lo abus se fá / tant continuat en la celebracio de las Matinas de la Nativitat del / Señor de anarsen del cor molts Beneficiats despres, que ha passat- / lo Bosser y haverlos pagat la distribucio, y altres que sen van antes / de passar la bolsa dexant recomanat que per ell cobre la distribu $=/$ cio, com en effecte se ha exprimentat moltas vegades essent tant / prejudicial aquest abus augment del culto divino, y danÿos a las / conseieneias de aquells; Perço fuit estatutum et ordinatum, que / en havant lo Bosser no pague a ningun resident que no sie in $=/$ teressent en lo cor, sino es que sien malalts y ajen avisat al señor / Apuntador y que lo Bosser no Pague fins al tercer nocturno, y / dit Bosser antes de pagar als llegitimament impedits dega primer / resaltaro a dit Apuntador". 
[114] Fol. 165v. «Die 14 May 1707. Cap. Pasch. Con.»: “[Margen: «Despedir un prevener»] [...] En attencio de la relacio sens- / ha feta de que lo nebot de M.o Joan Som no es de profit per la Iglesia / per ser inutil de poder apendrer cosa fuit resolutum que des=/ pedesca".

[115] Fol. 165v.: «Die 17 May 1707. Cap. Pasch. Con.»: "[Margen: «examen a Cellerá»] [...] Havent demanat / la admissio a les didtribucions del cor de N.a S.ta Ig.a lo R.nt Joan Cellera / obtentor del bene.i de Sant Marti primer en dita Ig.a fundat fou / resolt que se examine more solito y que sen fasse relacio de aquell".

[116] Fol. 166v.: «Die 4 Junÿ 1707.»: "[Margen: «Admissio de Cellera»] [...] Havent Heg fet relacio lo señor sobrestant / de capella y M.o Isidro Serrada organiste de haver examinat / de cant, a M.o Cellera p.btre y bene.at de esta Santa Ig.ta / obtentor del benefici baix invocacio de Sant Marti primer nuncu = / y tenir una suficiencia y la veu ajudada fuit resolutum que / se admete a totas las distribucions del cor en N.a S.ta Ig.a etiam a les / de Espes y que sie escrit al llibre de la apuntadoria com los demes / residents".

[117] Fol. 169r.: [«Die Octava Novembris 1707.»:] "[Margen: «Bestraurer 10£ al / manxador»] Item fou resolt que dit señor receptor bestraga al manxador a compte de / son salari deu liures".

[118] Fol. 170r.: «Die 24 February 1708.»: "[Margen: «Admissio del D.r Bonau»] [...] Fou resolt admetrer / a les distribucions del cor de nostra Santa Ig.a etiam a les de Espes al D.r Fer= / min Bonau obtentor del benefici de Santa Barbara de Guilla y Nyer".

[119] Fol. 170r.: [«Die 24 February 1708»:] "[Margen: «Entra a 8 hores al offici / en la quaresma»] Item fou resolt que tots los dies de festa de la quaresma en que hi haurá pre= / dica y no será dia de diumenge, que se entre al offici a les vuit hores de la / matinada respecte de haverse de celebrar dos officis y vespres".

[120] Fol. 170v.: [«Die 6. Marty 1708»:] “[Margen: «pagar lo espes»] Item fuit resolutum pagarse la distribucio de espes als señors / capitulars y beneficiats per lo señor receptor de censals [Degà de Berga]".

[121] Fol. 174r.: [«Die XXIV. Prodictorum Capitulum Pasch.Con.tes 1708»:] "Per cantar los Evengelis ab salari acostumat de $10 £$ - M.o Joan Forcada B.t ad / mes a la comunitat / Per cantar las Epistolas ab salari acostumat de $10 £$ soes $5 £$ / la Ig.a y alores $5 £$ lo estador de Vilamitjana - M.o Joseph Bonet p.btre / y / Andreu Vilanova C.tor / Mestre de Capella - [esp. en blanco] / Organiste ab salari de 100£ y $50 £$ per la jubilacio - M.o Isidro Serrada. / Baxoniste ab salari de $50 £$ - M.o Fhelip Jansana p.e / Faristolers de cor major y menor - Los cantors / Corneta ab salari de $70 £$ - Joseph Planes / Posar i llevar los obits als señors capitulars - Los cantors / Contrahalt - [esp. en blanco] / Martirologi ab salari de $4 £$ soes $2 £$ la Ig.a y / $2 £$ lo estador de Vilamitjana - M.o Jansana / y / M.o Vianova / Tenor ab salalri de $50 £$ - Carlos Subies / [Fol. 174v.:] Traurer los gossos de la Ig.a ab salari de $1 £ 10$ - los preveners / Encendrer y apagar lo Rotlle ab salari de $1 £ 10$ - los preveners / Manxador y escombrador ab salari de $20 £$ - Pere Fahena".

[122] Fol 175r.: «Die 25. p.torum Cap. P. Con.tes»: “[Margen: «No tenir breviaris / en lo cor»] [...] Fuit resolutum que nin / gun resident puga tenir breviari en lo cor sino que sie a Ma / tines y Laudes y [...] los señors capitulars y no / en las demes horas canonicas, y en cas de contrafuncio Que lo señor apuntador / apunte de aquella hora tant als capitulars com els beneficiats".

[123] Fol. 175r.: [«Die 25 p.torum Cap. P. Con.tes»:] "[Margen: «Abusos en lo cor / sobre lo cantar»] Desitjant extinguis los abusos se exprimentan en lo chor en orde / [Fol. 175v.:] a no fer dos punts, y no dexar de acabar lo vers lo un cor al altre; fuit / resolutum que en tot y per tot se observe lo que esta establit en Capitols / Pascuals de lany 1700. fol.41 y aixi mateix ratificam lloham y aprobam / lo estat y ordinacio feta a 16. de Abril 1698. fol. 4. circa recusatio / nem acis [a qui es] viendi cappas pro parte Beneato.m husis Cath."

[124] Fol. 175v.: [«Die 25 p.torum Cap. P. Con.tes»:] "[Margen: «privacio als que estan / parats ab abits devant / lo chor»] Item statuim y ordenam que lo señor Apuntador tinga tot cuidado / y diligencia 
en apuntar a tots los residents desta S.ta Ig.a aixi capitu / lars com bene.ats, que antes de comensar las horas canonicas en lo chor / com son matines, prima, tersia, [etc] estan parats ab ábits de chor / passejantse o estant en conversa devant lo chor; per quant se exprimenta / que moltas vegadas noÿ ha apenes ningu que cante dins lo chor / com aixi esta ordenat altres vegades".

[125] Fol. 181r.: «Die 3. 7.bris 1708.»: "[Margen: «Revocacio de offi.l / de cantar las epistolas»] [...] Fuit resolutum que per certes causes y rahons nostre animo movens / se revoque de oficial nostre a M.o Joseph Bonet p.btre y beneficiat de N.a Yg.a / y que se li notifique per part del lloch tinent de Daga, y se ha fet / nominacio loch super cantar las Epistolas a M.o Pere Net p.btre / y beneficiat de dita santa Ig.a".

[126] Fol. 181v.: «Die 27. 8.bris 1708.»: “[Margen: «Nominacis de / Mestre de Capella»] Convocato Ben.ts In sacristia Inquo Interfuerunt ommes supradicti / fou elegit y nomenat per mestre de capella de nostra Santa / Iglesia, lo R.nt Gabriel Argany p.btre sens ningun salari per avers[e] / aixi conningut y aver ell condecendit liberament en aqueix parte per / patir la Iglesia per causa de la guerra grans atrassos y sols- / s[ame]nt nunc se li done missa de tres sous y la distribucio del chor / y las tersas per los minyons com se acostume".

[127] Fol. 182v.: «Die 19.X.bris 1708.»: "[Margen: «Poss.o a favor de M.o / Fran.co Vilanova»] [...] Fuit resolutum que es done possessio al R.nt Francisco Vilanova / p.btre i bene.at del benefici baix la invocacio de S.t Simon y Juda, / en nostra Ig.a istituit y fundat y que se li entregue la possessio / y que sie admes a las distribucions del chor etiam a las de Espes".

[128] Fol. 183r.: «Die 12. Januarÿ 1709.»: “[Margen: «Preveners»] [...] Havent lo señor canonge Joan Rovira / obrer de nostra Ig.a representat lo molt se necesitaba fer cotas als preve / ners y alguna roba per Joseph Forcada que es lo ultim prevener que ha / tornat aqui i fuit resolutum ques dexava tot a la mera disposicio de dit / señor obrer".

[129] Fol. 183r.: [«Die 12. Januarÿ 1709.»:] "[Margen: «Campana de Santus»] Se dexa al cuydado del señor obrer per a que fasse fer obrarse la campana / de Santus que está rompuda".

[130] Fol. 185r.: [«Die 12. Marty 1709»:] "[Margen: «no donar rame / llets lo dijous sant»] Item fuit resolutum que de qui en havant lo dijous sant nos donia / ramellets als señors capitulars en la funcio del lavatori".

[131] Fol. 186v.: [«Die 16. Aprilis 1709. Cap. Pasch. Con.tes»:] "Per cantar los Evangelis ab salari acostumat de $10 £$ - M.o Joan Torrada / p.btre y ademes a la com.t / Per cantar las Epistolas ab salari acostumat de $10 £$ soes $5 £$ la / Ig.a y altres $5 £$ lo stador de Vilamitjana - M.o Pere Net / p.btre y comunitari / Mestre de capella ab salari de $100 £$ - M.o Gabriel Ar- / ganÿ / Organiste ab sal. de $100 £$ y $50 £$ per la jubilacio - M.o Isidro Serrada / p.e y comunitari / Baxoniste ab salari de 50£ - M.o Felip Jansana / [Fol. 187r.:] Faristolers del cor major y menor los cantors - los cantors / Corneta ab salari de $70 £$ - Joseph Planes / Posar y llevar los abits de cor - los cantors / Contrahalt - [esp. en blanco] / Martirologi ab salari de $4 £$ soes 2 lliures la Ig. / y altres dos lliures lo estador de Vilamitjana - Vilanova y M.o / Joseph Fuentes / Tenor ab salari de $50 £$ - Carlos Subias. / Traurer los gossos de la Ig.a ab sal. de $1 £ 10$ - Los preveners / Encendrer y apagar lo Rotlle ab salari de $1 £ 10$ - Los preveners. / Manxador y Escombrador ab salari de $20 £$ - Pere Fahena".

[132] Fol. 188r.: [«Die 17. Aprilis 1709. Cap. P. Con.»:] "[Margen: «avisar als cantors»] Item fuit resolutum q.[ue] lo seño Dega amoneste als cantors per a que un / poch antes de cantar lo Te Deum entren al chor per la falta de residens / hi ha en lo Chor; y fent al contrari sels apunte".

[133] Fol. 190r.: «Die 26 Aprilis 1709. Cap. P. Con.tes»: "[Margen: «Salari del / mestre de Cap. / $100 £$ » Item fuit resolutum que al R.nt Gabriel Argany se li donan 100£ / de salari de mestre de capella, y comensara a correr lo dia p.r / de Maig". 
[134] Fol. 191r.: «Die 31 May 1709»: “[Margen: «Terramotos»] [...] Havent sempre, en cas de algun treball reconegut als S.ts Patrons, y expri=/ mentarse ara frequents terramotos y altres calamitats sens amenassa y que actualment se estan / patint, fuit resolutum que vuÿ se comense rogativas a Deu Nostre S.r y per ser lo temps tant / acupat de la octava de Hábeas que tots los dies se digue a la la Collecta Deus qui Populo / suo in aficcione clamantse y despres de completas antes de reservar se canten las lletanias de Maria / SS.ma y en lo lloch de Admirable Sacraments se cantás lo vers tantum ergo sacramentum".

[135] Fol. 192v.: «Die 18. Septembry 1709.»: [“Margen: «Admissio M.o Farrer / Beneficiat»] [...] fou resolt admetrer / a las distribucios del cor etiam a las de Espes al R.nt Andreu Farrer de Alas / p.btre y beneficiat del benefici baix invocacio de S. en dita Ig.a fundat / [Fol 193r.:] en attencio de haver fet relacio lo M.e de capella sent habil de cant haventlo examinat en / presencia dels S.rs Ard.ca de Cerdanya y S.r Cabiscol Comissary per est effecte elegits".

[136] Fol. 193r.: «Die 4. Januarÿ 1710.»: "[Margen: «Fundacio de Pedro»] [...] Attenet y considerant q. lo R.nt Joan Bap.ta / Padró p.btre ohim rector de Arsovell ha instituit y fundat en nostra Santa Iglesia Cathedral una / una causa pia per donselles a maridar y per missas celebrar dotada de $82 £ 10$ com del acte de funda / cio consta rebut en poder de Fran.co Cellera notari publich de la present ciutat a 18. de maig de / 1702 que esta autentich en lo calaix de causes pias y de la acceptacio de aquella en lo / llibre de conclusions dia 1. de Agost 1702. fol. 92. [...] / [Fol. 193v.:] se ha resolt que / per la anima de dit diffunt fundador se celebre un obit general solemne a cant / de orgue y missas resadas per los señors Capitulars [...] tots anÿs perpetuament se cele $=/$ bran en nostra Ig.a per los señors Capitulars presents y / esdevenidors mitg anÿ de missas resadas de caritat sis sous quiscuna / en los Altars los parexerá per la Anima de dit R.nt Joan Baptista $\mathrm{Pe}=/$ dró en los mesos de Janer, Febrer, Mars, Abril Maig y Junÿ y la [de] un obit General solemne á cant de orgue lo dia vint de Mars q. / mori dit fundador si impedit no será ó sino lo dia subseguent no impe $=/$ dit ab tochs de campanas lo vespre antes despres de tocades les oracions si / y conforme se fa ab lo obit del S.r Bisbe Lloris y altres obits generals $c o=/$ mensant a fer les celebracions de dites misses lo present anÿ en dits sis mesos [...] Per la distribucio del qual / obit se aje de donar al celebrant per la caritat de la missa vuit sous / als assistents Capers y Mestre de Serimonies dos sous a quiscun als S.rs / Capitulars per sa distribucio quatre sous y de moment a dits señors / á solas dos sous a quiscun dels Beneficiats y Cantors per la distribucio / dos sous ÿ als dits Cantors per lo cant de orgue dos sous a cada / [Fol. 194r.:] hu de ells [...]".

[137] Fol. 194r.: «Die VIII Martÿ predicti anni» [«1710»:] “[Margen: «Bestraurer als cantors»] [...] Fuit resolutum que lo recep $=/$ tor pague la mesada als cantors finida aquella en virtut del paper que / lintregarán los oÿdors de comptes y si lo interim ans de acabarse lo mes / algu de ells necesitava de bestreta que acudia al cononge Net que se / a offert bestraurerlos".

[138] Fol. 195r.: [«Die 25. Martÿ predictorum 1710»:] "[Margen: «Absolta general»] Item si lo capitular morirá en la present ciutat lo dia antes de son enterro / se li fará absolta general, ab asistencia dels señors capitulars sens estipen $=/$ di y de tots los beneficiats y residents de N.a S.a Ig.a ab la canturia y se / donará la distribucio al beneficiats $=2 £$ als cantors $2 £$ al mestre de / capella $=8 £$ als preveners $=1 £$ a cada un, al vedell $=2 £$ als acolits dit diner, $/$ a quiscun y a las creu lo mateix que a la professo del enterro tot lo / qual gasto aja de ser a carrech del capitular diffunt".

[139] Fol. 195r.: [«Die 25. Martÿ predictorum 1710»:] "[Margen: «Comissio»] En quant a la admissio que demanen los R.nts Joan Castellnou Andreu Muntan y Emanuel Soler / beneficiats en attencio de ser sis o set los admesos en lo chor de nostra Santa Ig.a y en la Pietat differe / xen ferlos participans del lucros de aquella capella ab lo motiu de tenir privilegi de no admetrer / mes que fins al numero de 36. fou resolt diferirlos y dilatarlos dita admissio". 
[140] Fol. 197r.: [«Die 6. p.torum Cap.m Paschale Continuantes 1710»:] "Cantar los Evangelis ab sal. de $10 £$ - R.nt Joan Torrada B.t y com.ri / Cantar les Epistoles ab salari de $10 £$ - R.t Pere Net p.e y comu.ri / Mestre de Capella - R.nt Gabriel Arganÿ / Organista ab sal. de $100 £$ y $50 £$ per la jubilacio - R.nt Isidro Serrada / Baxonista - M.o Felip Jansana / Faristolers - Los cantors / Faristolers del cor major - Los cantors / Faristolers del cor menor - Los cantors / Corneta - vacat. / Llevar y posar los obits del cor - los cantors. / Contrahalt - [esp. en blanco] / Martirologi - Vilanova y Fuentes / Tenor - Carlos Subias / Traurer los gossos de la Ig.a - los preveners / Encendrer y apagar lo Rotlle - los preveners / Manxador - Pere Fahena”.

[141] Fol. 198r.: «Die 8. May 1710 C. P. C.»: "[Margen: «Admissio del D.r / Montan V. de S. Mig.l»] [...] fou resolt que se admetie / al R.nt D.r Francisco Muntan p.btre y vicari de la parroquial de Sant Miquel / a las distribucions del cor de nostra Santa Iglesia com en effecte se admet falta / gratia de examine".

[142] Fol. 198v.: «Die 10. p.torum Cap. Pasch. Con.» [«May 1710»:] "[Margen: «admissio de Bene.ats»] [...] Fuit resolutum que sihan $a d=/$ mesos ab totas las distribucions del cor de N.a Ig.a etiam a las de Espes los R.nts Joan / Castellnou beneficiat del benefici de Sant Sepulcre, Andreu Muntan B.t / del benefici de Sant Mathias y Emanuel Soler de de Santa Tecla more / solitu encontinent".

[143] Fol. 199r.: «Die 18 p.torum» [«7.bris 1710»:] “[Margen: «Admissio»] [...] Fuit resolutum que se admetie a les distribucions del chor de N.a S.a Ig.a / tant de menuda com de Espes al R.nt Joan Ponsá y Barcelona p.btre y beneficiat del benefici de / Corpus X.pti en dita Ig.a fundat".

[144] Fol. 199r.: «Die 18. 8.bris 1710.»: "Item fuit resolutum admetrer a las distribucions del chor de nostra Ig.a al R.nt Joseph / Bosch p.re y beneficiat del benefici baix invocacio de Sant Nicolau en la present Ig.a / fundat factia gracia de examine per ser familiar del señor Ard.a de Berga".

[145] Fol. 199v.: «Die 25 predictorum» [«Nobembrÿ 1710»:] "[Margen: «Estamparse los villansicos de / Nadal»] Item fuit resolutum que lo mestre de capella fassa imprimir los villansicos que se / han de cantar lo dia de Nadal del corrent anÿ 1710".

[146] Fol. 199v.: «Die 18 X.bris 1710.»: “[Margen: «lo dia de S.ta Llucia no hi ha / presencia per ningun»] [...] Haventse disputat / en capitol si lo dia de Santa Llucia mentres se canta lo offici major a cant de / orga per la Confreria dels Sastres sis reputen per p.nts al chor los que diuhen / missa i fuit resolutum que in posterum noy aja presencia per ningun capitular / mentres se celebrará dita missa major lo referit dia de Santa Llucia y que en la / distribucio dels 30 [sous] que hi haja fuis acrescendi entre los S.rs Capitulars interessats / y los Bene.ats y Cantors noy tenen cosa per quant en la missa matinal ques / canta lo mateix dia ja lucran sa distribucio y asso se observe axi sempre fins / altra deliberacio".

[147] Fol. 200r.: [«Die 18. X.bris 1710.»:] "[Margen: «Lletania de N.a S.a»] Item fuit resolutum que se augmente la fundacio que fa lo S.r D.n Francisco Portaria Ardiaca / de Cerdanya lo adjutor de la Lletania de nostra Señora per tots los dissaptes del estiu / celebradora desde Pascua de resurreccio fins á 31. de 7.bre en la mateixa conformitat que esta / continuada en lo forro del acte que esllegit y per aceptar aquella se fa comissio als S.rs / Cononges Zaydin y Ermengol Ubach".

[148] Fol. 200r.: «Die 23. X.bris 1710.»: “[...] Havent rebut carta / del Secretari del despaig universal lo señor Marques de Rialp, que de ordre del rey nostre / S.r Carlos iii (que Deu g.de) participava y dava noticia de haver ses reals armas y dels Il.tres / aliats baix la conducta del Mariscal Señor Compte Guidorvaldo de estar Ambers han / alcansat una gloriosa y señalada victoria en lo camp de Alcarria [...] Almenar lo dia [esp en blanco] y / altra a las portas de Zaragoza lo dia 20.de Agost del mateix; fonch conclós donar graci- / as a Deu nostre Señor y sa Mare SS.ma y Advocada nostra [...] y perso fou elegit comissari lo dit señor / Canonge Penitencier Joan Ubach pera disposar la festa, la qual consisti en unas com- / pletas solemnes a cant de orga y ministrils y un Te Deum Laudamus. Lo mateix dia / se canta al tart antes de entrar a matines ab professo rodant las naus de la Ig.a y / com impedis la continuacio las pascuas de la 
Nativitat del Señor se dilatá lo offici solem=/ ne fins lo dia 27. ques celebra la festivitat de Sant Juan Evangelista y en exa diada / despres de totas las horas canonicas y despres de haver cantat ab diaca y subdiacala / missa conventual de dit sant, o, del corrent post Tertiam, se cantá post nonam / una missa solemne votiva de B. M. V. En accio de gracias a tant Divina y soberana / protectora ab predica o sermo que predica lo molt R.nt P. Lector Matheu Casals / Augustino lector de nostra Ig.a Catredal ab asistencia del G.dor y ciutat combidats / de part nostra y solits villansicos de la Capella. A la tarde tambe se continua ab la / mateixa solemnitat y asistencia cantant les Vespres Solemnes y despues de Completas / se feu solemne professo ab asistencia de la Ciutat Confrerias y Banderas per la nau / de la Ig.a y passa claustros per no haver pogut anar per los carrechs per causa / de la neu. No tant in futuram rei memoriam que en dita professo se portava baix / talem per quatre R.tns presbiteros y dos dignitats tenint los cordons del costat com / es de estil, la caixa nova ab lo cos del glorios Sant Od, lo qual fou collocat an lo / mateix lloch ahon estava antes en sa propia Capella, adornat sols y renovat / lo retaule / [Fol. 200v.:] lo retaule y nicho fet á expensas de la Ciutat, y com esta per sos comissaris / nos suplicas nos dignassen trasladar lo cos Sant de la caixa vella a la nova / que en lo interim que es feya lo retaulo nou estava collocada al altar major / a la caixa novament fabricada mes ben labrada y fabricada ab differents / retaulons de la historia del Sant [...] sent esta diligen / gia despres de Matines a la nit en la sacristía y dits Capitulars ab assis / tencia de dos capellans y lo mestre Escultor collocaren la caixa nova / ab lo cos de dit glorios Sant Od en lo altar major la nit del dia 26. / y lo endemá dia 27. se portá a la solempne professo se cantá als claus / tros dos villancicos y se dexa y colloca la mateixa tarde del dis 27 . / en sa propia capella y nicho dientli la antiphona sacerdot et Pon= / tificex \& C. y lo semmaner la collecta del Reso y fou axi cónclosa y / acabada la solemnitat y funccio que sie en gloria de la SS.ma Tri / nitat de Maria SS.ma y del Glorios Patro y nostre Prelat Sant / Od. Amen".

[149] Fol. 200v.: «Die 7. p.torum» [«Jannuary 1711»:] “[Margen: «Rogativas»] [...] Haventse tingut noticia que la / ciutat de Gerona se tobava assitiada per los Enemichs, y molt apretada / fuit resolutum ques fassen tres dias seguits rogativas descubrint / [Fol. 201r.:] Lo SS.m antes de Completas y los demes dies que es canten las Lletanias en lo presbiteri".

[150] Fol. 201r.: «Die 30. Aprilis 1711.»: “[...] Havent proposat los señors Ard.a Salles y de Ruis / [Fol. 201v.:] y canonge Fran.co Montaner que en honra y gloria de Maria SS.ma de / Urgell desitjaven que la fundacio que te feta lo S.r Ard.a de Cerdanya D.n Fran.co / portaria de cantarse la lletania despres de completes tots los dissaptes de de la / de la festivitat de Pascua de Resurrecio fins lo dia de Sant Geronim no pot - / tenir effecte fins sis anys immediats y consecutius a la mort de dit señor Ard.a / Innata e especial devocio a la Reyna dels Angels patrona de esta S.ta Ig.a / han suplicat al molt H.e Capitol se dignas acceptar de que fins y a tant / tinga effecte dita fundacio ara sie despres dels dits sis anÿs o be antes per / qualsevol causa ora ho se posas en execucio lo cantarse dita lletania de N.a / S.ma en lo modo y forma que esta contingut en lo acte de d[it].a fundacio obli / gantse a pagar la mateixa distribucio expressada en lo mateix acte $\mathrm{co}=/$ mensant lo dissapte primer vinent que sera a 2. de Maig del corrent a.[n]y [...]".

[151] Fol. 203r.: [«Die 21. predictorum Aprilis Cap. P. Con. 1711»:] "Evangelis - lo R.nt Fran.co Vilanova B. Com.ri / Epistolas - lo R.nt Pere Net bene.at Com.ri / Mestre de Capella - lo R.nt Gabriel Arganÿ / Organista - lo R.nt Isidro Serrada B. Com. / Baixonista - lo R.nt Felip Jansana / Faristolers - los cantors / Faristolers del cor major - los cantors / Faristolers del cor menor - los cantors / Corneta - Joseph Planes / Contralt - [esp. en blanco] / Martirologi - Andreu Vilanova / y / lo R.nt Fran.co Alamany B. Com.ri / Tenor - Carlos Subias / Traurer los gossos de la Ig.a - los preveners / Encendrer y apagar lo Rotlle - los preveners / [Fol. 203v.:] Manxador - Pere Fahena".

[152] Fol. 204r.: «Die 24 pr.rum Cap. Pasch. Con.» [«Aprilis 1711»:] "[Margen: «No ixir del chor»] [...] com se exprimentie tots los dies lo / gran abus queÿ ha en ixir los residents del chor de nostra iglesia / fuit resolutum que lo señor Dega amoneste y avise als beneficiats / y demes residents de dita igle- 
sia a cetero vagan ab mes cuidado en / ixir del chor antes de dirse la Salve despres de nona y axi mateix / que avisie al President de la Comunitat que se ha donat orde al apuntador que execute lo que esta disposat y ya antecedentment sels / ha dit que per gonÿar la distribucio de quiries en la missa conven / tual era menester residir des de quiries fins a Santus y per gonÿar / la de Santus se hauria de estar fins acabada la missa conventual / altrament se apuntará als consuetudinaris".

[153] Fol. 204r.: «Die 25 p.rum Cap. Pasch. Con.» [«Aprilis 1711»:] “[...] Fou feta comissio al S.r / Ardiaca Mayor que veÿa si per via de Tolosa y al señor / Canonge Penetencier per via de Bar.na se encontrarian mes / barartos y millors los llibres de chor y avariguar quen tinguen / ne fassan relacio".

[154] Fol. 205r.: «Die 2. Junÿ 1711»: "Item fou resolt fer venir quatre llibres de chor de psalmodias, y perso fou / feta comissio al señor Canonge Penitencier per a que cuide de ferlos ve / nir per medi del D.r Lles mestre de cerimonias desta Santa Ig.a de Barcelo / na".

[155] Fol. 208r.: «Die 12 Octubry 1711.»: "[Margen: «Com.o»] Item fonch resolt y feta comissio al R.nt Isidro Serrada p.btre Bene.at / y mestre de capella y organista de nostra santa Iglesia y a Miquel / Cases de la present ciutat per anar al camp de Calaph pera aportar al / señor compte de Muret lo que falta á compliment de las quinse mil lliures / que en lo mes de juny del corrent any demana al Capitol per lo / p.ne y subvencio de las tropas auxiliars de nostre rey y señor que / Deu g.e y que per est effecte los comissaris Ard.ca de Berga y Canonge / Net los enoreguen dit diner".

[156] Fol. 209v.: [«Die 12. Aprilis p.torum Cap. P. Con. 1712»:] "Evangelis - lo R.nt Joan Torrada / B.t Comunitari / Epistoles lo R.nt Pere Net - lo R.nt Pere Net / B.t Comunitari / Mestre de capella Gabriel Arganÿ / Organiste lo R.nt Isidro Sarrada - lo R.nt Isisdro Sarrada / Baxoniste - Felip Gensana p.btre / Faristolers - los cantors / Faristolers del cor major - Los cantors / Faristolers del cor menor - Los cantors / Corneta - Joseph Planes / Posar y llevar los abits del cor - Salmurri y Vilanova / Contralt - / Martirologi - M.o Alanÿ y Vilanova / Tenor - Carlos Subias / Traurer los gossos de la Iglesia - Los preveners / Encendre y apagar lo Rollo - Los preveners / Manxador - Pere Fahena".

[157] Fol. 210v.: [«Die XIV. Aprilis predictorum Cap.m Pasch Con.tes 1712»:] “[Margen: «Donar tres diners mes als / cantors de la lletania dels / dissaptes»] Fui etiam resolutum que als que cantaran les lletanies en los Dissaptes per la / fundacio [que] feu lo señor Ard.ca de Cerdanya D.n Fran.co Portaria encara que / en la fundacio no hi ha sino tres diners per quiscun dels dos que cantaran / que sels done tres diners mes a cada un dels cantors y tres diners mes al mestre / de serimonies del jus accrescendi que hi ha en dita fundacio".

[158] Fol. 210v.: [«Die XIV. Aprilis predictorum Cap.m Pasch. Con.tes 1712»:] "[Margen: «Albar de S.t Ermengol en dias / de S.t dixi missa del S.t y no / de Réquiem»] Fuit resolutum que en los dias de santos en lo albar de Sant Ermengol sian los / aparatos pera dit missa del sant y no de réquiem".

[159] Fol. 212v.: «Die 7. Juny 1712.»: "[Margen: «Admetrer a Joan Pusalgues»] [...] fou resolt admetrer / a la capella de N.a Ig.a al licenciado Joan Pusalgues que toca lo violi y se li / assenyala de salari $80 £$ y se li dona las distribucions del chor y obits".

[160] Fol. 212v.: [«Die. 7 Juny 1712.»:] "[Margen: «Admissio del corneta de / Lleyda»] Item fou resolt admetrer a dita capella al R.t Fran.co Serrat p.btre dit lo cor=/ neta de Lleyda que ha proposat lo señor Degá y se li ha fet comissio per a que / fassa que dit corneta de Lleyda vinga a dita capella y que li escriga / que se li done $80 £$ de salari las distribucions del cor y missa de tres - / sous cada dis que ab tot vindra a tenir $200 £ "$ ".

[161] Fol. 214r.: «Die 16 7.bris 1712.»: “[Margen: «M.e de capella Fortó»] [...] Fuit resolutum anomenar en mestre / de capella de nostra Santa Ig.a al licenciado Joseph Fortó ab lo salari de cent lliu= / res Bar. Ademes de las distribucions y altres lucros".

[162] Fol. 220r.: [«Die 2. May p.torum Cap. Pasch. Con.1713»:] "Evangelis - Joan Torradá Ben.t Com.ri / Epistolas - Pere Net Ben.t Com.ri / [Fol. 212v.:] Mestre de Capella - Joseph Forto / Organista - 
Isidro Serrada / Baixonista - Felip Jansana / Faristolers - Los cantors / Faristolers de cor major - Los cantors / Faristolers de cor menor - Los cantors / Corneta - Joseph Planes / Llevar y posar los abits del cor Salmurri y Vilanova / Contralt - [esp. en blanco] / Martirologi - M.o Fran.co Alamny B. Com. / y Vilanova / Tenor - Carlos Subias / Traurer los gossos dela Iglesia - Los preveners / Encendre y apagar lo Rotlle - Los preveners / Manxador - Pere Fahena".

[163] Fol. 222r.: «Die 10. May 1713.»: “[Margen: «de reform. Eccte»] [...] Fou resolt nemine discrepante que se observe / lo silensi en lo chor, y que lo señor cabiscol ab tota vigilancia cuide de fer senyal als / que parlaran en lo chor y no obehint y continuant en parlar en lo chor quels fasse / mulctar en la forma acostumada".

[164] Fol. 232r.: «Die 4 Aprilis 17i4»: “[Margen: «Pacies.»] [...] Fuit resolutum que lo S.r obrer pague al / mestre de capella y cantors lo que acostuma pagar á aquells lo Ard.a de Andorra / per cantar las passias per trobarse dit Ard.ca dins Barcelona y que dit S.r obrer / ho assente en lo llibre de la obra o de la grossa pera recobraro de dit Ard.a de Andorra".

[165] Fol. 233v.: [«Die XVII. Aprilis 1714.»:] "Evangelis - lo R.t Joan Torrada B.t Com. / Epistolas - lo R.t Pere Net Ben.t Com. / Mestre de capella ab salari de 100.£ - Joseph Fortó / Organista - Isidro Serrada B. Com. / Bayxonista - Felip Jansana major - los cantors / Farsitolers de cor menor - los cantors / Corneta - Vaccat / [Fol. 234r.:] Llevar y posar los abits del cor - Salmurri y Vilanova / Contralt - Vaccat / Martirologi - M.o Fran.co Alamany B. y Vilanova / Tenor - Carlos Subias / Traurer los gossos de la Iglesia - Preveners / Encendrer y apagar lo Rotlle - Preveneres / Manxador - Pere Fahena".

[166] Fol. 234v.: [«Die 18 Aprilis 1714»:] "Item fuit resolutum que se observen totas las conclusions y ordinacions fetas / fins vuy en ordre â la observansa del cor y als que faltaran y no las observa= / ran que lo señor cabiscol despres de haver picat sino se esmenan que los mulc $=/$ tia fentlos apuntar segons la faran a sa caneguda y que ho diga en prib. / al Apuntador".

[167] Fol. 235v.: «Die 30. p.torum 1714» [«Aprilis»:] “[Margen: «Asistir al Juanet»] Item fuit resolutum que lo señor obrer done la mateixa providencia tant en lo / tocant al menjar com calsar y vestir per lo Juanet altre dels cantors de N.ra / Santa Iglesia qual se ha acostumat donar á qualsevol dels preveners fent / que aquell estiga assistit com los demes preveners".

[168] Fol. 239r.: «Die 5. Aprilis 1715»: “[Margen: «Cantar evangelis»] Item per haverse promogut a la rectoria de Tiurana lo R.nt Joan Torrada / p.btre y Beneficiat Comunitari y nomenat oficial per cantar los Evangelis / fou nomenat per dit offici lo R.nt Francisco Alamany p.btre y B.t comunitari / ab lo salari acostumat y que aquest li corre del dia que dit M.o Torrada faltara / en havant".

[169] Fol. 241r.: [«Die Septima May 1715 p.torum Cap. Pasch. Con.»:] "Evangelis - Fran.co Alamany B.t Com.ri / Epistolas - Pere Net Bene.at Com.ri / Mestre de Capella - Joseph Forto / Organista Isidro Serrada Ben.t Com.ri / Baxonistes - Jansana y Juglá / Faristolers - los cantors / Faristolers de cor major -los cators / Faristolers de cor menor - los cantors / Corneta - vacat / Contralt - vacat / Martirologi - Alamany y Vilanova / Tenor - vacat / Traurer los gossos de la Iglesia - los preveners / Encendre y apagar lo Rotlle - los preveners / Manxador - Pere Fahena".

[170] Fol. 242r.: «Die 9. predictorum Cap. Pas.Con.» [«May 1715»:] "[Margen: «De reformatione»] [...] Fuit resolutum que se / observen totas las conclusions ordinacions statuts y usos fins vuy fets y fetas tant en / orde ab bon regimen del chor de nostra Ig.a com altrament $\mathrm{i}$ en consideracio que differents / Bullas Apostólicas y constitucions Tarraconenses priven de que nos paseje dins la Ig.a / catedral mentres se celebren los divinos officis i fou perso feta comissio al señor Canonge / Montaner per a que les mire y examine y ne fassa verho a capitol".

[171] Fol. 242r.: «Die 9. predictorum» [«May 1715»:] “[Margen: «No arrahonar al cor»] Item fuit resolutum que attes se exprimenta lo gran desorde hi ha de arrahonar / en lo cor mentres se celebren los 
divinos officis, que en havant mentres se celebra $=/$ ran dits divinos officis se estiga ab tota decencia en lo chor y que no se arraho / ne en ell y los que ho faran tant capitulars com beneficiats y cantors, que lo señor / cabiscol los pique y si hi tornara y no exprimentara esmena despres de haver picat lo S.r Cabiscol quel fassa apuntar del que podria guanyar aquella hora cononica".

[172] Fol. 242r.: «Die 9. predictorum» [«May 1715»:] "[Margen: «Anar ab pausa als / responsoris»] Item fuit resolutum que nos vage ab la acceleracio ques va en orde als responsoris / y que perso se avise als residents per a que vagen ab la deguda pausa segons / los dies".

[173] Fol. 244r.: «Die 28 predictorum» [«Juny 1715.»:] "Fuit resolutum que a Joseph Parra cantor de nostra / santa Ig.a se li done per lo salari de tenor cent lliures a mes de las distribucions del chor / y ses posat sustentor de ella y lo señor cabiscol li dona trenta lliures cada anÿ per lo / salari de sota cabiscol que venint lo cas en dita Ig.a no hi haurá sino un sota ca / biscol a les hores dit señor cabiscol li dona $60 £$ que venint est cas lo capitol no li / donara sino $70 £$ per dit salari de thenor y que li corre del dia vuit del corrent en havant".

[174] Fol. 244r.: «Die 28 predictorum» [«Juny 1715.»:] "Item fuit resolutum donar de salari a Emanuel Cumbiet per lo offici de thenor de dita / Ig.a sinquanta lliures a mes de las distribucions del chor y trenta lliures que li done lo / S.r Cabiscol per lo offici de sustentor lo qual salari li corre del dia sis del p.nt en havant / ab esta advertencia que se li diga que se aplique en apendrer lo que li toca per / poder menar lo cor que si dins mig any no es capas per menarlo ques pendra / altra determinacio".

[175] Fol. 246v.: «Die 19. July 1715»: “[Margen: «Perpetuacio de Fortó»] [...] Fou resolt ques perpetue / en lo offici de mestre de capella ab lo mateix salari al licenciado / Joseph Forto mestre de capella de N.a Ig.a y per firmar lo acte se / fa comissio al S.r Dega y quel firme more solito. Y fou de contrari / sentir lo S.r Cang.e Rovira".

[176] Fol. 247v.: «Die 24 predictorum» [«7.bris 1715»:] “[Margen: «Alternar les dignitats / ab los S.rs Canonges»] [...] En attencio de haverse experimentat al=/ guna falta en lo chor en alguns dies solemnes dobles y obits per recusar les / dignitats alternar ab los señors canonges. sobre lo pendrer cappes fuit re / solutum que sempre que se suponga poderi haver falta que les digni / tats degan alternar ab los señors canonges axis en dias solemnes com / dobles y obits".

[177] Fol. 247v.: «Die prima octobris 1715.»: "Fou resolt que lo P. Salvador Sans re / ligios Agustino se admetia per sota cabiscol de N.a Ig.a ab lo salari de / trenta lliures y las distribucions del cor fins a Capitols Pasquals / y que se li diga que en lo interim se aplique en apendrer de cant de / orga".

[178] Fol. 248r.: «Die 7. p.torum» [«January 1716»:] “[Margen: «Espes. / Dates»] Item fuit resolutum que de aqui al devant totas las missas de las dates tingan / de charitat vuit sous; y axi mateix las missas dels setze obits de reduccio / so es del dotze un cada mes y dels quatre un cada festa anyal y totas las / missas dels demes obits que no son reduits tingan la mateixa charitat de / vuit sous quiscuna".

[179] Fol. 249r.: «Die 11. p.torum» [«Aprilis 1716»:] "Fuit resolutum / que lo S.r Canonge Rovira com a obrer pague les passies se han can / tades per la capella lo present any 1716. que son al carrech del señor / Ard.a de Andorra per haver demanat lo mestre de capella la satisfacio / per tots los cantors".

[180] Fol. 250v.: [«Die 28. Aprilis 1716.»:] "Evangelis - M.o Fran.co Alamany B.t Com.ri / Epistolas - M.o Pere Net Bene.at Com.ri / Mestre de capella - M.o Joseph Forto p.btre / Organista - M.o Isidro Serrada B.t Com. / [Fol. 251r.:] Baxonistas - Jansana, Jugla, y Rossell / Faristolers - Los cantors / Faristolers de cor major - Los cantors / Faristolers de cor menor - Los cantors / Corneta - Vaccat. / Contralt - Vaccat / Martirologi - Alamany y Vilanova / Tenor - Joseph Flores de cor menor y Fra / Sans de cor major / traurer los gossos de la Ig.a - Los preveners / Encendrer y apagar lo Rotlle - Los preveners / Manxador - Pere Fahena".

[181] Fol. 251v.: «Die 30 p.torum Cap. Pasch. Con.tes» [«Aprilis 1716»:] “[Margen: «de reform. Eccles.e»] [...] fuit resolutum que se observem / totes les cónclusions ordinacions estatuts y usos fins vuy 
fets y fetas tant / en orde al bon regimen del chor de nostra santa Ig.a com altrament / y que suposat lo sota cabiscol Domingo Torreno no se li ha comodada / la veu y axi no se de profit per la Ig.a ques despedesca".

[182] Fol. 251v.: [«Die 30 Aprilis 1716»:] "[Margen: «Estar decents en lo cor»] Item fuit resolutum que lo señor cabiscol avise a tots los residents / del cor, que a les hores canoniques vagen ab la deguda forma, puix / tots han de procurar lo augment del culto divino, majorment havent / reparat esta falta lo S.r Bisbe y quels diga al mateix temps que en lo / cor estigan units a les cadires y no uns al cap del cor y altres al peu / y que fassen millor assistencia en lo cantar".

[183] Fol. Fol 252r.: [«Die 30 Aprilis 1716»:] “[Margen: «Tenir capas»] Item fuit resolutum que per quant se ha exprimentat differents vegades la gran falta se fa / en no arribar a temps per apendrer capes en las quatre festes [a]nyals del anÿ de tal manera que moltes / vegades ha de estar parat lo cor, perso fuit resolutum que als que hauran de tenir capes en las ma / tines di dits quatre festes [a]nyals sels done so es als señors capitulars un sou y als bene.ats sis diners".

[184] Fol. 252r.: [«Die 30 Aprilis 1716»:] "Item fou feta comissio al señor Canonge Verges que junt ab lo señor obrer fassen corregir / lo salteri del cor los versos que hi falten".

[185] Fol. 253v.: [«Die 13. may 1716 p.torum Cap. P. Con.»:] "[Margen: «Missas votivas»] item fou resolt que les missas votivas se fan al Glorios Sant Ermengol / per pluja sien pagades y ques done de distribucio als señors capitulars / dos sous y un sou als bene.ats y cantors".

[186] Fol. 254r.: «Die 4. Agusti 1716.»: "[...] fuit resolutum que las funcions [que] se / han de fer per lo claustro processionalment tant de estiu com de ivern se / fassen dins la nau de la Ig.a catedral duplicant las obligacions o altres / [Fol. 254v.:] cantars segons se offeresca en consideracio de estar lo claustro en po / situra tant indecent, acceptantse empero la celebracio de obits que / per dits se haja de anar a fer las absoltas en la capella de N.a I.a de la Pie / tat y que en estos se fassa com se acostuma".

[187] Fol. 256v.: «Die 22. p.torum» [«Septembris 1716»:] “[Margen: «Admissio de Flores»] [...] fou admes per / tenor de la catedral Joseph Flores ab salari de sexanta lliures / y que li corre del dia tretse del corrent en havant".

[188] Fol. 257v.: «Die 27 p.torum» [«Septembris 1716»:] “[Margen: «Fer p.snt al Ard.a de Cerdana / per sos grans atxaques»] [...] En attencio de trobarse / a notorio lo señor Ard.a de Cerdanya D.n Francisco Portaria ab grans / indisposicions y atxaques de forma que no li es posible lo poder resi / dir fou resolt ferlo present a totes les distribucions del cor de esta Ig.a y / que la present no servesca de exemplar".

[189] Fol. 258r.: [«Die 2. January 1717.»:] "[Margen: «Donar sis diners / als Bene.ats»] Item fuit resolutum que per contemplacio del señor Bisbe se done á quiscun / Beneficiat de la molt H.re Capitol y sa mera y libera voluntat / y que per so refirmen acte dits Beneficiats y que prometian que en havant / nols pretendran de justicia sino de mera gracia y que axi mateix se / donen als cantors".

[190] Fol. 260v.: «Die 14 predictorum» [«Aprilis 1717»:] "Evangelis - M.o Francisco Alemany p.btre y B.t Com. / Epistolas - M.o Pere Net Bene.at Com. / Mestre de Capella - M.o Joseph Forto p.btre / Organista - M.o Isidro Serrada / Baxonistas Gensana, Juglar y Rossell - / [Fol. 261r.:] Faristolers - Los cantors / Faristolers de cor major - Los cantors / Faristolers de cor menor - Los cantors / Corneta - Vaccat / Contralt - Vaccat / Martirologi - M.o Alemany y Vilanova / Thenor - Flores de cor men.r y Fr. Sans del cor maj.r / Traurer los gossos de la Iglesia - Preveners / Encendre y apagar lo Rotlle - Preveners / Manxador - Pere Fahena".

[191] Fol. 262r.: [«Die 16 Aprilis 1717 predictorum»:] "Item fou resolt que se observen adunguem totas las conclusions fetas / fins vuy per lo bon regimen de la Ig.a y augment del culto Divino y que lo señor / cabiscol las fassa observar no permetent que ningu arrahona ni que / estiga incluent al chor y si exprimenta lo contrari que pique y que se / avise als beneficiats". 
[192] Fol. 266v.: «Die 15 predictorum» [«February 1718»:] “[Margen: «Admissio als obits al / porter menor»] [...] haventse llegit una suplica / presentada per Lluis Mir y Rey porter menor de nostra S.ta Ig.a ab / la qual suplica que se admete a las distribucions del chor; fuit resolutum / que en attencio de no ser p.btro y no haver may acostumat lo capitol / admetrer a beneficiat algun a las distribucions del chor que no haja / estat p.btro; penso per gracia especial lo admet a la distribucio dels / obits y no a altres".

[193] Fol. 267r.: «Die 15. predictorum» [«Marty 1718»:] “[Margen: «Admissio de Rossell»] Item fuit resolutum admetrer a les distribucions del chor al R.nt Matheu Rossell be / neficiat del benefici de Sant Simón y Juda en nostra Ig.a fundat".

[194] Fol. 267v.: «Die 19. p.torum» [«Aprilis 1718»:] “[...] En attencio de trobarse ja p.btro lo / M.o Lluis Mir y Rey p.btre y porter menor de nostra Ig.a fou / resolt admetrerlo a totas las distribucions del chor etiam a les / de Espes y ques pose a la a puntadori[a]".

[195] Fol. 268v.: [«Die 4 may 1718»:] "Evangelis - M.o Fran.o Alemany B. Com. / Epistolas M.o Pere Net Ben. Com. / Mestre de Capella - M.o Joseph Forto organista / Organista - M.o Isidro Serrada / Baixonistas - Gensana y Rossell / Faristolers - los cantors / Faristolers de cor major - los cantors / Faristolers de cor menor - los cantors / Corneta - Vaccat / Contral - [esp. en blanco] / Martirologi - Alemany y Vilanova / [Fol. 269r.:] Thenor - Joseph Flores de cor menor y / Fr. Sans de cor major / Traurer los gossos de la Iglesia - los preveners / Encendrer y apagar lo Rotlle - los preveners / Manxador - Pere Fahena".

[196] Fol. 269v.: «Die 5 predictorum» [«May 1718»:] “[Margen: «de reform. Ecct.e»] [...] fuit resolutum que se avise als cantors que sian puntuals a venir / a venir al Te Deum y que en lo chor se tinga tot silencio y que seyes / tiga ab tota decencia y que las antífonas y responsoris se digan / ab molta pausa y ques com confirmin tots los estatuts y conclusions fins / vuy fetas per lo bon govern de la Ig.a".

[197] Fol. 269v.: «Die 6 predictorum» [«May 1718»:] "[Margen: «Grossa»] [...] fuit resolutum que quant sera lo temps del Benedicite despres del offici / y altre que tots los señors capitulars hisquen a dit lo Benedicite y despres si volen / tornar dins del chor que pugan tornari: y que mentres se cante lo / S.t Evangeli ningu puga entrar ni exir al altar major: y per / guanyar la grossa se haja de residir una hora sino que se estiga ocupat / per los negocis de la Ig.a pero que se haja de avisar".

[198] Fol. 269v.: «Die 7. predictorum» [«May 1718»:] "fuit resolutum que lo señor sobrestant de capella amoneste als / cantors que un dia a la semmana y sempre que lo mestre de / [Fol. 270r.:] capella los cridará vagen aprobar".

[199] Fol. 273r.: «Die 23 predictorum» [«X.bris. 1718»:] "[Margen. «Admissiode M.o / Cases] [...] havent fet relacio lo señor mestre de ca / pella de haver examinat de cant al R.t Magi Cases beneficiat del benefici de la / Assumpcio de Maria SS.ma y haverlo trobat habil de cant fuit resolutum / que se admetia a les distribucions del chor etiam a les de Espes".

[200] Fol. 273v.: [«Die 17. February 1719.»] «Testes sunt Janitores»: “[Margen: «Donar dos sous als can / tors en los enterros de / capitulars»] Item fou resolt que per quant los cantors a las professons ques fan / quant se apsorta lo câdaver de algun S.r Capitular noy tenen dis / tribucio de dos sous, que en havant vingan compresos dits cantors / endita distribucio dels dos sous sens que lo mestre de capella endita / distribucio hi tinga doble sino dits dos sous".

[201] Fol. 273v.: «Die 18. predictorum» [«February 1719»:] "[Margen: «No poder los cantors / anar a tocar a casa / privada de particulars»] [...] Lo señor Dega ha fet relacio de haverlo enviat a buscar la nit / passada lo señor Bisbe y haverli participat formarse en gros / y fort empeño entre lo G.dor de la Plasa y tinent de Rey sobre / [Fol. 274r.:] lo fer anar un Musich a tocar en la particular casa de cada un y que / perso fore be se prohibis a tots los musichs de la Capella de la Ig.a el que no / puguessen tocar en casa alguna de particular de la ciutat valentse del disposat / per la Institucio Tarraconense que tal prohibeix y que per tant ho par- / ticipas al molt Ilt.re Capitol per a que manas y ordenas als cantors en pena / 
de deu lliures y trenta dies de preso se abstingan del sobredit; pero al Dega li apa / regue no reportaro al Capitol per no Immiscuirlo en algun empeño ab los / dits Señors G.dor y Tinent de Rey y de comu acort de dit S.r Dega feu lo mandato / verbal als cantors; pero havent proposat lo referit vuy dia al Capitol / este ni assenti a la sobredita resolucio ni aproba lo sobredit mandato, res / pecte de que fins vuy lo S.r Bisbe no se ha may immiscuit ab los officials de Capitol / y no obstant atenent a la publica quietut y obviacio de tot escandol se / ha resolt que lo señor Dega de part del Capitol prohibesca a tots los officials / musichs lo anar a tocar a casa de particular ni etiam de Capitular y en / esta conformitat los ho ha participat lo mateix dia".

[202] Fol. 276r.: [«Die 26 Aprilis 1719»:] "Evangelis - M.o Fran.co Alamany Bene.at comu.ri / Epistolas - M.o Pere Net Bene.at comunitari / Mestre de Capella - Francisco Andreu / Organista - M.o Isidro Serrada / Baxonistas - Jansana y Rossell / Faristolers - Los cantors / Faristolers de cor major - Los cantors / Faristolers de cor menor - Los cantors / Corneta - Joseph Girona / Contralt - Joseph Boluda / Martirologi - Alamany y Vilanova / Thenor - Joseph Flores de cor menor y Fr. Sans del major / Traurer los gossos de la I.ga - Los preveners / Encendre y apagar lo Rotlle - Los preveners / Manxador - Pere Fahena".

[203] Fol. 279r.: [«Die 9 May 1719 p.torum»] «T.[ESTE]S Janitory»: "Item fou nomenat per cantar las epistolas al R.nt Joan Cellera p.btre / y bene.at comunitari”.

[204] Fol. 280v.: «Die 19 X.bris 1719»: "[Margen: «Adm.o del D.r Marti»] Fou admes a las distri / bucions del chor etiam a las de Espes lo D.r Joseph Marti R.nt de matines B.t del bene.i de Sant / Bartomeu en la S.ta Ig.a de Urgell fundat".

[205] Fol. 283r.: [«Die 16. Aprilis 1720»:] "Evangelis - M.o Fran.co Alamany B.t comu.ri / Epistolas - M.o Pere Net Bene.at comu.ri / Mestre de capella - Francisco Andreu / Organista - M.o Isidro Serrada / Baxonistas - Jansana y Rossell / Faristolers - Los cantors / Faristolers de cor major - Los cantors / Faristolers de cor menor - Los cantors / Corneta - Joseph Girona / Contralt - Joseph Boluda / Martirologi - Alamany y Vilanova / Thenor / Joseph Flores de cor menor y R.t Sans del major / [Fol. 283v.:] Traurer los gossos de la Ig.a - Preveners / Encendre y apagar lo Rotlle - Preveners / Manxador - Pere Fahena".

[206] Fol. 284r.: «Die 17 Aprilis 1720.»: "Item fou resolt que lo señor cabiscol avise als sustentors que un / quant antes de entrar al offici y a vespras assistescan a la Ig.a / y que registron los llibres afi de que mentres se cante no ajan / de registrar".

[207] Fol. 284r.: [«Die 17 Aprilis 1720.»:] "Item fou resolt que en lo resar las horas canonicas se vaja ab pausa / y que en los salms se fasca la media y que los sotacabiscols se estigan / alli afi de que si hi ha algun que fassa al contrari ho remedien".

[208] Fol. 284r.: [«Die 17 Aprilis 1720.»:] "Item fuit resolutum que los responsoris y antífonas las $\mathrm{di}=$ / gan dos so es lo un lo responsori y lo altre la antífona".

[209] Fol. 284r.: [«Die 17 Aprilis 1720.»:] "Item per quant se exprimenta gran falta en lo chor a causa que / ningun beneficiat vol pendrer semmanes fuit resolutum que / lo señor Dega fassa patent als presidents de la comunitat esta / gran falta y axi en attencio de tenir obligacio dita comunitat / [Fol. 284v.:] de donar dos semmaners per lo servei del chor de nostra iglesia / que dits presidents representon esta falta a dita comunitat y avista / de ella es de la obligacio que se anomene cada semmana dos semmaners per lo cor de nostra Ig.a".

[210] Fol. 284v.: [«Die 17 Aprilis 1720»:] "[Margen: «Asistir lo M.e de capella / a la una hora en lo cor»] Item fuit resolutum que lo mestre de capella tots los dilluns dimecres / y divendres al punt de la una hora de la tarda assistesca al cor / perque si hi ha algun beneficiat que vulla apendrer de cant, puga / y que en havant no se admetia a las distribucions del cor a bene / ficiat algun que primer no haja per lo 
espay de dos mesos / apres de cant pla y que sie habil y que en assso nos puga dis / pensar en manera alguna".

[211] Fol. 285v.: «Die 24. [Aprilis 1720] predictorum»: "[Margen: «Residir los arxivers al / arxiu»] Item fuit resolutum que los S.rs arxivers de escriptures estigan / cada dia una hora en lo arxiu y perso se fan presents a totas / las distribucions de chor, ab que ajan de residit una hora canonica / a fi de poder guanyar la grossa".

[212] Fol. 287r.: «Die 11. Juny 1720»: “[...] fuit resolutum que se admete a les distribu / cions del chor de N.a Ig.a etiam a les de Espes al R.t Fran.co Andreu mestre de / capella bene.at del benefici de Sant Matheu".

[213] Fol. 291r.: «Die 13 [Augusti 1720] p.torum»: "[Margen: «Pesta»] [...] haventse noticia certa é indi= / vidual que en la ciutat de Marcella y sos contorns se habrasaria del mal de / la pesta lo que es molt contingent poderse extendrer per estos payssos lo / que Deu no permitia per sa divina misericordia perso y per placar / [Fol. 291v.:] la ira de Deu lo millor medi sia acudir als Gloriosos sants implorant / per medi de estos la divina misericordia fuit resolutum que lo dia / de Sant Roch se fasse festa y professo y se celebria un offici sol $=/$ lemne suplicant al sant se digne librarnos de un tant gran cas $=/$ tich com se amenassa".

[214] Fol. 292r.: [«Die 24 Septembris 1720»:] “[Margen: «Adm.o de M.o Suñer»] Item fou admes a las distribucions del chor de la present Ig.a Cath. etiam a les de / Espés lo R.nt Anton Sunyer beneficiat del benefici baix inuscacio de Sant Llorens en / dita Santa Ig.a fundat".

[215] Fol. 292v.: «Die prima 8.bris 1720.»: “[Margen: «Perpetuacio de Flores»] [...] fou perpetuat a las distribuci / ons del chor de nostra Santa Ig.a Joseph Flores thenor de ella ab lo salari / que te assenyalat en attencio de servir ab amor a la Ig.a".

[216] Fol. 292v.: «Die 10.[8.bris 1720] predictorum»: “[Margen: «Que M.o Pau Cassany aprengue / un poch mes de cant»] [...] havent fet relacio los señors $\mathrm{Ca}=/$ biscol y Canonge Zaydin de haverse examinat devant de ells de cant p. [rese]ents / señor mestre de capella y necessitar de algun temps mes per ser habil / afi de [ser] admes a las distribucions del chor, lo R.nt Pau Cassany p.btre bene / ficiat de nostra santa Ig.a i fuo resolt que inseguint la conclusio presa / en Capitols Pasquals que se observe aquella y que se li diga que aprenga / un poch mes de cant y despres si es habil que se admetia".

[217] Fol. 295r.: «Die 26 [Novembris 1720] p.torum»: "[Margen: «Adm.o de M.o Cas=/ sanÿ»] Item fou admes a las distribucions del chor lo R.nt Pau Cassanÿ bene.at de nostra / santa Ig.a ab lo con[sentiment] que de procurar en aplicarse en la practica del cant pla".

[218] Fol. 295r.: «Die 4. X.bris 1720.»: “[Margen: «Ciutat de Ceuta re / dimida dels moros»] “[...] Haventse llegit una carta del Ex.mo S.r Don / Francisco Caetano de Aragon llochtinent de G.dor en lo p.nt Principat de Cataluña / de 30. del mes passat ab que avisa al Capitol que las armas del Rey nostre / S.r que Deu g.de [...] han librat la ciutat de Ceuta del siti ab que la tenian opresa / los moros per lo spaÿ de mes de vint y sis anÿs, ab perdua gran de dita mala / secta [...] fou feta comissio als S.rs Canonges Pintor / y Zaydin afi de que anassen a repetirne enorabonas al S.r Bisbe al S.r D.n Igna / ci de Ruis Jutge de la R. A. Ques troba en esta ciutat com y al S.r Governador / y per a que dits señors comissaris acordien ab dit señor en lo dia y hora se deu / ra cantar lo Te Deum".

[219] Fol. 295v.: [«Die 12 X.bris 1720»:] "[Margen: «Admissio de M.o Pere / Boxadera»] Item fou admes a las distribucions del chor de nostra santa Ig.a etiam / a les de Espes lo R.nt Pere Boxadera beneficiat de dita santa Ig.a en / attencio de haver apres de solfa mes de quatre mesos".

[220] Fol. 297r.: «Die 8. Aprilis 1721.»: “[Margen: «Adm.o de M.o Montan»] [...] fou resolt admetrer a las distribucions del / chor etiam alas de Espes al R.nt Joseph Muntan p.btre y beneficiat del bene.i / [Fol. 297v.:] de S.ta Catharina Martir en dita Ig.a fundat". 
Presencia musical en la catedral de La Seu d'Urgell en la primera mitad del siglo xvili

[221] Fol. 299r.: [«Die 29.Aprilis. 1721»:] "Evangelis - M.o Fran.co Alamany bene.at comunitari / Epistoles - M.o Pere Net bene.at comunitari / Mestre de capella - M.o Fran.co Andreu / Organiste M.o Isidro Serrada / Baxonistes - M.o Rossell y M.o Gensana / Faristolers - Los cantors / Faristolers de chor major - Los cantors / Faristolers de chor menor - Los cantors / Corneta - Joseph Girona / Contralt Joseph Boluda / Martirologi - M.o Alamany y Vilanova / Tenor - Flores y Fr. Sans / Traurer los gossos de la Ig.a - Los preveners / Encendrer y apagar lo Rotlle - Los preveners / [Fol. 299v.:] Manxador -Pere Fahena".

[222] Fol. 300r.: «Die 2 May 1721»: "Item fuit resolutum que quant se de cantaran les hores canoniques en / lo chor se vaja ab tota pausa y que lo un chor no puga comensar lo / un vers que primer lo altre chor no haja acabat lo altre y que en esta / conformitat lo señor cabiscol ho previnga als sota cabiscols y als benefici $=/$ ats".

[223] Fol. 302v.: «Die 16. 7.bris 1721»: "[Margen: «Examinar al Famulo»] [...] fou feta comissio al S.rs Canonges / [Fol. 303r.:] Pintor y Zaydin per examinar de cant al Famulo".

[224] Fol. 304r.: «Die 13 [X.bris 1721] p.torum»: "[Margen: «Examen del / Famulo»] Item havent fet relacio los señors canonges Pintor y Zaydin com elegits per exa / minar de cant a Joan Inglesa beneficiat de nostra S.ta Ig.a afi / de esse admes a las distribucions del cor de esta Santa Ig.a y esser este habil sicut / ceteri y havent los vots estats paten lo Señor Ard.a de Cerdanya posa / desentiment al que se resolgue prorrogarse fins al dimars primer / vinent".

[225] Fol. 304v.: [«Die 16 X.bris 1721»:] "[Margen: «Famulo»] [...] haventse proposat si se admetia o no lo R.nt Joan In / glesa bene.at de nostra S.ta Ig.a a las distribucions del chor fuit / resolutum que no per no tenir la bastant practica de solfa".

[226] Fol. 304v.: «Die 10. Jan. 1722.»: “[Margen: «Epistola»] [...] aventse / donades les servituts Y haver tocat lo torn de cantar lo Evan / geli al S.r D.n Carlos de Apestegui dit S.r nol ha volgut".

[227] Fol. 308v.: [«Die 21 Aprilis 1722»:] "Evangelis - M.o Fran.co Alamany bene.at com. / Epistolas - M.o Pere Net bene.at com. / Mestre de Capella - M.o Fran.co Andreu / Organista - M.o Isidro Serrada / Baxonistas - Rossell y Jansana / Faristolers - Los cantors / Faristolers de chor major - Los cantors / Faristolers de chor menor - Los cantors / Corneta - Joseph Girona / Contralt - Joseph Boluda / Martirologi - Alamany y Vilanova / Thenors - Flores y Fr. Sans / Traurer los gossos de la Iglesia - Los preveners / Manxador - Pere Fahena".

[228] Fol. 312v.: «Die 14 [July 1722] p.torum»: "[Margen: «Roma»] [...] fuit resolutum ques compa / rega en Roma per la causa del benefici de Sant Matheu / que obté lo R.nt Fran.co Andreu / mestre de capella de nostra / Ig.a a per.tuacio del capitol y per so fou ordenat al dega escriga / a son agent".

[229] Fol. 318v.: «Die 13. Aprilis 1723.»: "Evangelis - M.o Fran.co Alamany B.t com.ri / Epistolas - M.o Pere Net bene.at commu.ri / Mestre de Capella - M.o Francisco Andreu / Organista - M.o Isidro Serrada / Baxonistes - M.o Rossell y Jansana / Faristolers - Los cantors / [Fol. 319r.:] Faristolers de cor major - Los cantors / Faristolers de cor menor - Los cantors / Corneta - Joseph Girona / Contralt - Joseph Boluda / Thenors - Flores y Fr. Sans / Traurer los gossos dela Ig.a - Los preveners / Manxador - Pere Fahena".

[230] Fol. 322v.: «Die 14 Septembris 1723.»: "[Margen: «Adm.o de M.o Campi»] [...] fuit re=/ solutum que atesa la gran pobresa de Pere Campi se admetia a las distri=/ bucions del chor etiam a les de Espes".

[231] Fol. 322v.: «Die 5.Octubris 1723.»: "[Margen: «Nom.o de manxador»] [...] fou nomenat en manxador y escombra / dor per mort de Joan Pere Sable a Pere Vila de la present ciutat ab lo / salari acostumat".

[232] Fol. 323v.: «Die 5.February 1724.»: “[Margen: «Servituts»] [...] haventse vuy dia de dissapte / more solito donades las servituts per la proxima semmana, toca / a Don Carlos de Apestegui lo torn de 
cantar lo Evangeli ab lo torn de / missa y no havent dit lo D.n Carlos volgut acceptar lo lo torn de cantar / lo Evangeli, ab lo motiu de quedarli en la proxima semmana la obli / gacio sols de fer llisso de escriptura lo dissapte solament de dita proxima sem / mana; tot lo que considerat per lo molt H.ble capitol y attesa la an = / tiga consuetut fins vuy observada de que lo capitular tocantli lo / torn de cantar lo Evangeli no volentlo acceptar queda privat del / torn de la missa, afi de que la Ig.a no quede deservida; ademes que / essent lo dupte del lector pendent en la Sag. Congreg. no vol lo capitol / privarse de la pocessio; y axi i fonch pr[o]nunciat dit D.n Carlos del torn de la / missa".

[233] Fol. 326v.: [«Die ii May MDCCXXIV.»:] "Evangelis - M.o Fran.co Alamany B.t commu.ri / Epistolas - M.o Pere Net B.t communitari / Mestre de Capella - M.o Fran.co Andreu / Organista - M.o Isidro Serrada / Baxonistas - M.o Rossell, y M.o Jansana / Faristolers - Los cantors / Faristolers de cor major - los cantors / Faristolers de cor menor - Los cantors / Corneta - Joseph Girona / [Fol. 327r.:] Contraalt - Joseph Boluda / Martirologi - M.o Alamany y Vilanova / Thenors - M.o Flores y Fr. Sans / Traurer los gossos de la Ig.a - los preveners / Encendrer y apagar lo Rotlle - Los preveners / Manxador - Pere Vila".

[234] Fol. 328v.: «Die 9. May 1724.»: “[...] havent / representat lo señor dega que lo mestre de capella li havia suplicat que / comensantse dema lo octavari de les animes de purgatori y que axis suplica / va que li concedis llicencia per fer un toch al mati y altre a la tarde / fuit resolutum que nos concedesca tal llicencia per que per ser lo poble / tant curt es bastant lo del hospital".

[235] Fol. 329r.: «Die 30. May 1724.»: “[...] Ha vista que lo señor mestre de capella ha fet relacio de haver examinat de / cant al R.nt Thomas Marques p.btre y bene.at de N.a S.ta Ig.a y no haverlo trobat / habil fuit resolutum que no se admetie y que se li diga que en lo interim / aprenga un poch de cant y que despres si será habil se admetra a las dis / tribucions del chor de dita Ig.a".

[236] Fol. 329v.: «Die 18. Septembris 1724»: “[...] Havent / nostre Dega proposat, que lo R.nt Misser Francisco Muntan p.btre y Rector de la Ig.a / Parroquial de Sant Miquel li havia entregat un paper ô Billet de data de primer / del corrernt mes de 7.bre y present any 1724. firmat per dit Muntan, en nom / de pretes President dels Beneficiats de esta Ig.a Cathedral de Urgell, en effecte / contenint, que dits Beneficiats per medi de son President major [...] que si lo Capitol no assenti a la justa representacio de dits Beneficiats en / augmentarlos la Distribucio de las Datas (encara que no congrua) a la de / dos sous per quiscun, y que lo Capitol hauria declarat per congrua la distribucio / de dos sous per los obits ordinaris, y que perso per est motiu haurian resolt / dits Beneficiats no asistir ningun a la celebracio de ditas Datas [...] y haventse llegit dit paper o Billet en ple Capitol y feta madura re / fleccio en y acerca son contingut considerant que la resolucio presa per dits / Beneficiats, y expressada en dit paper, de no voler assistir a la celebracio de / Dates y demes en ell expressat, es attentativa y ab ella se ha procehit de fet y de / propria autoritat, disposant en fet propri reluctant y repugnant á asso lo / dret, en la Clement. 2. de reb. Eccles. non alienand. [...] ser com es menos decorosa e in $=/$ decent a dits Beneficiats semblant resolucio los quals no dehuen reparar per / los interessos, si sols attendrer al major Culto Divino, y sufragi de las Animas del / Purgatori $=$ Com tambe dita resolucio notoriament redunda en detriment del / Culto Divino y en manifest prejudici de las Animas del Purgatori = Oposarie / y ses contraria ex Diámetro dita resolucio a la Consuetut Immemorial y / antiquísima de esta Ig.a, consistint en que dits Bene.ats Insimul ab los- / Capitulars de esta Cathedral han assistit a la celebracio de ditas Datas y / [Fol. 330r.:] entre altres obligacions y carrechs y servituts que incumbiesen als dits Beneficiats en la missa / de ditas datas es cantar dos Beneficiats lo gradual y altres dos lo tracte á eleccio dels sustentors / de dita Iglesia, juntament girar los fulls dels llibres del chor, quant se cante dita Missa lo que / es molt conforme al dret comu que disposa qui de Altare vivit altari servire debet com tambe / al dret Municipal de esta Iglesia y ordinacions de ella [...] feta per lo Capitol en temps del señor Bisbe Arnaldo, en Capitol Pasqual celebrat / als 16. de las kalendas de Juny 1340.ibi: Ordinat acin stituit, quod triginta et ser presbyteri qui / habent Intus dictam Eccl.am altaria ipsa et Bene- 
ficia, ex quibus possent sufficienter et decenter / sustentari; nec non quatuor Pueri vocati Prevenarÿ et Eorum succesores in dictis Bene.is sine / de cetero et dicantur Benea.ti en dicte Eccl.a Urg.nt et infra ibi: Et quia p.btri et Prevenarÿ su $=/$ prascripti in fundatione seu institutione primera predictorum. Suorum Bene.og sunt obligati / ad interessendum in dicto choro horis diurnis pariter \& nocturnis etc. Com axi mateix dita / consuetut es conforme a les institucions y fundacions dels dits Beneficis, en los quals los funda $=/$ dors obligan als obtentors en haver de residir y assistir en las horas Canonicas diurnas $/$ y nocturnas en lo chor de dita Ig.a: acte de fundacio del Benefici baix invocacio de Sant / Bernat feta per los Marmessors de Bernat Condominis lo dis 20. del mes de Maig del any 1413. [...] / [Fol. 330v.:] Es tambe la referida consuetut molt conforme a la sentencia arbitral del señor / Bisbe Despuig proferida per y entre lo Capitol de una y dits Bene.ats de part / altra promulgada aceptada y emologada per ditas resp.s parts al primer del / mes de Juliol 1553. en poder de Joan Sollá not. publich y secret. de dit S.r Bisbe; en / y abla qual vehint lo señor Bisbe que los Beneficiats no tenian charitat, ni dis=/ tribucio alguna en ditas Datas, ordena y disposa en sa dita sentencia per ell / pronunciada y dularada, que lo Capitol donas trenta lliures quiscun any als / Beneficiats de distribucio en la celebracio de ditas Datas a fi y effecte de que en / aquellas junt ab los Capitulars assistissen y residissen sentencia arbitral del señor / Bisbe Despuig [...] Considerant aixi mateix que los Bene.ats ab la referida resolucio clarament con $=/$ trafan al jurament que tenen prestat en las provisions de sos resp. [ectiu]s Beneficis / es a saber de observar los estatuts de dita Ig.a y cumplir a les sevituts y obli=/ gacions de aquells. / Considerant tambe que lo Capitol pot estatuir independent ment del señor / Bisbe y sens son consentiment en las cosas consernents la ordinacio del / chor, lo culto divino y servey de la Iglesia. [...] Lo dret de presidir en lo chor regirlo y governarlo corrigir las faltas y castigar / los excessos, que en ell se cometen no se radica en Persona alguna, si no que / resideix en lo mateix Capitol. [...] Competeix tambe al Capitol la jurisdiccio y facultat de mulctar als Bene.ats / no sols de dret comu y atesa la disposicio. / [Fol. 331r.:] en termens del Capitol de la S.ta Ig.a de Bar / celona la matexa Rota 8. Februarÿ 1694. [...] sino tambe attesa la general consuetut dels Capitols de Espanya de quates $=$ / tantur molts DD. y varias decisions de la Rota. [...] Esta facultat de mulctar no sols competeix al Capitol per disposicio de dret Comu, General con / suetut dels Capitols de Espanya sino tambe per dret municipal estatuts y ordinacions de / dita Iglesia, com consta difusament en lo llibre de Constitucions o Consueta de dita Ig.a / Constitutcio 12. ibi: Item cum invenimus quod Precentor debet tenere succentorem et ipsi / duo tenentur repere chorum legendo et cantando et habent correctionem Prelatis, et cano $=/$ nicis, et clerecis. / Refundintse y dimanant esta facultat del Capitol al Primiser, Cantor, o Cabiscol que / significan una mateixa cosa. [...] Considerant mes havant que en la Iglesia de Deu no hi deu haver sersura com sia una / vestidura inconsutil, y que los Beneficiats y demes sacerdots de qualsevol manera / [Fol. 331v.:] se consideren, encara que pretengan tenir certas prerrogativas / y esser mem $=$ / bres separats y componen un cos ab lo Capitol en lo tocant als actes y jureccions / del chor, y demes que consernexen lo Culto Divino. [...] es incongruo diforme y molt disonant que quan los Capitulars / assistexen en la Celebracio dels dits Aniversaris que de temps immemorial / se celebran en esta Cathedral per sufragi de las Animas del Purgatori, los - / dits Beneficiats no hi assistescan, antes be cum máxima scirura et scandalo / sen vagen del chor e Ig.a; En termens de professons en que no volian asssitir / los Beneficiats de dita Cathedral de Lleyda ho digue la Rota in dicta Illerdensi / processionum: observantho com axis ho han observat fins vuÿ des del dia / primer de Setembre que se comensaren a celebrar ditas datas; exprimentantse / de esta falta com se exprimeta que los demes dels Bene.ats no assistexen / y abandonan la residencia en las horas cononicas y celebracio de la missa / conventual patint en asso com se si se dexa considerar gran diminucio / lo Culto Divino y violant la lley de las fundacions de los resp. [ectius] Beneficis / Consuetut y Estatuts de dita Ig.a En forsa dels quals dits Beneficiats / dehuen assidue residir a las horas canonicas diurnas y nocturnas / que se cantan y celebran en dita Iglesia com sobre queda establert / essent axi que de temps immemorial hi han assistit sempre ab la / sola distribucio de un sou per cada un Beneficiat, y es equivocacio/ manifes- 
ta que lo Capitol haja declarat per distribucio dos sous / per cada un Beneficiat en la celebracio dels Anniveraris o obits / ordinaris: Per tot lo que y altrament del millor modo y manera / que se pot y se deu fonch resolt que per totas las faltas que dits / Beneficiats han comes en no assistir a la celebracio de dits Anniversa / ris signanter en la missa y absoltes en tant grave dany y notori / detriment del Culto Divino y prejudici del sufragi de las Animas del / Purgatori, que per lo passat cada un de dits Beneficiats sie mulctat / com se mulcta en un sou tantsolament per totas las faltas y per li / es devenidor y del dia que sels notificará sie mulctat com se mulcte / cada Baneficiat en quatre diners cada vegada [que] faltaran / a la celebracio de ditas Datas; y lo señor Canonge Rovira es de vot / contrari perque la distribucio que dexan de guanyar serveix / de pena; y juntament fonch resolt que lo sobre chalendat / [Fol. 332r.:] Paper dels Beneficiats sia continuat y transcrit al peu de esta resolucio y lo origi $=/$ nal posat al calaix dels Beneficiats y que dita resolucio sia notificada á quiscun / dels Beneficiats per medi de noste Cabiscol. / Sequitor papirus dicta Communitaris / La comunitat de Urgell, per medi de son President major, ab expressa commissio, de la / que consta en lo llibre de conclusions, y resolucions de dita comunitat dia y any en / ell continguts, passa ab lo pr.nt a la comprehencio del molt Il.tre Capitol de la Santa / Iglesia de Urgell, que si be dit molt Il.tre Capitol no assent a la justa representacio / de dita comunitat de augmetar la distribucio de las Datas a la (no encara con=/ grua) de dos sous per quiscuna, distribucio per dit molt Il.tre Capitol per los obits / ordinaris per congrua declarada; y en virtut de axo resolgue dita comunitat no / assistir a la celebracio de ditas Datas, no empero ha presumit faltar a la assistencia / dels officials deu donar per dita celebracio y demes: Pero ab la present declaracio / que dits officials qui son los R.nts Anton Celleres, Francisco Anglada, Marti Jover / Fran.co Salmurri Pere Net, Joan Barbes Sagimon Armengol, Francisco Alamany / Sebestia Clunet y Lluis Mir que al temps de dita celebracio cumpliran ab sos resp.s / carrechs, no entenen ab llur assistencia lucrar la distribucio corresponent a la / missa y absoltes de ditas Datas; ans be expresse no protestan: y per a que en tot / temps conste de dita resolucio y presentacio de ella a dit molt Il.tre Capitol de la / qual te dita comunitat feta sa conclusio firma lo present sellat ab lo sello de / dita comunitat Dat. en nostra casa de la comunitat de Urgell al p.r del mes / de Setembre de mil set cents vint y quatre. / Muntan Prese. Major pro Com.te Urgellis".

[237] Fol. 332v.: «Die 17 octobris 1724»: “[...] Lo Señor Ard.a Major Areny Prefecte del / chor de la Santa Ig.a de Urgell per absencia de son Cabiscol ha fet / relacio que per notificar als Beneficiats de la pretesa comunitat de / esta Cathedral la resolucio ques prengue lo dia 18. de Setembre / proxim passat, ha entregat á Andreu Vilanova cantor y servus / communis de la matexa Ig.a un membrete o Bitllet per cada un / de dits Beneficiats lo qual es del thenor seguent = En execucio de la / resolucio per mon Capitol presa als 18. del mes se Setembre del cor=/ rent any 1724. y per los motius en aquella expressats, y cumpliment / de las obligacions que me incumbiesen per raho de ma Dignitat / que obtinch y offici notifico a un R.nt M.t Francisco Muntan p.btre y R.t / de la Ig.a Parroquial de Sant Miquel, ques per totas las faltas que un / ha comes fins lo dia presenten la celebracio de las Datas se ha mulctat / per totas ellas en un sou tant solament, y per las que foran comessa / per dit respecte del dia present en havant ara per a les hores y a les / hores per ara que de un. mulctat ipso ipso en quatre diners / per quiscuna de las Datas que faltava Seu de Urgell y Octubre 14 de / 1724 = Ard.a Major Arenÿ Prefecte del chor de la Santa Ig.a de Urgell / en absencia del Señor Cabiscol de dita Ig.a = Et porte a dit Andreu Vila=/ nova ha fet la relacio seguent $=$ de que dits Membretes o Billets que / hi ha entregat dit Señor Ard.a major en dit nom los ha posat en / mans proprias del R.nt Francisco Anglada, R.nt Anton / Celleres, Joan Barber Onofre Vidal Joseph Muntan Francisco / Salmurri Joan Ponsa y Barcelona Lluis Mir y Rey Marti Jover / Pere Campi, R.nt Magi Cases, lo qual ab furia fui trossos de dit Billet / Joan Cellera qui feu trossos de dit Billet, R.nt Joseph Pubill qui li digue / que ell no estava subjecte al Capitol y axis que li trisques del devant / y que no volia lo paper cridant y alborotantse, a M.t Fran.co Mestre / qui nol volgue acceptar dient que ha ell se li presentacian los papers / ab altra cerimonia que es ab notari y testimonis, M.t Fran.co Mun / tan que tampoch nol volgue 
Presencia musical en la CATEdral de La SEU d'Urgell en la PRIMERa mitad del Siglo xViII

aceptar y digue lo mateix que digue / [Fol. 333r.:] Misser Mestre, M.o Joseph Canals qui nol volgue acceptar a M.o Pere Babot / y a M.o Andreu Farrer los quals billets foren entregats tots per ell dit Vilanova / lo dia16. de dit mes y any antes de entrar als Divinos officis".

[238] Fol. 333r.: «Die quinta X.bris 1724»: “Lo señor Dega ha pro/ posat que lo señor Don Andres de Apestegui vicari Gen. Del Señor Bisbe hi havia / donat un recado per part de su Ilt.ma qu en consideracio de haver la santedat / de nostre SS.m Pare Benet tretse dispensat un tant un tant gran jubileu u honra y gloria / de Maria SS.ma y Benefici dels faels Christians al toch de las tres Ave Marias / so es de la aurora, mitg dia y primer enfoscant y que per a que aquells pugan / lograr ab mes facilitat lo benefici de las indulgencias, que disposas lo molt Il.tre / Capitol de donar orde per a que se fassan los tres tochs necessaris en ditas horas, / despres de tocar la desperta fassia tres senyals per la Ave Maria de la auro / ra ab la campana grossa, y axi mateix que per los altres dos tochs donie or / de al campaner que los executie so es un al mig dia escajan de fer lo ques feya / a la una o al primer toch de vespres y lo altre a la hora acostumada de la nit / com be estila".

[239] Fol. 333v.: «Die 30. January 1725.»: “[...] per trobarse mort lo R.nt / Pere Net p.btre qui cantava las Epistolas y lo R.nt Francisco Alamany / qui cantava los Evangelis trobarse previst de la Rectoria de ciutat / fou resolt nomenar com se nomena per cantar ditas Epistolas al / R.nt Joseph Pubill p.btre y beneficiat comunitari de esta Ig.a y per / cantar los sants Evangelis lo R.nt Joan Graell arxibe beneficiat / comunitari de dita Santa Ig.a".

[240] Fol. 333v.: «Die 13 [Marty 1725] p.torum»: "[...] fou admes de nou a las distribucions / del chor etiam a les de Espes lo R.nt Fran.co Andreu p.btre y Mestre / de Capella y bene.at del benefici de Sant Matheu apostolic del / qual ha tingut gracia Ap.ca de subrogacio injuribus collitigantis".

[241] Fol. 335r.: [«Die 17 Aprilis 1725] p.torum»: "Evangelis - M.o Joseph Pubill B.t comunitari / Epistolas - M.o Joan Graell B.t comunitari / Mestre de Capella - M.o Fran.co Andreu / Organista - M.o Isisdro Serrada / Baxonistas - M.o Rossell y M.o Jansana / Faristolers -Los cantors / Faristolers de chor major - Los cantors / Faristolers de chor menor - Los cantors / Corneta - Joseph Girona / Posar y llevar les capes ab salari de $2 £$ cada hun - M.o Flores y Fr. Sans / Contraalt - M.o Joseph Boluda / Martirologi - M.o Joseph Pubill / Thenors - M.o Flores y Fr. Sans / [Fol. 335v.:] Traurer los gossos de la Ig.a - Los preveners / Encendrer y apagar lo Rotlle - Los preveners / Manxador - Pere Vila".

[242] Fol. 336v.: «Die 19. Aprilis 1725.»: "[Margen: «Cantar la missa als / combregars»] [...] fuit / resolutum que sempre y quant esdevindrá a portarse lo viatich á algun / señor capitular malat que tant al anar com al tornar a la Iglesia / lo santissim viatich cantie la musica".

[243] Fol. 337v.: «Die. 26. Juny 1725.»: "[Margen: Admetrer al chor al D.r / Bellsolell luego que sia p.btro»] [...] haventse llegida una suplica presentada per lo D.r Pasqual Bellso=/ lell Beneficiat de dita Ig.a ab la qual suplicava que en attencio / de disitjar esser promogut als Sagrats ordes, fos sa señoria servit / decretar que luego de que dit D.r Bellsolell sera promogut al $\mathrm{sa}=$ / grat orde de presbiterat, lo admetia a les distribucions del cor de dita / Santa Ig.a, afi de que su señoria Il.trma lo no tinga escrupol en / ordenarlo ab sol titol del Benefici que obte baix invocacio / de Sant Bernat en dita Ig.a fundat; fuit resolutum que ates lo / suplicat se consent en admetrer a dit D.r Pasqual Bellsolell a dites / distribucions sempre y quant fara constar de la cartilla del pres / biterat com ara per les hores lo admeten a les referides distribucions / onmis modo meliori [...]".

[244] Fol. 339r.: «Die 30 Octubris 1725.»: “[...] lo señor Dega ha proposat que lo p.[resen]t / R.nt Joseph Bosch beneficiat del benefici de Sant Nicolau en la Ig.a Catedral de / Urgell fundat durant sa enfermedat encomaná lo cantar la llisso que li tocava / per raho de son benefici cantar de obligacio al R.nt Joan Graell, y que si dit Graell / continuaria en est exercici pagantli lo estipendi que se li pagava al difunt / fuit resolutum que continue en cantar dita llisso y que se li pague son esti=/ pendi”. 
[245] Fol. 341r.: [«Die Septima May 1726.»:] "Evangelis - Lo R.t Joseph Pubill B.t Com.ri / Epistolas - Lo R.t Joan Graell B.t comunitari / Mestre de Capella - Lo R.t Francisco Andreu / [Fol. 341v.:] Organista - Lo R.t Isidro Serrada / Baxonistas - M.o Rossell y Jansana / Faristolers - Los cantors / Faristolers de cor major - Los cantors / Faristolers de cor menor - Los cantors / Corneta - Joseph Girona / Contralt - M.o Joseph Boluda / Martirologi - M.o Joseph Pubill / Tenors - Presentat Sans y M.o Flores / Traurer los gossos de la Iglesia - Los preveners / Encendrer y apagar lo Salomo - Los preveners / Manxador Pere Vila".

[246] Fol. 342v.: «Die nona [May] p.torum»: “[Margen: «Llibres de Epist. y Evang.»] [...] fuit resolutum ques fassan portar dos llibres un de Epistolas y altre / pera que no se hajan de portar los missals pera cantarlas".

[247] Fol. 343v.: «Die 4. Juny 1726.»: “[Margen: «admissio de M.o Codina»] [...] fou admes a las distribucions del chor etiam a les de / Espes lo R.nt Joan Codina p.btre y beneficiat del benefici baix invo= / cacio de Sant Antoni de Padua en la p.nt Ig.a instituit y fundat / en attencio de haver fet relacio lo R.nt Francisco Andreu mestre de / capella haverlo trobat habil de cant despres de haverlo examinat".

[248] Fol. 344r.: «Die 8 Octobris 1726»: / [Fol. 344v.:] “[...] havent Joseph Flores presentat suplica al capitol dient voler / pendrer un benefici a personat y que no troba que se obligue / per lo censal que deu crear de $300 £$ y que pagara los gastos / y entregara en continent cent lliures per part de la quitacio del / censal y entrat que haura a la comunitat cedira los guaniables / en quitacio de dita obligacio fuit resolutum que se fasse la dita / obligacio ab que si antes de quitar dit Flores moris que los individuos / y singulars de capitol ho paguen allo que faltara haver quitat a fi que la / iglesia no patesca detriment algun".

[249] Fol. 344v.: «Die 5 Novembris 1726»: “[Margen: «admissio de M.o Pera»] [...] fou resolt admetrer a las distribucions del chor etiam de Espes al R.nt / Joan Pera p.btre y Beneficiat del Benefici baix invocacio de Sant Clement / en dita Iglesia fundat en attencio de haverse fet relacio de esser habil / de cant"

[250] Fol. 344v.: [«Die 5 Novembris 1726»:] "[Margen: «admissio de Flores»] Item fou admes en ditas distribucions lo R.nt Joseph Flores beneficiat / dels benefici de Sant Joan deu corones en dita Ig.a fundat en atten / cio de haverse fet relacio esser habil de cant".

[251] Fol. 345v.: «Die 7. January 1727.»: “[Margen: «Sobre admissions»] [...] Haventse llegida una suplica presentada / per part de M.o Thomas Marqués Beneficiat del Benefici de la nativitat / de nostra señora de M.o Fran.co Gallart Beneficiat del Benefici de Sant / Joan de Gollacia, de M.o Joan Inglesa Beneficiat del Benefici de Sant $A n=/$ toni Abat de M.o Jaume Borrell Beneficiat del Benefici de Sant Nicolau / demanant la admissio a las distribucions del chor de la S.ta Ig.a de Urgell / fuit resolutum que se examinen de si son o no habils de cant: y lo S.r / Ardiaca de Berga Salles y de Rius diu que no pose dissentiment a dita / resolucio acceptat a dit mossen Borrell que per provist acepte aptica / es de parer que se admetie = lo señor Ard.a Major fou de parer que / se examinen = lo señor Ard.a de Andorra que no = lo señor Cabiscol / que no = lo S.r Canonge Montaner es de parer que se examinen / lo señor Canonge Rovira que se examinen = lo S.r Canonge Verges $/$ que no $=$ lo S.r Canonge Bosquets que se examinen = lo S.r Cang.e / Pintor que no = lo S.r Canonge Riu que no = lo S.r Canonge Zaydin / que se examinen = lo S.r Canonge Fiter que se examinen lo S.r / Canonge Ubach que se examinen $=$ lo S.r Canonge Net que no $=y$ lo / señor Dega que se examinen".

[252] Fol. 347r.: «Die 11. February 1727.»: "[Margen: «admissio de M.o Fuster»] [...] fou admes a les distri / bucions del cor de nostra Santa Ig.a etiam a les de Espes lo R.nt Francisco Fuster benefici=/ ciat de Sant March en dita Santa Iglesia fundat en attencio de haver / estat habil de cant".

[253] Fol. 348r.: [«Die 29 Aprilis 1727»:] "Evangelis - M.o Joseph Pubill bene.at comunitari / Epistolas - M.o Joseph Graell bene.at comunitari / Mestre de Capella - M.o Francisco Andreu / Organista - M.o Isidro Serrada / [Fol. 348v.:] Baxonistas - M.o Gansana y M.o Rossell / Faristolers - Los cantors 
/ Faristolers de chor major - Los cantors / Corneta - M.o Joseph Girona / Posar y llevar les capes ab salari de / dues liures cada un - M.o Flores y Fra. Sans sota.[ca]piscols / Contral - M.o Joseph Boluda / Martirologi ab lo salari acostumat - Los preveners / Tenors - M.o Flores y Fra. Sans sota.biscols / Traurer los gossos de la Iglesia - Los preveners / Encendrer y apagar lo Salamo - los preveners / Manxador - Pere Fahena".

[254] Fol. 357r.: «Die 3. Septembris 1727.»: "[Margen: «Resolucio presa / contra los benefi: / ciats y ordre do $=$ / nat als musichs.»] [...] Attes y considerat que los beneficiats continúen en sa desa / tencio de faltar y no voler asistir als funerals dels señors capitulars, com se exprimentá lo dimecres / dia primer en ques doná principi al funeral de Don Alexandro de Ribas sacristá y canonge / prelat de nostra Santa Ig.a, en que tots desempararen lo cor menos los musichs y algun altre / que per oficial devia asistir: fou resolt se donas orde al mestre de capella y de mes musichs de la / capella que de aquell dia en havant se abstinguessen de asistir a ninguna funccio per la comu / nitat axi en comu de capella com en particular de musich, y que qualsevol que fes lo contrari / se tingues desde luego per despedit del servey del capitol: y lo mateix dia despres de vespres lo / señor Degá passá en noticia del R.nt Francisco Andreu mestre de capella la subdita resolucio / qui offerir des de luego passarla als demes musichs".

[255] Fol. 361r.: [«Die 13. Aprilis 1728»:] "Evangelis - Lo R.t Joseph Pubill B.t communitari / Epistolas - Lo R.t Joan Graell B.t communitari / Mestre de Capella - Lo R.t Francisco Andreu / Organista - Lo R.t Isidro Serrada / Baxonistas - M.o Jansana y M.o Rossell / Faristolers - Los cantors / Faristolers de cor major - Los cantors / Faristolers de cor menor - Los cantors / Corneta - Joseph Girona / Posar los abits del cor - M.o Andreu y M.o Girona / Posar y llevar las capas ab salari de dues lliures quiscu[n] - M.o Flores y Fra. Sans sotacabiscols. / Contraalt - M.o Joseph Boluda / Martirologi - Los preveners / Thenors - M.o Flores y Fra. Sans / Traurer los gossos de la Iglesia - Los preveners / Encendrer y apagar lo Rotlle - Los preveners / Manxador - Joseph Abella".

[256] Fol. 362r.: «Die 17. [Aprilis 1728] predictorum»: "[Margen: «Sobre los prevene=/ rs perden la veu.»] [...] Lo señor Dega ha proposat / que suposat que los preveners que perden la veu que antes lo señor Bisbe los posava al / seminari y estudiavan y ara la Iglesia los deu sustentar, fore bo que axi com los señors ca $=$ / pitulars han de tenir criat que prenguessen dits preveners fentlos estudiar calsantlos / y vestirlos la Ig.a cada anÿ: fuit resolutum que se execute axi com lo señor Dega ho / proposa".

[257] Fol. 362v.: «Die 19. [Aprilis 1728] predictorum.»: "[Margen: «Statut sobre no passejarse / ni tenir colloquis impertinents / dins la Ig.a Cathedral»] [...] Attenent y conside=/ rant que una de las cosas mes principals per las quals quiscun anÿ celebram / los Capitols Pasquals, es lo llevar los abusos, y excessos se cometen y exprimenten en / esta Santa Ig.a tant en la decantacio de la horas Canonicas Celebracio de lo[s] Divinos / officis, com demes funccions Ecc.ticas, per a que in ómnibus se observe y guarde la mo= / destia, decencia, y reverencia y veneracio que tots devem tenir servar y guar- / dar al temple y casa de Deu, y axi mateix se canten y celebren resp.e los Divinos officis ab grave / dat devocio y attencio manan los Sagrats Canons y Sants Pares ab sas Constitucions Gene / rals y Provincials Tarraconenses: Attenent semblantment que si be santament se troba / per nostres antecessors ordenat y disposat ab varias y differents conclusions ordina $=/$ cions y Estatuts conformes a las sobre referidas disposicions et maxime a nostres / Constitucions Tarraconenses y Constitucio de Sant Pio V. que comensa: cum primum / Apostulatus officium (etc) dada en Roma a las Kalendas del mes de Abril 1566. ab que / severament se prohibiexen intra Ecc.tam les deambulacions y colloquis imperti=/ nents y altres differents cosas: Perso desitjant obiar los excessos y abusos se / podrían cometrer intra Ecc.tam tant en la decantacio y celebracio resp.e de las ho $=/$ ras Canonicas y Divinos officis com altrament conformantmos y arreglantmos - / al disposat y santament ordenat per San Pio V. y nostres constitucions Tarra $=/$ conenses, per a que tengam tots la decencia modestia veneracio y reveren / cia al temple de Deu, que devem tenir y observar: confirmant tots los Esta $=/$ tuts conclusions y resolucions a est effecte fets y fetas amonestam y exortam / a tots los 
residents tant Capitulars com Beneficiats y demes, que alteran / tant ab habits de chor, com sens ells nos passejen ni tingan colloquis $\mathrm{im}=/$ pertinents dins la Iglesia, altrament en las contrari se prossehira contra / ells si y conforme decret seria permes. Y axi mateix per a que totas las / funccions Ecc.ticas se cumplian ab la devocio y attencio ques deu a major / gloria de Deu Culto Divino y edificacio dels seculars, ordenam y estatuim / que ningun dels Residents puga exir ni entrar comensadas las horas ca / nonicas y Divinos officis per la Porta del cancell o rexa del chor, a la / reserva dels que per raho de son offici o ministeri deuhen anar al / Presbiteri o Sacristía, sino solament per la porta principal del cor y que / ningun puga exir del cor fins dita la Salve o Antiphona y Collecta que / segons rubricas se deu dir a la conclusio de las horas Canonicas; baix la pena / de privacio de la distribucio corresponent a la hora canonica o qualsevol / altra funccio, y no menos que ningun puga lucrar la distribucio de / Kiries sini es in choro interessent fins al Santus y la de Santus / [Fol. 363r.:] fins al Agnus inclusive; y semblantment que tots los residents tant Capitulars, com Bene.ats / y demes degan anar processionalment quant se cantan los responsoris o absoltas sens poder con $=/$ versar ni confabular baix la pena de ser privats de la distribucio a ditas absoltas corresponent[s]: y / per a que vinga a noticia de tots ordenam que la present resolucio y estatut sia fixat dins del cor / Encarregant al Apuntador invigile sobre lo predit y axi mateix observe y practique en lo / apuntar als residents si y conforme esta disposat en la consueta de nostra Santa Ig.a".

[258] Fol.363r.: «Die prima 27. May 1728.» "[Margen: «Petició del S.r Bisbe / sobre la festa de / N.a S.ra de [la] Pietat»] [...] Havent lo Señor Canonge Bus / quets reportat al Capitol un recado de part del Señor Bisbe, ab que expressa su Ilt.ma que essent / tant proxim la celebracio de la festa de nostra Señora de la Pietat fore notat de que la musica / no assistis a la Celebracio de dita festa y que un dels Señors Capitulars ab los demes que vol= / guessen assistir no autorirás aquella cantant la missa, y que per tant havia de de deures / al Capitol el que concedis en assistir com com acostumava; lo que reflectit per lo Capitol / no obstant de no esser merexedors los Beneficiats de mninguna gracia per lo[s] escandalos / de son obrar en las funccions en que han faltat, se ha resolt el que assistesca la mu / sica per redundar en major culto de Maria SS.ma y per complaurer a su Ilt.ma / y que si conviden ja que no hi ha temps per anar a la Estacio se assitesca a la missa com se ha acostumat los demes anÿs".

[259] Fol. 368v.: «Die 7. February 1729.»: “[Margen: «Adm.o del D.r Nicolau / Marti»] [...] fou admes a les distribucions del / chor de nostra Santa Ig.a etiam a les de Espes al R.nt D.r Nicolau Mar / ti p.btre y Beneficiar del Benefici baix invocacio de Santa Margari / da en dita Ig.a instituit y fundat".

[260] Fol. 368v.: «Die 8. February 1729.»: “[...] Haventse llegi / das sinch suplicas la primera presentada per lo R.nt Thomas Marques [...], altra presentada / per lo R.nt Francisco Gallart [...] altra per lo R.nt Joan Inglesa [...], altra per lo R.nt Antoni Bertran [...] y la ultima per lo R.nt Macia Riu [...] ab las quals demanen y supli / can la admissio a las distribucions del chor de dita Ig.a [...] fuit fuit resolutum que se admeten tots los sobredits per son orde y an / tiguitat [...] que entregue quiscun son titol al secretari per posaro per son / orde y que se examinon en lo del cant menos lo R.nt Macia Riu / que per ser germá de Canonge se li despense lo examen".

[261] Fol. 369v.: «Die 25. Aprilis 1729.»: “[Margen: «Admissio de M.o Boluda / y M.o Campos»] [...] foren admesos a las distribucions / del chor de dita Santa Ig.a etiam a les de Espes los R.nts Joseph Boluda / p.btre y Beneficiat del Benefici baix invocacio de la Anunciata y lo R.nt / Nicolau Campos Beneficiat del Benefici de Sant Francesch en dita S.ta Ig.a / instituits y fundats".

[262] Fol. 370v.: «[Die 4 May 1729] predictorum»: "Evangelis - M.o Joseph Pubill B.t com.ri / [Fol. 371r.:] Epistolas - M.o Joan Graell bene.at communitari / Mestre de Capella - M.o Francisco Andreu / Organista - M.o Isidro Serrada / Baxonistas - M.o Rossell y Jansana / Faristolers - Los cantors / Faristolers de chor major - Los cantors / Faristolers de cor menor - Los cantors / Corneta - M.o Joseph Girona / Posar los abits del cor - M.o Vilanova y M.o Girona / Posar y llevar les capes ab salari de $2 £$ quiscun - M.o Flores y Fra. Sans / Contraalt - M.o Joseph Boluda / Martirologi - Los preveners / Thenors - M.o 
Presencia musical en la catedral de La Seu d’Urgell en la Primera mitad del Siglo XViII

Flores y Fra. Sans / Traurer los gossos de la Ig.a - Los preveners / Encendrer y apagar lo Rotlle - Los preveners / Manxador - Joseph Abella".

[263] Fol. 372r.: [«Die quinta May 1729.»:] "Item fuit resolutum que les Matines de Corpus Sant Od, y Sant Ermengol se canten / ab tota solemnitat y ab musica".

[264] Fol. 372r.: «Die 6. May 1729.»: “[...] Item fuit resolutum que les constitucions de Tarragona ara novament celebrades que / prohibiesen tot vestit de color y las mascaras y valls publichs se observen al peu de la / lletra y que ningun capitular no puga anar vestit de color ni portar capes de color / y que no pugan ballar publicament ni disfrasarse, y que axi lo vestit com la capa / sia negra y no de altre color y perso se ha fet lo estatut del tenor seguent".

[265] Fol. 372v.: [«Die 6. May 1729.»:] “[Margen: «Tocar una campaneta cada / vegada que ha de respondrer / lo chor»] Item fuit resolutum que quant se celebre en lo Altar major y lo cor ha de res=/ pondrer ques toque una campaneta cada vegada que lo chor haura / de respondrer per lo mestre de cerimonies y ques comense a tocar dita campa / neta lo dia de Sant Isidro".

[266] Fol. 375v.: «Die 4 8.bris 1729.»: "[Margen: «Evangelis M.o Campi»] Item per los atxaques que lo R.nt Joseph Pubill beneficiat com / munitari esta patint, quel impedeixen de poder cantar los Evan / gelis en la Catedral fou nomenat per cantar dits Evangelis / lo R.nt Pere Campi beneficiat communitari”.

[267] Fol. 377v.: [«Die 25. Aprilis 1730.»:] "Evangelis lo R.nt Pere Campi - lo R.nt Pere Campi B.t com. / Epistolas - Lo R.nt Joan Graell B.t com. / Mestre de Capella - M.o Fran.co Andreu B.t / Organiste - M.o Isidro Serrada B.t / Baxonistas - M.o Matéu Rossell y M.o Jansana / Faristolers - Los cantors / Faristolers de cor major - los cantors / Faristolers de cor menor - Los cantors / Corneta - M.o Joseph Girona / Posar los abits de cor - M.o Vilanova y M.o Girona sacristans / Posar y llevar les capes ab salari de $2 £$ cada un - Fr. Sans y M.o Flores / Contraalt - M.o Joseph Boluda / Martirologi - Los preveners / Tenors - M.o Flores y Fr. Sans / [Fol. 378r.:] Traurer los gossos de la Iglesia - Los preveners / Encendrer y apagar lo Rotlle - Los preveners / Manxador - Joseph Abella".

[268] Fol. 378v.: [«Die 26 Aprilis 1730»:] "[Margen: «De reform.»] Item fuit resolutum que se observen totas las conclusions ordinacions y estatuts / fins lo dia present fetas per lo major lustre y compliment dels Divinos officis y ho / ras canonicas y que lo señor cabiscol las fassa observar ab aquells medis mes pro / porcionats; y que ningu se puga passejar per lo tras cor, sino que revestit $\mathrm{di}=/$ rectament entre en lo chor y se sente en sa cadira sens poderse tanpoch passe / jarse per lo chor".

[269] Fol. 378v.: [«Die 26 Aprilis 1730»:] "[Margen: «Estar ab la palma en la ma»] Item fuit resolutum que los señors capitulars lo Diumenge de Ram estigan / en lo chor ab la palma en la ma tot lo temps se cantará la passio".

[270] Fol. 379r.: [«Die 27 Aprilis 1730 predictorum»:] "Item fuit resolutum que los faristols portatils se traguen del chor y que quant se haja de can / tar los entren los preveners".

[271] Fol. 379r.: [«Die 29 Aprilis 1730 p.torum»:] "[Margen: «Sal. de Thomas Andreu»] Item fuit resolutum que a Thomas Andreu se li done sinquanta lliures de salari a vista / [Fol. 379v.:] que ha servit y serveix a la Iglesia".

[272] Fol. 379v.: «Die 2. May 1730.»: “[...] fuit resolutum que en attencio / que a M.o Thomas Andreu se li ha assignat sinquanta lliures de salari / que no se estampen los villansicos de matines de Nadal y que los S.rs / commissaris destinats miren com se dega deshogar la Iglesia".

[273] Fol. 382v.: [«Die X. Aprilis 1731.»:] "Evangelis - M.o Pere Campi B. com. / Epistolas - M.o Joan Graell B. com. / Mestre de Capella - M.o Fran.co Andreu B.t / [Fol. 383r.:] Organista Lo R.t Isidro Serrada / Baxonistas - M.o Mateu Rossell y Gensana / Faristolers - Los cantors / Faristolers de cor major - Los cantors / Faristolers de menor - Los cantors / Corneta - M.o Joseph Girona / Posar los abits de cor - M.o Vilanova y Gerona Sarriga / Posar y llevar las capas ab salari de $2 £$ cada un - M.o Flores y Fra. Sans / Contraalt - M.o Joseph Boluda - / Martirologi - Los preveners / Thenors - M.o Flores y 
Fra. Sans / Traurer los gossos dela Iglesia - Los preveners / Encendrer y apagar lo Rotlle - Los preveners / Manxador - Joseph Avella".

[274] Fol. 383v.: «Die 11. [Aprilis 1731] predictorum.»: “[...] fuit resolutum que aquelles ad un guem [al peu de la lletra] / se observen, y que lo estatut fet en Capitols Pasquals en orde als collo= / quis y passetg dins la Iglesia y totas y qualsevols conclusions y ordina= / cions fetas per lo bon regim y govern de la Iglesia y celebracio dels / Divinos officis se obseven al peu de la lletra".

[275] Fol. 383v.: [«Die 11. Aprilis 1731»:] "Item fuit resolutum que tots los cantors no obstant de gosar de la / presencia de les Matines, des del dia de la Concepcio fins als Reis que / [Fol. 384r.:] que assistescan a les Matines y Laudes de la ante vigilia de Nadal, y que M.o Flores no obstant / de gaudir de dita presencia haja de asistir a ditas Laudas tots los dias dobles, y que quant dit / Flores quant estiga ocupat per servir a la capella fora de la Iglesia, que haja de donar / la providencia per a que altre per ell cumple la falta que fa al cor".

[276] Fol. 384r.: [«Die 11. Aprilis 1731»:] "Item fuit resolutum que lo dia de la Concepcio la missa se cante ab tota solemnitat / de musica violins y demes".

[277] Fol. 384r.: «[Die 13 Aprilis 1731] predictorum»: "Item fuit resolutum que los villansicos del dia de Nadal de las Matinas de dit dia / antes de posarlos en musica se degan presentar en Capitol y este los dega revistar / pera aprobarlos y reprobarlos".

[278] Fol. 387r.: [«Die 29. January 1732.»:] "[Margen: «Adm.o de Areny»] Item fuit resolutum que si hi ha lloch, se admetia a les distribucions del chor de N.a Ig.a / etiam a les de Espes al R.nt Francisco Arenÿ p.btre y Beneficiat del Benefici del Sant Se / pulchre endita Santa Iglesia fundat, y que per ser nebot del G.n S.r Ard.a major / Areny que sie sens examen com se acostume en estos".

[279] Fol. 387r.: «Die 12. February 1732.»: “[Margen: «Adm.o de M.o / Areny»] [...] En attencio que lo señor cabiscol ha fet / relacio no ser los Beneficiats admesos sino trenta nou, que lo R.nt Francisco Arenÿ / quedie admes a les distribucions del chor etiam a les de Espes".

[280] Fol. 388v.: [«Die 29. Aprilis 1732.»:] "Epistolas - M.o Joan Graell Ben.t Com.ri / Evangelis - M.o Pere Campi B.t com.ri / Mestre de Capella - M.o Francisco Andreu Bene.at / Organista - M.o Isisdro Serrada B.t / Baxonistas - M.o Felip Jansana y M.o Rossell / Faristolers - Los cantors / Faristolers de cor major - Los cantors / Faristolers de cor menor - Los cantors / Corneta - Joseph Girona / Posar y llevar les capes ab salari de / $2 £$ a cada un - M.o Flores y Fra. Sans / [Fol. 389r.:] Contraalt - M.o Joseph Boluda Bene.at / Martirologi - Los Preveners / Thenors - M.o Flores y Fra. Sans / Traurer los gossos de la Iglesia - Los preveners / Encendrer y apagar lo Rotlle - Los preveners / Manxador - Joseph Abella".

[281] Fol. 389v.: [«Die 30 Aprilis 1732»:] "Item fuit resolutum que lo Estatut ques feu lo any 1728 ques troba / en lo cor de la Ig.a se observe, y que los que contrafaran a ell sian / apuntats de aquella hora contravindran al dit Estatut; y / [Fol. 390r.:] axi mateix que aquells ques passejaran per la Iglesia y conversaran mentre se canten / y celebren los Divinos officis que los residents que seran trobats axi passejar y conversant / sian apuntats per aquella hora en que passejaran y conversaran dins dita Iglesia".

[282] Fol. 390r.: [«Die 2. May 1732.»:] "[Margen: «No valerse dels / Preveners»] Item fuit resolutum que ningun señor Capitular se valga dels Preveners / per ajudarlos missa, sino que sia per accident un dia o altre, y ques / done orde al mestre de capella que no permitia que los dits preveners / [Fol. 390v.:] vagen per ciutat a buscar neu ni altres coses; y que lo señor sobres $=/$ tant de capella ab lo mestre de capella procuren a fer venir algun / minyo per servir la Iglesia".

[283] Fol. 394r.: «Die 9 Desembris 1732.»: “[Margen: «Funeral»] [...] fou / resolt que en havant sempre que se offeresca algun funeral de Capitol y altre ex / traordinari tinga obligacio lo señor capitular que tindra los obits aquella semmana / sia tingut y obligat a cantar la missa del funeral y si los obits van per torn aquell / señor capitular que tindra lo torn de dir los obits lo haja de cantar". 
[284] Fol. 395r.: [«Die 10. February 1733.»:] "[Margen: «Sindicat»] Iem fou fet sindicat ad lites lloant y aprobant a Joseph Girona cumsupra / substituendi".

[285] Fol. 396v.: «Die 21 Aprilis 1733.»: "Epistolas - M.o Joan Graell B. com. / Evangelis - M.o Pere Campi B. com. / Mestre de Capella - M.o Francisco Andreu B.t / Organista - M.o Isisdro Serrada B.t / Baxonistas - M.o Falip Jansana y M.o Rossell / Faristolers - Los cantors / Faristolers de cor major - Los cantors / Faristolers de cor menor - Los cantors / Corneta - Joseph Girona / Posar y llevar les capes ab salari de $2 £$ cada un - M.o Flores y / Contraalt - M.o Joseph Boluda B.t / Martirologi - Los preveners./ Thenors - M.o Flores B. / [Fol. 397r.:] Ttraurer los gossos de la Iglesia - Los preveners / Encendrer y apagar lo Rotlle - Los preveners / Manxador - [esp. en blanco]".

[286] Fol. 397v.: «Die 24 Aprilis 1733.»: “[Margen: «Sota cabiscol»] [...] Avista la gran falta se exprimenta de sota cabiscol en lo chor / de nostra Santa Ig.a que quant M.o Joseph Flores sustentor se tro / ba desganat o indispost va aquell de mala manera y contra lo decoro / y augment del culto Divino; fuit resolutum ques diga al mestre de / capella que probe al R.nt Francisco Ribo si ab lo temps sera capas per / lo empleo de sota cabiscol y que dit mestre probat quel aja ne fassa / relacio al Capitol".

[287] Fol. 403r.: [«Die XI May 1734.»:] "Epistolas - M.o Joan Graell Ben.t comunitari / Evangelis - M.o Pere Campi Ben.t comunitari / Mestre de Capella - M.o Francisco Andreu B.t / Organiste M.o Isidro Serrada B.t / Baxonistes - M.o Felip Jansana y M.o Mateu Rossell / Faristolers - Los cantors / Faristolers de cor major - Los cantors / Faristolers de cor menor - Los cantors / Corneta - Joseph Girona / Posar y llevar les capes ab salari de $2 £$ cada un - M.o Flores y M.o Moga / Contraalt - M.o Joseph Boluda p.e / Preveners / Thenors - M.o Flores y M.o Moga / Traurer los gossos de la Ig.a - Los preveners / [Fol. 403v.: ] Encendrer y apagar lo Rotlle - Los preveners / Manxador - Francisca Abella".

[288] Fol. 405r.: [«Die 17. May 1734.»:] "Item per lo be que Pere Terres ha servit y serveix a la Capella suplint algunes faltes / fuit resolutum que se li donen de gracia y per remuneracio vint y sinch lliures".

[289] Fol. 406r.: «Die 28 Septembris 1734.»: “[Margen: «Dispensa de cantar / missa»] [...] Lo S.r D.r y Canonge Pere Fiter / ha manifestat al Ilt.e Capitol que per tremolarli la veu y las mans no podia cantar / missas suplicantli se servis dispensarli lo cantar Missas puig renunciaba al torn de las mis / sas al que vingut be lo Ilt.e Capitol a vista de la rahons ponderadas".

[290] Fol. 410r.: [«Die 26. Aprilis 1735.»:] "Epistolas - M.o Joan Graell Ben.t Com.ri / Evangelis - M.o Pere Campi Ben.t Com.ri / Mestre de Capella - M.o Francisco Andreu / Organiste - M.o Isidro Serrada / Baxonistes - M.o Felip Jansana y M.o Rosell / Faristolers - Los cantors / Faristolers de cor major - Los cantors / [Fol. 410v.:] Faristolers de cor menor - Los cantors / Corneta - Joseph Girona / Posar y llevar les capes ab salari de dos lliures cada un - M.o Flores y M.o Moga / Contralt - M.o Buluda / Thenors - M.o Flores y M.o Moga / Traurer los gossos de la Iglesia - Los preveners / Encendrer y apagar lo Rotllo - Los preveners / Manxador - Fran.ca Avella".

[291] Fol. 411 v.: «Die 28. Aprilis 1735.»: "[Margen: «acomodar los llibres de cor»] [...] fou feta / comissio al señor canonge Zaydin per a que fassa venir uns dos cens perga $=/$ mins per acomodar los llibres del chor de la Ig.a".

[292] Fol. 411v.: [«Die 28. Aprilis 1735.»:] "[Margen: «pagar $7 £$ al missa can / tant»] Item fuit resolutum que al S.r Capitular que cantara la missa del funeral / dels señors capitulars que moriran se li pague la charitat de aquella y / que per ella se li donen set sous".

[293] Fol. 415r.: «Die 3 January 1736.»: "[Margen: «Escriurer a M.o Thomas / Andreu si vol lo orga»] [...] En atencio que es mort lo R.nt Isi- / dro Serrada p.btre Beneficiat y Organista de nostra Ig.a y vacat; Perso lo orgue; fuit resolu- / tum per la major part que lo S.r Ardiaca de Berga de particular escriga al R.t Thomas / Andreu p.btre Bene.at y organista de Agramunt si vol venir a servir lo orgue y si / vol 
dit orgue se li donara de salari cent sinquanta lliures fins tinga Benefici en la Ig.a Cathe- / dral y en tenir Benefici en dita Ig.a que no se li donara de salari sino cent lliures".

[294] Fol. 415v.: «Die 10 January 1736.»: “[Margen: «presentar a sort lo Benefici de / N. S. de la Concepcio per mort / del R.nt Isidro Serrada»] [...] Per quant per mort / del R.nt Isidro Serrada p.btre y Beneficiat del Benefici baix invocacio de la Concepcio de Maria / Santísima se troba vacat lo dit Benefici de la Concepcio en la p.nt Iglesia instituit y fundat / del qual es Patró lo Señor Dega y lo Capitol; y per la veu de dit Capitol preten lo Señor Cang.e / Barthomeu Verges presentar dit Benefici com a Turnari; y dit Señor Degá preten tam=/ be presentarlo com á compasió que es de dit Benefici; Per tant per evitar lites y discordies / entre Germans, consentint los interessats, fuit resolutum ques trague a sort lo dit Bene.at / si diu presentarlo dit Capitol o dit Señor Degá, y encas hisque la sort a favor del Ca / pitol que lo dit Señor Canonge Verges presente aquell en nom del Capitol com a / Turnari y passantli lo torn, adherintse a dita presentacio lo dit Señor Degá com á / compatro: y haventse fet la sort, posant dos Redolins en la capsa de fusta de la aula / Capitular ab lo nom en lo un, de Capitol, y en lo altre redoli lo de Decanus per Jo= / seph Cruells Prevener fou tret un redoli ab lo nom de Capitol y havent tocat la sort / al dit Capitol ha presentat dit Benefici lo dit S.r Canonge Verges com a Turnari a la qual / presentacio se ha adherit dit Seño Degá com á compatró, quedant dit S.r Canonge Ver / ges abdicat del torn en las futuras vacants de beneficis, no obstant qualsevol acci / dent hi haja en dit Benefici; la qual presentacio ha fet de la Persona de Ermengol / Duque clergue son nebot familiar del Ilt.m S.r Bisbe, qual presentacio fou admesa y se / maná fossen despedidas lletras de General edicte segons estil Reguitas [..] / Testes Sunt R.ndi Martinus Jover et Sebastianus Clunet p.btri et Beneficiati dita / Sancta Ecc.tie cu Janitores Janua aula Capitularis".

[295] Fol. 418v.: [«Die 17 Aprilis predicti anni 1736»:] "Epistolas - M.o Joan Graell bene.at com. / Evangelis - M.o Pere Campi bene.at com. / [Fol. 419r.:] Mestre de Capella - M.o Francisco Andreu bene.at / Organista - M.o Thomás Andreu p.btre / Baxonistas - M.o Jansana y M.o Rossell / Faristolers Los cantors / Faristolers de chor major - Los cantors / Faristolers de chor menor - los cantors / Corneta Joseph Girona / Posar y llevar les capes ab salari de dos lliures cada un - M.o Flores y M.o Anton Moga / Contra-alt - M.o Joseph Boluda / Thenors - M.o Flores y M.o Anton Moga / Traurer los gossos de la Iglesia - Los preveners / Encendrer y apagar lo Rotlle - Los preveners / [Fol. 419v.:] Manxador - Francisca Abella".

[296] Fol. 422v.: «Die 24. juny 1736.»: "Convocato Capitulo In quo Inter fuerunt ommes prediciti: lo Señor Canonge / Zaydin com a Adjunt nomenat per lo Molt Ilt.re Capitol proposá haverli / entregat su Ilt.ma, respecte la difficultat tenia, sobre la applicacio de la segona / missa conventual en los dias que se celebran de sant y se deu dir missa de feria tant / en quaresma com com en temporas, lo paper de dupte que segueix / Duda. / Como no obstantes diferentes declaraciones de la Sagrada Congrigacion: Tus= / culan. 16. novembris 1652. Congregatio Concilis; Censurit, Cononicos Cathedralis / teneri quotidie ad Celebratoniem misse Conventualis, non obstante qxacumg? / Consuetudine Contraria. / Die 3. Septembris 1539. Respondem Epicops Fundi, dixit: Placcit, Episcopam / precepisse, ut occurrente festo duplici in quadragessima, quatuor yemporibus, et / vigilys, tam in Cathedrali quam in Collegiatis ecclerys, duo missa nempre de ferto / ac de feria cantentur. Hoc vi Habilis, adquos spectet, servetur, ab Amplitudine / tua in vigilandum erit / In Aretnia 11. Marty 1604. Congregatio Concily Censurit, Canonicos esse cogentos / ut illis diebus, quibus ex reebricis missalis tenentur duas missas conventuales / cantent, siguidem negue ambabus, negue alteri carum satisfit celebratione / Missa private cum mentali applicatione / Die 9 July 1644. Congregatio Concily Censurit, Canónicos Ecclesie Cathedralis Civitatis / Castellana, Anniversarcorum Celebratione non satisfere celebrationi misse / conventualis. Y otras mas modernas. Puede la Santa Iglesia Catedral de / Urgell satisfacer en los dias feriales, en que ocurre fiesta de Santo, a la segunda / missa conventual con celebracions de obito Debiéndose las missas conventuales / [Fol. 423r.:] aplicar solamente [...] Lo sobredit se diu de part del S.r Bisbe y apareixent que lo dubte está no bastantament expressiu de 
la / veritat se diu com se segueix / Si no obstant que la Santa Iglesia de Urgell del temps del S.r Bisbe Espes, que á mes de 200 anys / y antes estava y esta en la antiquísima observancia, e immemorial possessio de aplicar unica $=/$ ment una Missa conventual cada dia profundatoribus, et Benefactoribus conforme aixi ho / prevenen las Constitucions Provincials celebradas en Girona en lo any 1717; Inseguint lo dis / posat per lo sagrat Conc. De Tren; deu lo Capitol, y quida obligat en conciencia aplicar en / las ferias de Quaresma, vigilias, y temporas de entra any en que ocorra offici de Sant en / los quals dias se han de cantar Dos missas, çoes, la una de festo post tertiam, y la altre de / feria post nonam, la primera per la intencio dels Fundadors que las han fundadas libres, / y la segona per obitum En atencio que las Rubricas sols disposan que en los dits dias, com / Quaresma, Temporas, y Vigilias, degan las Iglesias Cathedrals cantar dos missas, y no / parlan de aplicar. / Haventse de advertir que lo S.r Bisbe Espes augmentá las distribucions á las horas / canonicas, y Missa Conventual que se celebrava, y aplicava pro Populo; pero no en quant aque- / lla que en los dias Ferials se aplicava per obitum, ans be en quant á esta no innová cosa. / se ha de consultar ab lo S.r D.r Ramon Sala perque diga son vot en escrits. / [Margen: «Resposta»] A la duda propuesta al muy Il.tre Cabildo de Urgel, si en los dias feriales, en que ocurriendo / fiesta de Santo, las Rubricas del Missal prescriven dos dos missas cantadas, una de Santo post / tertiam, otra de feria post nonam á cuya celebracion precisan tambien varias declaracio $=/$ nes de la Sagrada Congreg.on del Concilio, puede satisfacer su Iglesia á la segunda missa con / celebración de obito, debiendo las Missas Conventuales, segun repetidas declaraciones de la / misma Sagrada Congreg.on aplicarse pro Benefactoribus. / Se responde en primero lugar que sin embargo de las declaraciones que se citan en dicha / duda, no es del todo cierta en las Iglesias Catedrales y Colegiatas la obligacion de cantar / conventualm.te la Segunda Missa en los referidos dias. / Porque aunque esto lo enseña Gavanto tom. 1. part. 3. tit. 11. n. 7. et seg. Fundado en aquellas / declaraciones, añadida la Bulas de Pio V. de el principio del Misal que prescribe con / precepto la observancia de sus Rubricas, á quien siguen algunos A. A. Como Marchino / de ord. Tract. 3. q. 2. cap. 30 n. 7. Tamburino de Jure Abbat. Tom. 2. disp. 5. q. 10. n. 37. Pasqua- / ligo tom. 2. quest. 894. / No obstante muchos otros A. A. Defienden lo contrario [...] cuyo fundamento es, porque segun S. Thomas quodlibet. 9. art. 15 la / obligacions grave o baxo de pecado mortal no debe afirmarse, quando / no consta de / ella en evidencia, lo que no se verifica de esta obligación, porque de las declaracio- / nes en que se funda Gavanto no consta autenticamente, y aunque constasse nota bi- / en el P. Tamburino que no se inferiria aun de ellas con evidencia la obligación ba- / de pecado mortal; y de la Bula de Pio V. observó el grande juirio del P. Jau- / rez in 3. p. Tom. 3 disp. 87. sect. 1 post 2. conclus. Que en ella el S.to Pontifice no / impone obligacion alguna de celebrar si solo en la suposición de celebrar / [Fol. 423v.:] manda que se celebra segun el Rito del Misal Romano nuevo, y haciendo los / mas de dichos Authores escrito despues de aquellas declaraciones que cita Gavanto / queda aun después de ellas muy probable, assi extrinseca, como intrinsecamente esta / opinion negativa de aquella obligacion. / En segundo lugar se dire, que aun en la suposiciones de seguirse la openion afirma / tiva de haverse de cantar dicha segunda Missa, aun constaria menos de la / obligacion de aplicar la pre Benefactoribus. Porque esta obligacion de aplicarla / las Iglesias Cathedrales o Colegiatas la Missa Conventual pro Benefactoribus que / se deduce del Cap. Cum Creatura, de celebrat Missary. Cuya observancia en las Ig-/ lesias Cathedrales de esta provincia reló el Conc: Prov. Tarraconense del año / 1717 se cumple bastantem.te con la aplicación de una Missa totdos los dias ni / hay Hut hor que la extienda á muchas Missas. Las Declaraciones de la Sagra- / da Congreg.on, la Bula de Pio V, y la opinion estrecha de Gavanto se salcian / con la celebracion de dicha Missa, segun las Rubricas del Missal, porque / todas aquellas solo prescriben el rito de la Missa, esto es que se celebre de fe- / ria, pero no imponen la aplicacion de ella, antes la dexan / libre a las Iglesias. / El fundamento de esta verdades, porque la obligacion de aplicar la missa / conventual por los fundadores, Bienechores, o obligaciones del Cavildo / no nace de algun precepto, o declaracion de la Iglesia, si solo estas la infie- / ran de la voluntad de los pios fundadores, cuÿa intencion no tuvo solo / la mira que en las Iglesias se diesse a Dios

Anuario Musical, 58 (2003)

185

(c) Consejo Superior de Investigaciones Científicas Licencia Creative Commons 3.0 España (by-nc) 
entero Culto, sino que tambien / debe presumirse quisieron para si y para los suÿos el fruto de los divinos / officios; y para que esta primitiva obligacion mas exactam.te se cumpliesse / han zelado los Pontifices, Congreg.tes y Prelados que de la Massa Comun / se señalassen distribuciones para la Assistencia a la Missa Conventual / por dichos fundadores. Todo esto se cumple con la aplicación de una missa / conventual por dichos fundadores, que no pudieron pretender mas- / pues la obligacion de la segunda Missa que prescriben las Rubricas y las citadas declaraciones, aunque sea muÿ antigua en las Iglesias / no lo es tanto como las mas de las Iglesias Cathdrales, y por consi- / guiente aunque la Iglesia a posteriorm.te haya impuesto la obligacion / de cantar dicha Missa segun el rito del missal, no ha querido / ni declarado que la aplicacion de ella debiesse adjudicarse a favor / de los fundadores, si solo ha intentado, que con la observancia de las Rubri / cas quedase libre a los Cavildos la applicacion de ellas. / Esta al parecer fue la mente del Ilt.mo Prelado de Urgel el señor Obispo Espés / que mas ha de ducientos años halló ya en su Santa Ig.a la costumbre de cele $=/$ brarse una Missa Conventual pro populo, y para que esta se guardase $/$ mas religiosamente aumento las distribuciones a las horas Canonicas y missa / conventual; pero al mismo tiempo dexo libre al Cavildo la applicacion / [Fol. 424r.:] de la segunda missa ferial en los dias, que segun las Rubricas del missal se celebrava ya, y permitio, / que se continuassen para estas las distribuciones fundadas por obitos, sin applicar mas distribuciones para / esta, como hizo para la primera, confirmando el grande juicio y zelo de aquel Prelado, y approbando la / antiquissima immemorial observancia de aquella Santa Iglesia de applicar por los fundadores una missa / conventual, y dexar libre la applicacion de la segunda; a la qual practica de este Cavildo se añade tambien / las de las demas Iglesias Cathedrales de esse Principado, pues segun la noticia, que de ellas se ha podido tener / en esta Ciudad, de ninguna se sabe, que applique dicha segunda missa pro fundatoribus, sigue la / destinan á particulares fundaciones. De los Authores que se han podido encontrar, no se ha hallado uno, q. / imponga dicha obligacion, y singularmente haviendose examinado todos los que cita el papel de la duda, y / con mas cuidado el lugar de Monacelli, por mas moderno, ninguno ay que estienda la obligacion a mas / de una missa conventual, lo que se salva con la applicacion de la missa de Santo, que es la principal del dias, / y principalmente corresponde al rezo, y cumplimiento del Divino Officio. / Por todo lo que parece, que con la mayor seguridad puede el muy Ilt.re Cavildo continuar en su antiquissima / immemorial costumbre, y observancia de applicar sola una missa conventual todos los dias pro Benefacto $=/$ ribus, y continuando la laudable costumbre de cantar la segunda missa ferial en los dias, que pres= / criben las Rubricas segun el rito del Missal applicar esta libremente, como ha hecho hasta aquí, ni se / le puede por razon o d[e]recho alguno imponer otra obligacion. Assi lo sentimos salvo semper. Barcelo $=$ / na a 7. de Julio 1736. / Dr.Joseph Coder Canonigo Penitencia / rio de la Cathedral de Barcelona. / D.r Joseph Vilar Dignidad de la Cathedral Barcelona / D.r Francsico Fonseca Benea.do en la Parroqia de San = / ta Maria del Mar / Fr. Agustin Antonio Minuart Agustino. / D.r Ramon Sala R.t de San Miguel de / Barcelona".

[297] Fol. 427r.: [«Die 7 May 1737»:] "Epistoles - M.o Joan Graell B.t com.ri / Evangelis - M.o Pere Campi B.t com.ri / Mestre de Capella - M.o Francisco Andreu / Organista - Maurici Espona / Baxonistas - M.o Jansana y M.o Rossell / Faristolers - Los cantors / Faristolers de chor major - Los cantors / [Fol. 427v.:] Faristolers de chor menor - Los cantors / Corneta - Joseph Girona / Posar y llevar les capes ab salari de dos lliures cada un - M.o Flores y Moga / Contraalt - M.o Boluda p.e / Thenors - Mo. Flores, Pera y Moga / Violinista ab salari de quaranta lliures - Pere Terres / Traurer los gossos de la Iglesia - Los preveners / Encendrer y apagar lo Rotlle - Los preveners / Manxador - Francisca Abella".

[298] Fol. 428v.: «Die Octava predictorum» [«May 1737»:] "Havent lo Señor Canonge D.n Benet Vadella representat al Capitol lo malament / lo havia tractat lo Mestre de Capella per haver picat perque arrahonava en lo chor, y altres rahons que se omitexen: fou feta commissio als Señors $\mathrm{Ca}=/$ nonges Pintor y Zaydin per a que digan a dit S.r Mestre, que se reportia en son / obrar, y que tinga als Señors Capitulars major veneracio, y que altrament / si no se reporta, que lo Capitol pendra resolucio de buscarne altre". 
[299] Fol. 430r.: [«Die Nona May 1737 predictorum»:] "[Margen: «dirse missa del reso»] Item fuit resolutum, que sempre que es devindrá haverse dexposar / algun dels cossos Sants, que nos diga en la Iglesia missa de réquiem / sino del reso".

[300] Fol. 431r.: [«Die undécima May 1737 predictorum»:] "[Margen: «Combregars»] Item fuit resolutum que als combregars dels señors Bisbes y Capitulars al anar y al tornar sia / ab musica, cantant al anar lo Himne Quiscum valt salvus esse, que es lo simbulo del Sant / Atasi, y al tornar lo Te Deum Laudamus y no per altre al anar".

[301] Fol. 431r.: [«Die 13. May 1737 predictorum»:] “[Margen: «Sorinyach.»] Item fuit fuit resolutum que se admetia a la Capella a Anton Sorinyach ab lo / salari de trenta lliures y demes ganancies de la Capella".

[302] Fol. 445v.: [«Die 22. Aprilis 1738.»:] "Epistolas - M.o Joan Graell B.t com. / Evangelis M.o Pere Campi B.t com. / Mestre de Capella - M.o Fran.co Andreu / Organista - M.o Maurici Espona / Baixonistas - M.o Rosell y Anton Surinyach / Faristolers - Los cantors / Faristolers de chor major - Los cantors / Faristolers de chor menor - Los cantors / [Fol. 446r..] Corneta - M.o Girona / Posar y llevar les capes ab sal. de $2 £$ quiscun - M.o Flores y Moga / Contralt - M.o Boluda / Tenors - M.o Flores M.o Pera y Moga / Violinista - Pere Terres / Traurer los gossos de la Ig.a - Los preveners / Encendrer y apagar lo Rotlle - Los preveners / Manxador - Maria Abella".

[303] Fol. 446v.: «Die 25 Aprilis 1738»: “[...] fuit resolutum que / mentres se canten les hores en lo chor nos pugue ple- / gar les capes ni tancar los llibres del chor y que lo S.r / obrer ho previnga als sacristants".

[304] Fol. 454r.: «Die X Jannuary 1739»: "[Margen: «Admissions»] [...] fuit resolutum que se admetian / [Fol. 454v.:] a las Distribucions del chor de nostra Santa Iglesia, etiam a les de Espés als R.nts Francisco Ribo / p.btre y Beneficiat del Benefici baix invocacio de Sant Joan Baptista de Llordat y al R.t $\mathrm{An}=$ / ton Dalmau p.btre y Beneficiat del Benefici de Sant Salvador den Esquiu en dita Santa Ig.a / fundats, ab la condicio que hajan de fer acte de promesa de que pretendran la admissio de la / comunitat que primer lo R.t Francisco Escuder no sia admes en ella y que per acceptar y fer / firmar dit acte se fa comisssio al señor Canonge Rodil".

[305] Fol. 456v.: [«Die 14. Aprilis 1739.»:] "Epistolas - M.o Joan Graell B.t com. / Evangelis M.o Pere Campi B.t com. / Mestre de Capella - M.o Fran.co Andreu B.t / Organista - M.o Maurici Espona / Baxonistas - Anton Surinyach / Faristolers - Los cantors / Faristolers de cor major - Los cantors / Faristolers de cor menor - Los cantors. / [Fol. 457r.:] Corneta - Joseph Girona / Posar y llevar les capes ab salari de dos lliures quiscun - M.o Flores y Anton Moga / Contraalt - M.o Boluda B.t / Thenors - M.o Flores, M.o Pera y M.o Moga / Violinista - Pere Terrés / Traurer los gossos de la Iglesia - Los preveners / Encendrer y apagar lo Rotlle - Los preveners / Manxador - Maria Abella".

[306] Fol. 458r.: «Die 17. [Aprilis 1739] predictorum. Cap. Pasch. Cont.»: "[Margen: «Cantar Evan. y Epist.»] [...] En attencio de ha=/ veri pochs capitulars per cantar Evangelis y Epistolas; fuit resolutum que quant no hi haja $\mathrm{ca}=/$ pitular per cantarles, que canten aquellas beneficiats donantlos un sou, llevantlo al capitu= / lar li tocará lo cantarles".

[307] Fol. 458r.: [«Die 18 Aprilis 1739»:] "[Margen: «Donar quatre parells de / sabates als infantons»] Item fuit resolutum que als infantons sels done tots los anys quatre parells de sabates, y que / sels advertesca que un parell sia guardat per avenir a la Iglesia a fi de evitar la indecen $=$ / cia ab que venen a servir en ella".

[308] Fol. 458v.: «Die 22. Aprilis 1739.»: "[...] Havent proposat lo señor canonge Pere Net, que en la Iglesia / hi ha minyons, que desitjan apendrer algunas, habilitats que los musichs de dita / Iglesia tenen y saben; y considerant que dita proposicio era molt justa y en profit / de dit minyons; fuit resolutum, que los cantors que tenen habilitats que dits / minyons volen apendrerlas que las ensenyen a aquells que desitjan apendrer / las". 
[309] Fol. 460r.: [«Die 4. May 1740.»:] "Epistolas - M.o Joan Graell B.t com.ri / Evangelis - M.o Pere Campi B.t com.ri / [Fol. 460v.:] Mestre de Capella - M.o Fran.co Andreu B.t / Organista - M.o Maurici Espona / Baixonistas - Antón Sorinyach / Faristolers - Los cantors / Faristolers de cor major - Los cantors / Faristolers de cor menor - Los cantors / Corneta - Joseph Girona / Posar, y llevar les capes ab sal. de $2 £$ cadas u - M.o Flores y Moga / Contralt - Joseph Boluda B.t / Thenors - M.o Flores M.o Pera y Moga / Violiniste - M.o Joan Pera / Traurer los gossos de la Ig.a - Los preveners / Ensendrer, y apagar lo Rotlle - Los preveners / Manxador - Maria Abella".

[310] Fol. 462r.: [«Die 10 May 1740»:] "Item fuit resolutum que a Anton Moga a mes de les $60 £$ que te per ser cantor de nos- / tra Iglesia se li done per lo offici de contrabaix trenta lliures cada any tantum et / amplius non petat, nec exposcat".

[311] Fol. 462r.: [«Die 10 May 1740»:] "Item fuit resolutum que a Anton Sorinyach y a Pere Terres per los officis tenen / en la p.nt Ig.a sels done de salari a quiscun $50 £$ cada any y a Joseph Potensa, y a / Fran.co Salvato per lo mateix fi $25 £$ a cadas u".

[312] Fol. 462r.: [«Die 10 May 1740»:] "Item foren admesos a las distribucions del cor de dita S.ta Ig.a etiam a les de Es- / pes als R.nts Anton Duque rector de Queralbs al R.nt Mathias Guilla, al R.nt Ma/ thias Thomas, al R.nt Maria Planes, y al R.nt Salvador Mages Bene.ats y a / Rafel Lafontena tambe Bene.at se admet a ditas distribucions nunc protunc / per quant sia sacerdot ex gratia particulari sens que servesca de exemplar".

[313] Fol. 467r.: [«Die 18. Aprilis 1741.»:] "Epistolas - M.o Joan Graell Ben. Com. / Evangelis M.o Pere Campi Ben. Com. / Mestre de Capella - M.o Francisco Andreu / Organista - Maurici Espona / Baxonistas - Sorinyach y Potensa / Faristolers - Los cantors / Faristolers de chor major - Los cantors / Faristolers de chor menor - Los cantors / Corneta - Joseph Girona / Posar y llevar les capes ab salari de $2 £$ cada un - M.o Flores y Moga / Contraalt - M.o Joseph Boluda / Thenors - Flores, Pera y Moga / [Fol. 467v.:] Violinista - Pere Terres / Traurer los gossos de la Iglesia - Los preveners / Encendrer y apagar lo Rotlle - Los preveners / Manxador - Maria Abella".

[314] Fol. 468v.: «Die 21. [Aprilis 1741.] predictorum»: “[Margen: «Orga»] [...] Per quant lo orga de nostra Santa Iglesia se troba espatllat / de forma, que se ha de valer lo organista del orga petit, y necesitar aquell / de compondrerse; fuit resolutum, que se fassa comissio als señors Ardiaca / de Andorra S.rs Canonge Zaydin y Net per a que fassan apariar, fer / y compondrer lo dit orga".

[315] Fol. 469r.: «Die 26. Aprilis 1741»: "[...] fuit / resolutum que se admetia a las distribucions del chor de nostra Ig.a etiam a les de Espés los R.nts / Joseph Gual p.btre y Beneficiat del Benefici baix invocacio de S. [esp. en blanco] en dita Santa Ig.a fundat / pers los R.nts D.n Od de Cubelles, Joseph Artigalas rector de Nabines, y Jaume Tapiro vicari de / Rialp pro tunc se admeten a dites distribucions quant hi haja lloch, no essent completat lo numero / dels quaranta beneficiats, ab lo benentes que se concorren dos dels tres, que lo un dells tinga / benefici incompatible ab altre, que se admetia primer al que tindrá libero y no compatible / son benefici".

[316] Fol. 470r.: [«Die 26. july 1741»:] "item fuit resolutum que se perpetue á Anton Moga en son salari de sota cabiscol y en las / distribucions del chor a fi de que se puga ordenar y per firmar lo acte de perpetuitat se fa / comissio al seño cabiscol".

[317] Fol. 474v.: [«Die 10. Aprilis 1742.»:] "Epistolas - M.o Joan Graell B.t Com. / Evangelis M.o Pere Campi B.t Com. / [Fol. 475r.:] Mestre de Capella - M.o Francisco Andreu Bene.at / Organista Maurici Espona / Baxonistas - Sorinyac y Potensa / Faristolers - Los cantors / Faristolers de chor major Los cantors / Faristoloers de chor menor - Los cantors / Corneta - Joseph Girona / Posar y llevar les capes ab salari de $2 £$ quiscun - M.o Flores y Bassa / Contralt - M.o Joseph Boluda / Thenors - Flores, Pera, y Bassa / Violinistas - Pere Terres y Salvato / Traurer los gossos de la Iglesia - Los preveners / Encendrer y apagar lo Rotlle - Los preveners / Manxador - Francisco Ponsa”. 
[318] Fol. [479v.:] «Die 8 January 1743»: “[...] Havent presentat una / suplica al Molt Ilt.re Capitol lo R.nt Pere Martir Sunyer vicari de Sant / Od per a que lo Capitol se dignas admeterlo a las distribucions del cor / de esta Santa Ig.a la qual suplica es com se segueix = Molt Ilt.re S.r / Pere Martir Sunyer p.btre habitant en la p.nt ciutat ab tot rendi- / ment representa a vos que per lo S.r Canonge y Estador de S.t Od se troba / nomenat vicari de la parroquia de S.t Od per la Administracio / [Fol. 478r.:] dels Sants sacraments als feligressos, y parroquians de ella; E com Molt Ilt.re S.r / la comiseracio dels V. S. hage acostumat a admetrer â dit curat â las distribucions del / chor de la present Iglesia; Perço humilment suplica â V. S. sia del servey del V. S. manar / lo admetrer â ditas distribucions offerintse â cumplir, y fer tot lo que los Ante / cessors curats han acustumat complir sempre que han estat admesos â ditas dis / tribucions, que â mes, que V. S. fara una obra de charitat, dit suplicant ho rebrá / â particular mesce com â rebuda de la gran bondat de V. S. off. [...]".

[319] Fol. 480r.: «Die 15 January 1743.»: “[...] Haventse tornat â llegir la suplica doná lo R.nt Pere Martir Sunyer / vicari de S.t Od als 8 del corrent mes, y any fou resolt que se admetra ex mira / gratia a las distribucions del chor de dita Ig.a, y que per dita Admissio ja / may se entrega adquirida possessio â dit suplicant respecte la residencia / ni â sos successors".

[320] Fol. [482r.:] [«Die 30 Aprilis 1743.»:] Epistolas - M.o Joan Graell Bene.at comunitari / Evangelis - M.o Pere Campi Bene.at comunitari / Mestre de Capella - M.o Francisco Andreu Beneficiat / Organista - Maurici Espona / Baxonistas - Sorinyac y Potensá / Faristolers - Los cantors / Faristolers de cor major - Los cantors / Faristolers de cor menor - Los cantors / Corneta - Joseph Girona / Posar y llevar les capes ab salari de $2 £$ quiscun - M.o Flores y M.o Pociello / Contralt - M.o Joseph Boluda B.t / [Fol. 482v.:] Thenors - M.o Flores, M.o Pera y Pociello / Violinistas - Pere Terres y Fran.co Salvato / Traurer los gossos de la Iglesia - Los preveners / Encendre y apagar lo Rotlle - Los preveners / Manxador - Francisco Ponsa".

[321] Fol. [489r.:] [«Die 21 Aprilis 1744»:] Epistoles - M.o Joan Graell B.t com.ri / Evangelis M.o Pere Campi B.t com.ri / Mestre de Capella - M.o Franco Andreu / Organista - Maurici Espona / Baixonistes - Sorinyac y Potensa / Faristolers - Los cantors / Faristolers de cor major - Los cantors / Faristolers de cor menor - Los cantors / [Fol. 489v.:] Corneta - Joseph Gerona / Posar y llevar les capes ab salari de 2\# - M.o Flores y Porciello / Contralt - Joseph Boluda B.t / Thenors - M.o Pera y Pociello / Violinistas, - Pere Terres y Fran.co Salvato / Traurer los gossos de la Iglesia - Los preveners / Encendre y apagar lo Rotllo - Los preveners / Manxador - Francisco Ponsa".

[322] Fol. 490v.: «Die 28 Aprilis 1744»: “[...] Fonch per la señoria resolt que se fasse com- / missio al S.r Ard.a Major a fi que fasse propia a Anton Mestre en Montsar- / rat y lo fasse nuntar en esta per sustentor y lo fassa examinar per lo Mestre / de Capella essent habil é ydoneo per lo chor per lo chor de n.ra S.ta Ig.a".

[323] Fol. 490v.: «Die 2. May 1745.»: "[...] Fuit resolutum que attenent sa Sr.ia que lo R.nt / Joseph Flores sustentor de nostra S.ta Ig.a se troba ja algo cansat y fatigat / [Fol. 491r.:] en son empleo / de sustentor, que dit R.nt sustentor exonerat quedi de dit empleo / de sustentor, y que en remuneracio del molt be se ha portat en dit offici / de sustentor se li done de salari trenta lliures cada any havent empero / de cantar algunas antifonas y responsoris; y que perço fou feta comissio / al S.r Cabiscol a fi que lay pordero y lo molt desitja lo Molt Ylt.e Capitol / son descans".

[324] Fol. [495v.:] [«Die quarta May 1745»:] "Epistoles - M.o Joan Graell B.t com.ri / Evangelis - M.o Pere Campi B.t com. / [Fol. 496r.:] Mestre de Capella - M.o Fran.co Andreu B.t com. / Organista Maurici Espona - Maurici Espona / Baixonistas - Sorinyach, y Sala ab / Sal. de $6 £$ al Sala / Cantor - Joan Mercader ab. sal. / de $6 £$ / Faristolers - Los cantors / Faristolers de Chor Major - Los Cantors / Faristolers de Chor menor - Los Cantors / Corneta - Joseph Girona / Posar, y llevar les Capes ab salari de $2 £$ - M.o Flores, y Porciello / Contralt - M.o Joseph Boluda B.t com. / Thenors - M.o Pera y Pociello / Violinistas 
- Pere Terres, y Fran.co Salvato / Traurer los gossos de la Iglesia - Los Preveners / Encendrer y apagar lo Rotllo - Los Preveners / [Fol. 496v.:] Manxador - Fran.co Ponsa".

[325] Fol. [497v.:] «Die 7 May [1745] predictorum»: "Item fuit resolutum, que fasse comicio als S.rs obres, Sobrestant de Capella / y Net a fi que fassen una ynstructa sobre la educacio, y ensenyansa / dels Prebeners, y demes los aparegui convenient, y que feta se reporti / en capitol".

[326] Fol. [498r.:] «Die 10. July 1745.»: “[...] fuit resolutum que en attencio, que lo D.r Anton Galceran p.btre y / rector de Sant Miquel Archangel de la present ciutát hagues la possessio de princi- / pal de ditat sa rectoria per ocasio de la mort natural de son germa lo D.r Fran.co Muntan y havernos presentát suplica ab la qual demaná a sa S.ria se dig- / nás admetrerlo a las distribucions del chor de n.ra S.ta Ig.a heventnos presen- / tat la cartilla de presbiterat, y acte de dita possessio de principal quedie admes / [Fol. 498v.:] a totas las distribucions del chor de n.ra S.ta Iglesia etiam a les de Espes".

[327] Fol. [513r.:] [«Die vigessima septa predictorum mensi, et anni»] [«Aprilis 1746»:] "Epistolas - M.o Joan Graell B.t com.ri / Evangelis - M.o Pere Campi B.t com.ri / Mestre de Capella - M.o Fran.co Andreu B.t com.ri / [Fol. 513v.:] Organista - Maurici Espona / Baixonistas - Sorinyach y Sala ab sal. / de $16 £$ al Sala / / Faristolers - Los cantors / Faristolers de chor major - Los cantors / Faristolers de chor menor - Los cantors / Corneta - Joseph Gerona / Posar y llevar les capes ab salari de $2 £$ - M.o Flores, y Taugis / Contralt - M.o Joseph Boluda B.t com.ri / Thenor - M.o Perá $¥$ / Violinistes - M.o Terres y Fran.co Salvato / Traurer los gossos de la Iglesia - Los preveners / Encendre y apagar lo Rotllo - Los preveners / [Fol. 514r.:] Manxador - Fran.co Ponsá”.

[328] Fol. [518v.:] «Die quinta Septembris predicti anni» [«1746»:] "Item Fonch per la S.ria resolt, que en attencio de haver tingut / carat lo dia vint, y nou del proxim passat mes de Agost de S. Mag. / en la que se digne encarregarnos que pues la Divina Mag.t lo ha posat / en lo govern de esta Monarquia de Espanya; y desitjant lo acert en / son regimen nos encarrega en que de nostra part contribuhiga / ab suplicas, y efficaces rogativas al S.r se digne donarli lo / acert per lo logro ques desitja, y en vista de que será lo dixonse / del present mes despres de haver cumplert ab las horas y Mis- / sa propia del dia se passia ab Professo al Altar Major y se / exposia lo santosim sagrament quedant exposát fins a las sinch / de la tarde en ques cantaran completas, y finidas estas se passará ab proffesso al Presbiteri, y se cantaran las leta- $/$ nias Majors y se reservará lo santissim".

[329] Fol. [521v.:] «Die Duodecima Decembris predicti anni» [«1746»:] “[...] Havent pre- / sentat suplica adit Molt Ylt.e Cap. lo R.nt D.r Joseph Marqués vicari de Sero y / Bené.at del Benefici de S.t Esperit segons en nostra S.ta Ig.a fundát a fi / y effecte que sa S.ria se dignés admeterlo als lucros y distribucions del / chor de dita S.ta Ig.a que acostuman guanyar y lucrar los Benefici- / ats y residents en dita S.ta Ig.a Et a S.ria Dominatione fuit resolutum / que dit D.r Joseph Marqués Beneficiat de dita Santa Iglesia / quedia admes a totes les distribucions del chor de dita / Santa Ig.a etiam a les de Espes".

[330] Fol. [523r.:] «Die vigessima prima mensis Marty predicti anni» [«1746»:] “[...] fuit resolutum, que a Maurici Espona organista del orga de nostra / Santa Iglesia li sian donadas setanta lliures en remuneracio del / molt treball que ha tingut, y emperdit en fer un llibre Major de Chor / per nostra Santa Iglesia que conte vuitanta sis fullas en foleo".

[331] Fol. [525r.:] [«Die decima octava predictorum mensi, et anni»] [«Aprilis 1747»:] "Epistoles - M.o Joan Graell B.t comunitari / Evangelis - M.o Pere Campi B.t com.ri / Mestre de Capella - M.o Fran.co Andreu B.t com. / [Fol. 525v.:] Organista - Maurici Espona / Baixonistas - Sorinyach y Sala / Faristolers - Los cantors / Faristolers de Chor major - Los cantors / Faristolers de Chor menor - Los cantors / Corneta - Joseph Gerona / Posar y llevar las capas ab salari de $2 £$ - M.o Flores y Taugi / Contralt M.o Joseph Boluda B.t com / Tenor - M.o Joan Pera B.t com. / Violinistas - M.o Pere Terres y Salvato / Traurer los gosos de la Iglesia - Los preveners / Encendrer, y apagar lo Rotllo - Los preveners / [Fol. 526r.:] Manxador - Francisco Ponsá". 
[332] Fol. [527r.:] [«Die vigessima predictorum mensi, et anni»] [«Aprilis 1747»:] "Item fuit resolutum ques fa comicio al S.r sobrestant de capella a fi que junt / ab lo S.r Obrer fassin una ynstructa sobre la educacio, y enesenyança / dels preveners y demes los apareguin convenient, y que feta y executada se / reporti a en Capitol".

[333] Fol. [533r.:] «Die 19 July 1747»: “[...] Fuit resolutum, que / per Musich de Nostra Santa Iglesia quedia admes Joan Baptista / Clusa de la ciutát de Balaguer ab salari de $60 £$ y la admissio del / chor de Nostra Santa Ig.a que as ella tindra $40 £$ mes / Item fuit resolutum ques fa comicio al S.r sacrista S.r Canonge D.r / Francisco Puget y al S.r Canonge D.r Jacinto de Bardaxi per a que / miron a quins dels residents de nostra Santa Ig.a se podra rebai- / xar son salari, y aplicarlo a dit Joan Baptista Clusa".

[334] Fol. [533v.:] «Die 24 8.bris 1747»: "[...] fuit reslotum que a / Mariano Taugis cantor de nostra S.ta Ig.a seli done de salari / vente lliures y la residencia fins a Capitols Pasquals primer hi / merits".

[335] Fol. 137v.: [Fol. 537v.:] [»Die 30 predictorum mensis, et anni»] [«Aprilis 1748»:] "Epistoles - M.o Joan Graell B.t com. / Evangelis - M.o Pere Campi B.t Com.ri / [Fol. 138r.:] Mestre de Capella - M.o Fran.co Andreu / B.t Com.ri / Organista - Maurici Espona / Faristolers - Los cantors / Faristolers de Chor major - Los cantors / Faristolers de Chor menor - Los cantors / Corneta - Joseph Gerona / Posar y llevar les capes ab sal. de $2 \mathfrak{f}$ - M.o Flores y Taugis / Contralt - M.o Joseph Boluda B.t Com. / Tenor M.o Pera B.t Com.ri / Violinistas - M.o Pere Terres y Salvato / Traurer los gosos de la Ig.a - Los Preveners / [Fol. 138r.:] Manxador - Francisco Ponsá".

[336] Fol. 139v.: [Fol. 539v.:] «Die 6. predictorum mensi et anni» [«May 1748»:] "Fuit resolutum que la renda del Ters del Vidal de Arcaixell se pose / en Encant publich lo dia de las rendas del S.r yll.m y que se fasse eixir / a Joseph Gerona sindich n.re posanthi dita a fi que n.re capitol puga / restablirse en la possessio en ques trobaba de fer lo arrendament de / dit y anes y que perço se fa comicisio al S.r Canonge Joan Dalmau".

[337] Fol. 140v.: [Fol. 540v.:] [«Die 28 juny 1748»:] "Fuit resolutum que lo R.nt Gili Esclusa p.btre y B.t del Benefici de Sant Sernimitut / en la S.ta Ig.a de Urgell fundat quedia admes en totes las distribucions del / chor de n.ta S.ta Ig.a etiam a les de Espes que acostuman lucran los demes / residents Beneficiats admesos en dit chor de n.ra S.ta Ig.a".

[338] [Fol. 542v.:] «Die 8. Octobris predicti anni» [«1748»:] “[...] Fuit resolutum que a quiscun dels musichs ab salari de n.ra S.ta Ig.a que falta / ran al chor de dita Santa Ig.a que de aquí en havant que faltaran que sia apuntat / quiscu de ells en sinch sous per cada vegada".

[339] [Fol. 544r.:] «Die 11 marty p.ti anni» [«1749»:] "[...] Fuit resolutum que quedia ad- / mes lo R.t Joseph Artigalas Beneficiat de nostra S.ta Ig.a en lo chor / y residencia de ella lucrant totas las distribucions etiam las de Espes que / se acostuman lucrar per los R.nts S.rs Residents B.ts de dita Ig.a”.

[340] [Fol. 544v.:] [«Die 15 marty p.ti anni»] [«1749»:] "Item Fonch resolt que havent fet lo S.r Degá patent sa S.ria los gra- / ves ynconvenients se siguien de que en la celebracio dels aniver- / saris de n.ra S.ta Ig.a se cantassen las Absoltas en la nau de la iglesia / y havent madarament reflectit sa S.ria sobre dits ynconvenients ha / resolt que en havant se recitian y cantian sens mourerse del chor / de nostra S.ta Ig.a".

\section{[Volumen 1749-1769]: ${ }^{8}$}

[341] Fol. [1r.:] [Die 23. Aprilis predicti anni 1749.:] "Epistoles - M.o Joan Graell B.t Com.ri / Evangelis - M.o Fran.co Ribo B.t Com.ri / Mestre de Capella - M.o Fran.co Andreu B.t Com. / Organista

8. Un volumen manuscrito de $530 \times 340 \mathrm{~mm}$., encuadernado cosido, con tapas de cartón forradas en piel de color marrón claro; tapa delantera deteriorada en su parte superior, con dos tipos de adornos: el primero (zona central-derecha), formado por dos rec- 
- Maurici Espona / Baixonistas - M.o Surinyach y Clusa / Faristolers - Los cantors / Faristolers de chor Major - Los cantors / Faristolers de chor menor - Los cantors / Corneta - Joseph Girona / Posar y llevar les capes ab salari de $2 £$ quiscun - M.o Flores y Taugis / Contralt - M.o Joseph Boluda B.t Com. / Thenor - M.o Joseph Boluda B.t Com.ri / [Fol. 1v.:] Violinistas - M.o Pere Terres y Salvato / Traurer los gossos de de la Iglesia - Los preveners / Encendrer y apagar lo Rotllo - Los preveners / Manxador - Fran.co Ponsá / [Fol. 2r.:] Sindich ad dites - Joseph Gerona cantor".

[342] Fol. [2v.:] «Die 24 Aprilis predicti anni» [«1749»:] “[Margen: «Missa de Nona»] [...] Fuit resolutum que ningun / S.r Capitular puga fer dir la Missa de Nona per ningun Beneficiat de nostra / Santa Ig.a sino que quiscun Capitular la digue, o, la fasse dir per altre S.r Capi / tular, y no per altra persona".

[343] Fol. [2v.:] «Die 26 Aprilis predicti Anni» [«1749»:] “[Margen: «Llibre de missas de / las dos ultimas semma / nas de Quaresma»] [...] Fuit reso- / lutum que sfasse lo llibre de missas de las dos ultimas semmanas de Quaresma / y que perço se fa commissio al S.r Canonge D.n Fran.co de Puget per a que fasse fer aquell / o per un dels cantors de n.ra S.ta Ig.a o per un religios Dominico y que lo fasse fer ab / aquella mes comoditat que comprenga y en cas de igual preu lo fasse fer per lo cantor / primer que per lo religios Dominico".

[344] Fol. [3r.:] «Die Trigessima predictorum mensi, et anni» [«Aprilis 1749»:] "[Margen: «Contralt y sus- / tentor] [...] Fuit reso- / lutum que al R.nt Joseph Boluda B.t de n.ra S.ta Ig.a se li donia per son salari / sinquanta lliures quiscun any de las $100 £$ que tenia de salari de contralt y / en quant al R.nt Joseph Flores B.t y sustentor del Chor de n.ra S.ta Ig.a se li / suspen lo salari de sustentor y que tinga lo mateix salari fins a altra deter- / minacio, y fins y atant que vinga lo altre sustentor de Lleyda".

[345] Fol. [3v.:] «Die 8 July predicti anni» [«1749»:] "[Margen: «Ben.t Subdiaca»] [...] Fuit resolutum que quedia elegit y nomenat per cantar las / Epistolas lo R.nt Joseph Gual p.btre y Beneficiat Communitari de nostra S.ta / Ig.a".

[346] Fol. [4v.:] «Die Xii Jannuary 1750.»: “[Margen: «Adm.o de Ben.ts»] [...] fuit resolutum / que quedian admesos en totas las distribucions del Chor de nostra S.ta Ig.a los R.nts / Joan Gual Anton Giberga p.btre y rector de la Parroquial Ig.a del lloch de Vilano- / va de Banat y lo R.nt Joan Gensana p.btres y Beneficiats de n.ra S.ta Ig.a etiam / a les de Espes lucran tot quan guanyan los demes S.rs B.ts residents en lo Chor / de dita S.ta Ig.a".

[347] Fol. [7r.:] [«Die decima quarta predictorum mensis, et anni» [«Aprilis 1750»:] "Epistoles M.o Joseph Gual B.t Com.ri / Evangelis - M.o Fran.co Ribo B.t Com.ri / Mestre de Capella - M.o Fran.co Andreu B.t C. / Organista Maurici Espona - Maurici Espona / Baixonistas - M.o Sorinyach y Clusa / [Fol. $7 \mathrm{v} .:]$ Faristolers - Los cantors / Faristolers de chor major - Los cantors / Faristolers de chor menor - Los cantors / Corneta - Joseph Girona / Posar y llevar les capes ab salari de $2 \mathfrak{f}$ quis / cun - M.o Flores y Taugis / Contralt - M.o Joseph Boluda B. C. / Thenor - M.o Joan Pera B. Com. / Violinistas - M.o Pere Terres y Salvato / Traurer los gosos de la Iglesia - Los preveners / Ensendrer y apagar lo Rotllo - Los preveners / Manxador - Fran.co Ponsa".

[348] Fol. [8v.:] [«Die 17 Aprilis 1750.»:] "[Margen: «Matines á la tarde»] Item fuit resolutum que se entre a Matinas per la tarde la / vigilia de S.t Lluch en attencio de haverse proposat per lo S.r / sacris[tar] ser lo temps mes comodo despues per justas causas".

tángulos subdivididos en cuatro partes simétricas con un dibujo en forma de aspa, y con un motivo floral en el centro; y el segundo (zona izquierda), formado por cuatro rectángulos con elementos florales; la contratapa presenta la misma distribución de rectángulos de la tapa, pero adornados solamente con motivos florales; cosidas a la tapa, lomo y contratapa, tres tiras de piel con dibujos en forma de aspa, y con líneas paralelas; el lomo, que, como la tapa, carece de título que identifique el volumen, presenta una etiqueta en su parte superior, con el número: «1026». 215 fols., en papel, anotados en tinta negra; los siete primeros folios, y el último, en blanco, no están numerados; desde el fol. 1, al fol. 200, se numeran únicamente cada diez; y a partir del fol. 200, sólo aparece numerado el fol. 207. 


\section{Índice Onomástico:}

AGUILAR, Pere; coro; 67, 71, 74.

ALANY; coro; 156.

ALEMANY, Francisco; coro; 151, 162, 165, 168, $169,180,190,195,202,205,221,227,229$, 233, 239.

ALLET, Miquel; 'prevener'; 44

ANDREU, Francisco; maestro de capilla; 202, 205, $212,221,227,228,229,233,240,245,253$, $254,255,262,267,273,280,285,287,290$, $295,297,302,305,309,313,317,320,321$, $324,327,331,335,341,347$.

ANDREU, Thomas; organista; 293, 295.

ARAGONES; 'prevener'; 79.

ARENY, Francisco; coro; 278, 279.

ARGANY, Gabriel; maestro de capilla; 126, 131, 133, 140, 151, 156.

ARTIGALAS, Joseph; coro; 339.

BARBER, Joan; coro; 54.

BASSA; tenor; 317.

BOLUDA, Joseph; contralto; 202, 205, 221, 227, $229,233,241,245,253,255,261,262,267$, $273,280,285,287,290,295,297,302,305$, $309,313,317,320,321,324,327,331,335$, $341,344,347$.

BONAU, Fermín; coro; 118.

BONET, Joseph; coro; 87, 92, 100, 111, 121, 125.

BOSCH, Joseph; coro; 144, 244.

CABANILLES; maestro de capilla de Valencia; 43, 44.

CAMPI, Pere; coro; 267, 273, 280, 285, 287, 290, $295,297,302,305,309,313,317,320,321$, $324,327,331,335$.

CAMPOS, Nicolau; coro; 261.

CANALS, Joseph; coro; 20.

CASES, Magí; coro; 199.

CASSANY, Pau; coro; 217.
CASTELLNOU, Joan; coro; 142.

CELLERÁ, Joan; coro; 115, 203.

CERVERA, Niño de; 'prevener'; 79.

CLUSA, Joan Baptista; bajonista; 333, 341, 347.

CODINA, fray Joseph; tenor; 6

CODINA, Joan; coro; 247.

COTS, fray Joseph; tenor; 6

COTS, Francisco; contralto y tenor; 43, 44.

CUMBIET, Emanuel; tenor; 174.

DALMAU, Jacinto; coro; 1.

ERMENGOL, Sagimon; coro; 83, 84.

ESCLUSA, Gili; coro; 337.

ESPONA, Maurici; organista; 297, 302, 305, 309, $313,317,320,321,324,327,330,331,335$, 341,347 .

FARRER, Andreu; coro; 135.

FERMIN; contralto; 44.

FLORES, Joseph; tenor; 180, 187, 190, 195, 202, $205,215,221,227,229,233,241,245,248$, $250,253,255,262,267,273,275,280,285$, 286, 287, 290, 295, 297, 302, 305, 309, 313, $317,320,321,323,324,344$.

FORCADA, Jaume; maestro de capilla; 2, 6, 27, 28 , $33,43,44,48,55,64,65,66,73,87,89,92$, 95,100 .

FORCADA, Joan; coro; 87, 111, 121.

FORCADA, Joseph; 'prevener'; 128.

FORTÓ, Joseph; maestro de capilla y organista; 161, 162, 165, 169, 175, 180, 190, 195.

FUENTES, Joseph; corneta; 8, 13, 36, 43, 44, 77, 86, 89, 98, 102, 140.

FULLA, Genis; coro; 17.

FUSTER, Francisco; coro; 252.

GALCERAN, Anton; coro; 326.

9. A continuación del apellido de cada músico, se anota el empleo por el que es citado en las actas capitulares, o bien por el que habitualmente se le ha identificado. Por "prevener", entiéndase mozo de coro, escolán, seise o infantico. No se han regularizado aquí nombres y apellidos, que se citan como aparecen en la fuente. Cuando un mismo músico se cita con diferentes grafías, se indican las variantes con referencias cruzadas. Los números a continuación de cada nombre, se refieren al número de entrada de cada acta capitular correspondiente en que aparece citado dicho músico. 
GALINDO CAPÓ, Blas; coro; 50, 51.

GENSANA, Domingo; bajonista y contralto; 21 , $31,38,60$.

GENSANA, Felip/Fhelip/Fhilip; bajonista; 6, 31, $35,43,55,59,65,73,80,87,92,100,105,111$, $121,131,140,151,156,162,165,169,190$, $195,205,221,227,233,241,253,255,262$, 267, 273, 280, 285, 287, 290, 295, 297.

GENSANA, Joan; coro; 346.

GERONA, Joseph; [vid. GIRONA, Joseph; corneta].

GERVET, Joseph; [vid. GIRVET, Joseph; tenor].

GIBERGA, Anton; coro; 346.

GIRONA, Joseph; corneta; 202, 205, 221, 227, 229, $233,241,245,253,255,262,267,273,280$, $285,287,290,295,297,302,305,309,313$, $317,320,321,324,327,331,335,336,341$, 347.

GIRVET, Joseph; tenor; 21, 31, 40, 50.

GRAELL, Joan; coro; 241, 244, 245, 253, 255, 262, $267,273,280,285,287,290,295,297,302$, $305,309,313,317,320,321,324,327,331$, 335,341 .

GRULLA, Jaume; maestro organero; 62 .

GUAL, Joseph; coro; 345, 346, 347.

INGLESA, Joan, famulo-coro; 223, 224, 225, 251. IVANCO; 'prevener'; 14.

JANSANA, Felip/Fhelip/Fhilip; bajonista; [vid. GENSANA, Felip/Fhelip/Fhilip; bajonista].

JOANET; 'prevener'; [vid. JUANET; 'prevener'].

JUANET; 'prevener'; 79, 85, 167.

JUGLÁ; bajonista; 169, 190.

JUGLAR; bajonista; [vid. JUGLÁ; bajonista].

MARQUES, Joseph; coro; 329.

MARQUES, Thomas; coro; 235, 251.

MARTI, Joseph; coro; 204, 237.

MARTI, Nicolau; coro; 259.

MERCADER, Joan; cantor; 324.

MOGA, Anton; tenor y contrabajo [vocal]; 287, 290, 295, 297, 302, 305, 309, 310, 313, 316.

MUNTAN, Andreu; coro; 142.

MUNTAN, Francisco; coro; 141, 236.

MUNTAN, Joseph; coro; 220.

194

(c) Consejo Superior de Investigaciones Científicas Licencia Creative Commons 3.0 España (by-nc)
NET, Pere; coro; $22,125,131,140,151,156,162$, $165,169,180,190,195,202,205,221,227$, 229, 233, 239.

OLIVELLES, Phelip; maestro de capilla del Palau de la Comptessa; 2.

PARRA, Joseph; tenor; 173.

PERA, Joan; tenor y violinista; 249, 297, 302, 305, $309,313,317,320,321,324,327,331,335$, 347.

PERALTA, Fermesí de; coro; 18.

PERET, 'de Llivia'; 'prevener'; 79.

PLANES, Joseph; corneta y cantor; 21, 31, 37, 55, 73, $77,87,92,98,100,107,111,121,151,156,162$.

POCIELLO; tenor; 320, 321, 324.

PONSÁ BARCELONA, Joan; coro; 143.

POTENSA; bajonista; 313, 317, 320, 321.

PUBILL, Joseph; coro; 239, 241, 245, 253, 255, 262, 266.

PUIG; coro; 25.

PUSALGUES, Joan; violinista; 159.

RIBO, Francisco; coro; 286, 304, 341, 347.

RIU, Joan; coro; 15, 16.

ROSELL, Matheu; bajonista; 190, 103, 195, 205, $221,227,233,241,253,255,262,267,273$, 279, 285, 290, 295, 297, 302.

RUBIO, Antonio; contralto; 23, 31, 39, 49, 55, 73, 104.

SALA; bajonista; 324, 327, 331.

SALVATÓ, Francisco; violinista; 317, 321, 324, 327, 331, 335, 341, 347.

SANS, padre Salvador; tenor; 177, 180, 190, 195, $202,205,221,227,229,233,241,245,253$, 255, 262, 267, 273, 280.

SARRADA, Isidro; organista y maestro de capilla jubilado; [vid. SERRADA, Isidro; organista y maestro de capilla jubilado].

SERRADA, Isidro; organista y maestro de capilla jubilado; $6,11,31,43,44,52,53,55,57,63$, $73,79,81,87,92,100,111,115,121,131,140$, $151,155,156,162,165,169,180,195,205$, $221,227,229,233,241,245,253,255,262$, 267, 273, 280, 285, 287, 290, 293, 294.

Anuario Musical, 58 (2003) http://anuariomusical.revistas.csic.es 
SERRAT, Francisco; corneta; 160.

SOBIES, Carlos; tenor; [vid. SUBIAS, Carlos; tenor].

SOLER, Emanuel; coro; 142.

SORINYACH, Anton; bajonista; [vid. SURINYACH, Anton; bajonista].

SUBIAS, Carlos; tenor; 55, 59, 73, 79, 82, 87, 91, $95,100,111,121,151,156,162,165$.

SUBIES, Carlos; tenor; [vid. SUBIAS, Carlos; tenor].

SUBIRATS, Carlos; coro; 51, 140.

SUNYER, Anton; coro; 214.

SURINYACH, Anton; bajonista; 301, 302, 305, $309,313,317,320,321,324,327,331,341$, 347.
TARRADA, Joan; coro; [vid. TORRADA, Joan; coro].

TAUGIS, Mariano; cantor; 327, 331, 334, 335.

TERRES, Pere; violinista; 288, 297, 302, 305, 313, 317, 320, 321, 324, 327, 331, 335, 341, 347.

TORRADA, Joan; coro; 92, 100, 131, 140, 156, $162,165,168$.

VIDAL, Jaume Joan; coro; 25, 68, 71.

VILANA; coro; 92.

VILANOVA, Andreu; tenor; 6, 31, 55, 73, 100, $111,121,140,151,156,162,165,169,180$, $190,195,202,205,221,227,233,237,262$, 267.

VILANOVA, Francisco; coro; 127, 151. 


\section{Índice de materias}

BAIXONISTA / Baixoniste; 6, 21, 31, 55, 73, 87, 92, $100,111,121,131,140,151,156,162,165,169$, $180,190,195,202,205,221,227,229,233,241$, $245,253,255,262,267,273,280,285,287,290$, $295,297,302,305,309,313,317,320,321,324$, $327,331,335,3341,347$.

CONTRALT / contraalt / contrahalt; 6, 23, 31, 49, 60, $72,73,87,92,100,104,111,121,131,140,151$, $156,162,165,169,180,190,195,202,205,221$, $227,229,233,241,245,253,255,262,267,273$, $280,285,287,290,295,297,302,305,309,313$, $317,320,321,324,327,331,335,341,344,347$.

CORNETA; $6,8,13,21,31,43,55,73,77,87,92,98$, $100,107,111,121,131,140,151,156,160,162$, $165,169,180,190,195,202,205,221,227,229$, $233,241,245,253,255,262,267,273,280,287$, $290,295,297,302,305,309,313,317,320,321$, $324,327,331,335,341,347$.

MESTRE de Capella; 1, 2, 5, 6, 8, 10, 16, 17, 20, 27, $28,29,30,31,33,43,44,45,48,52,55,64,65$, $66,69,73,75,78,79,81,83,85,87,88,92,95$, $100,108,110,111,116,121,126,131,133,140$, $151,155,156,161,162,164,165,169,175,180$, $190,195,199,200,202,205,210,212,212,227$, $229,233,235,240,241,245,247,253,254,255$, $262,267,273,280,285,286,287,290,295,297$,
$298,302,305,309,313,317,320,321,322,324$, $327,331,335,341,347$.

ORGA/ Orgue; 11, 47, 62, 314.

ORGANISTA / Organiste; 6, 31, 55, 73, 87, 92, 100, $111,121,131,140,151,155,156,162,165,169$, $180,190,195,202,205,221,227,229,233,241$, $245,253,255,262,267,273,280,285,287,290$, 293, 295, 297, 302, 305, 309, 313, 317, 320, 321, $324,327,330,331,335,341,347$.

PREVENER / minÿo / infantons; $14,24,48,79,82,88$, 106, 114, 126, 128, 167, 256, 270, 282, 307, 308.

SACABUTX / sacapuxo / sacaputxo; 6, 31 .

SARGANT; 21

TENOR / Thenor; $6,21,31,55,73,87,92,100,111$, $121,131,140,151,156,162,165,169,173,174$, $180,190,195,202,205,215,221,227,229,233$, $241,245,253,255,262,267,273,280,285,287$, $290,295,297,302,305,309,313,317,320,321$, 324, 327, 331, 335, 341, 347.

VILLANSICOS; 145, 272, 277.

VIOLÍ; 276.

VIOLINISTA / violiniste; 297, 302, 305, 309, 313, 317, 320, 321, 324, 327, 331, 335, 341, 347. 